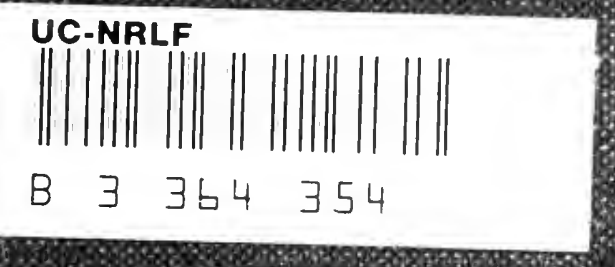


$$
\text { . }
$$ 





THE DEVELOPMENT OF SYMBOLIC LOGIC 



\title{
THE DEVELOPMENT
}

\author{
OF \\ SYMBOLIC LOGIC
}

A CRITICAL-HISTORICAL STUDY OF

THE LOGICAL CALCULUS

BY

A. T. SHEARMAN, M.A.

LONDON

W ILLIAMS AND NORGATE

14 HENRIETTA ST., COVENT GARDEN

I 906 


$$
\cdots+1^{2}
$$




\section{P R E F A C E}

THE form that the present work has taken is due to some correspondence that I had with Mr. W. E. Johnson in the year I 903 . He pointed out to me the error of thinking of the various symbolic systems as being radically distinct, and as competing with one another for general acceptance. Rather, he held, it is correct to adopt the view that there is available at the present time what may be called the Logical Calculus, and that towards the creation of this Calculus most symbolists have contributed.

This idea has been worked out in the following pages. I have traced the growth of the subject from the time when Boole originated his generalisations to the time when Mr. Russell, pursuing for the most 
part the lines laid down by Peano, showed how to deal with a vastly wider range of problems than Boole ever considered. My attention has been occupied, that is to say, upon the questions to whom we are most indebted for those rules of procedure that may be said now to constitute the Calculus, what important differences of opinion have arisen as the subject has been gradually thought out, and which of the conflicting views we find it correct to adopt. The investigation has thus been quite as much critical as historical, for, in demonstrating who have contributed to the creation of the Logical Calculus, it has been necessary constantly to point out, in the first place, why certain views have to be rejected as being incorrect, and secondly, wherein one of two suggestions, both of which are excellent, shows an advance upon the other.

Portions of some of the chapters have appeared in a paper which has been published in the Proceedings of the Aristotelian 
Society (N.S. vol. v.), and which was entitled "Some Controverted Points in Symbolic Logic." Judging from the kind communications which I have received from several logicians with reference to this paper, I think that the insertion of these sections is likely to prove useful. My opinion upon the questions I then discussed has not, as a result of further thought, undergone any change, but after reading Mr. Russell's work, The Principles of Mathematics, I have been careful to point out that the view which I expressed as to the relation of Mathematics to Logic is to be regarded as preferable only to the doctrines that were in vogue prior to the time of Peano's analysis of mathematical notions.

It is unnecessary here to refer to the various writers whom I have considered, since they will be mentioned in the appropriate places throughout the book. But I should like to say how much I owe in the way of equipment for my task to Dr. Venn 
and Mr. Johnson. It was the former who a good many years ago created in me a taste for the study of Symbolic Logic, and he has ever been ready both to give me information and to discuss points in which I was interested. Mr. Johnson's articles in Mind, by throwing light on some of the more difficult questions of Formal Logic, and by exhibiting in a very clear manner the unity running throughout the Logical Calculus, have been to me of the greatest service.

University College, London,

February, 1906. 


\section{O N T E N T S}

\section{INTRODUCTION}

PAGE

\section{CHAP'TER I}

SYMBOLS AS REPRESENTING TERMS AND AS REPRESENTING PROPOSITIONS

INTRODUCTORY .

I. On the Primary and on the Exclusive use of

Literal Symbols . . . . . 10

II. Real and SUPERficial Differences betweEn Systems . . . . . . . . 22 III. Symbolic Logic and Modals . . . $\quad 2_{4}$

\section{CHAPTER II}

SYMBOLS OF OPERATION

I. Symbols of Operation are not Essential in Logic

II. Question whether it is Expedient for the

Logician to adopt Mathematical Symbols 34 III. Symbols to denote Logical Addition, Subtraction, and Division . . . . . 38 IV. Other Symbols of Operation . . . . . 5 I

V. Symbolization of Particular Propositions . 56 VI. Symbolization of Hypotheticals and of DisJUNCTIVES • $\cdot \underset{\mathrm{ix}}{\cdot} \cdot{ }^{\circ} \cdot{ }^{\circ} 59$ 


\section{CHAPTER III \\ THE PROCESS OF SOLUTION}

I. The Solution of the Direct Problem . . 64 (I) Analytical Method . . . . . 64

(2) Diagrammatic Method . . . . 80

II. 'The Solution of the Inverse Problem . $\cdot 84$

CHAPTER IV

CONCERNING A CALCULUS BASED ON INTENSION

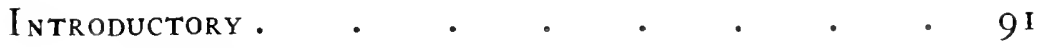

I. The Doctrines of Castillon • • • 94

(I) Castillon's Fundamental Notions • • 95

(2) Illusory Particulars . • . . • I I I

(3) Inconvertibility of Real Particulars and of Universal Negatives • • • 122

(4) Castillon's Treatment of Hypothetical and of Problematical Judgments • • • 124

(5) Derivation of the Notion of Quantity • - 128

(6) Comparison of Castillon's Symbolism with

Mrs. Bryant's • • • • • I 3 I

II. The General Question of an Intensive

Logic . • • • • • • 133

( I) A Logic based on Connotation . . $\quad$ I 34

(2) A Logic based on Comprehension • $\quad 138$ 


\section{CHAPTER V}

THE DOCTRINES OF JEVONS AND OF MR. MACCOLL

INTRODUCTORY .

I. Criticism of Jenons . . . . . I 45

II. Criticism of Mr. MacColl . . . . I 49

(1) His Employment of Literal Symbols . . 150

(2) His Treatment of Modal Propositions . 152

(3) His Doctrine of a Universe of Unrealities . I6I

\section{CHAPTER VI}

LATER LOGICAL DOCTRINES

INTRODUCTORY .

I. Treatment of Multiply-quantified Propositions i 73

II. The Impossibility of a General Treatment of Copule. . . . . . .

III. The New Treatment of Mathematical Conceptions. . . . . . 196

\section{CHAPTER VII}

THE UTILITY OF SYMBOLIC LOGIC . . 22I 



\section{THE DEVELOPMENT OF}

\section{SYMBOLIC LOGIC}

\section{INTRODUCTION}

My object in writing this book is to show that during the last fifty years there has been a definite advance made in Symbolic Logic. By any person commencing the study of this discipline it is not unnaturally soon concluded that there exist several "systems," marked off from one another by fundamental differences. Such systems he is inclined to describe according to the character of the view that the founder entertained as to the import of the proposition. Thus there is the compartmental view, the predication view, the mutual exclusion view, and so on. But subsequent 
study enables the reader to perceive that, in adhering to such a conception, he is hiding the points of likeness and magnifying the points of difference between the proposed methods of treating the subject, and he is thus led to look rather at the net result of the different efforts. That is to say, instead of continuing to speak of several isolated systems, he proceeds to study the calculus that is now available, and to the construction of which most symbolists are seen to have contributed.

The calculus that we have said now exists enables us to solve with comparative ease problems relating to qualitative objects.* We are able, after the performance of certain processes that are in accordance with a few logical laws, to arrive at conclusions respecting any class or group of classes that is involved in the premises. These con-

* If we adopt the Peanesque standpoint we may say that the calculus can deal with either qualitative or quantitative objects. But the statement in the text really expresses the truth of the matter, for before mathematical assertions can be dealt with by Peano they have to be expressed as implications. 
clusions may show the relation of such class or group to all the other classes involved, or we may employ the process of elimination and show the relation to certain only of the other classes. On the other hand, starting with certain conclusions we are able to discover premises whose presence accounts for them.

Now, before the time of Boole none of the problems with which the calculus deals could have been solved, unless they were of the very simplest description. He was the first to reach any generalisations of logical doctrines. ${ }^{*}$ There certainly had been some gropings towards the desired end before his time. Venn refers to some of the earlier attempts, and in particular to the work of Lambert. Venn shows that

* Venn, Symbolic Logic, ed. i. p. xxviii., says that Boole was the originator of all the higher generalisations. The paragraph is omitted in the second edition. Of course Venn would still hold that Boole was the originator of many of the higher generalisations, but would allow that other logicians have, since the publication of the Laws of Thought, generalised in certain directions. The point of Venn's statement is that before Boole's time there were no generalisations at all. 
this eighteenth century logician had in the following respects made considerable advances towards the Boolian position. $\mathrm{He}$ had recognised that addition, subtraction, multiplication, and division have an analogue in Logic, had perceived the inverse nature of the second and fourth of these operations, had enunciated the principal logical laws, had developed simple logical expressions, had seen that his own method would deal with complicated problems, and in one place had observed that the process corresponding to division is an indeterminate one.*

Venn also points out that Lambert's coadjutors were Ploucquet and Holland, and that all three took their impulse from Leibnitz and Wolf.

It is certainly desirable in an historical account of the subject to notice these earlier writers, but the fact must not be forgotten that none of them did actually succeed in solving any of the more complicated prob-

$$
\text { * Venn, Symbolic L.ogic, Introduction, p. xxxi. }
$$


lems. I do not think that such writers must be considered as the founders of Symbolic Logic. Had they framed any generalisations the case would have been different. Or had Boole been acquainted with their ideas, and founded his generalisations upon these, it would obviously have been essential to include such writers among those who have assisted in erecting the symbolic structure, but he was not familiar with their work.

Still, though Boole is the man to whom we are indebted for having first constructed a logical calculus, the one that he produced was of a decidedly complicated character. Moreover, several processes that form a highly important part of Symbolic Logic he did not bring within the scope of his investigations. And occasionally he made mistakes. Several minds have contributed in unfolding the symbolic methods at present available. We shall have to notice the writers who have made improvements on Boole's procedure, or have corrected 
him, or who have grappled with problems that he did not touch.

My order of exposition is as follows. In the first three chapters I suppose that we are confronted with a complicated set of premises and are required to draw a certain conclusion from them, or that we are given a certain conclusion and are required to assign premises from which it may have been drawn. At each stage in the solution I shall endeavour to show which logician it is who has proposed the best method of procedure to be adopted at that point. In this way I hope to make clear that there has been real development from the time of Boole, and that the principal contributors to the development are Venn, Schröder, Keynes, Johnson, Mitchell, C. Ladd-Franklin, and Peirce.

Then in chapter iv. I prove that those who have been engaged in elaborating the calculus were justified in proceeding by way of an extensive rather than by way of an intensive interpretation of the 
proposition. Chapter v. is occupied with an analysis of the work of two distinguished logicians, namely, Jevons and $\mathrm{Mr}$. MacColl, both of whom have, indeed, proceeded by way of extension, * but who have in my opinion fallen into serious errors. Up to this point the investigation is concerned with what may be called the ordinary Symbolic Logic, and with its ordinary employment. In the next chapter I refer (I) to the logicians who have shown how the principles that are utilised for the manipulation of propositions with single quantifications may also be utilised in the case of double and multiple quantifications; (2) to the view that, though such multiple quantifications may be successfully manipulated, it is not possible to treat copulæ in a general manner, and so arrive at such a Logic as the expression "Logic of Relatives" naturally suggests to the mind; and

* Jevons, as Venn points out, professed to interpret the proposition in an intensive manner, but dealt with the subject rather from the extensive standpoint. (See Venn, Symbolic Logic, note on P. 453.) 
(3) to Frege, Peano, and Russell, who have shown that, when certain distinctions are made which the older symbolists passed by as unimportant, and when a suitable interpretation is given to the conceptions of quantitative mathematics, both the comprehensiveness and the utility of Symbolic Logic are greatly increased. Finally, having thus traced the development of the subject, I devote a chapter to the consideration of the uses of Symbolic Logic, both in its less and in its more extended application. 


\section{CHAPTER I}

SYMBOLS AS REPRESENTING TERMS AND AS REPRESENTING PROPOSITIONS

THE first step in the solution of a complicated problem is to take the premises, which are given as a rule in words-as a rule, for the cawing of a rook and the flying of a union-jack may be premises, since they are statements, though of course not propositions, * - and to put them into some other form, in order that they may be easily manipulated. The customary way is to take letters either to represent the classes or to represent the statements involved. The question then arises as to which of these two the letters should be taken to represent. $\dagger$ Having answered

* See MacColl in Mind, N.S. No. 43 .

$\dagger$ The argument in the next few pages has reference to problems of the earlier Symbolic Logic. I hold that in the 
this question, we shall be able to see which logicians have been proceeding on the right lines, so far as this point is concerned.

\section{There are here three considerations} that must be kept quite distinct if the subject is to be profitably discussed. In the first place, it is possible to affirm that symbols may under one set of conditions represent terms, and under another set of conditions represent propositions, and then it has to be decided which of the two available uses it is expedient primarily to adopt. Secondly, it may be held that it is a matter of indifference whether symbols stand for terms or for propositions. And,

case of such problems it makes no difference, so long as the appropriate rules are observed, whether we let our symbols stand for terms or for propositions. But, when we come to deal with problems that are not included within the scope of the Boolian treatment, I admit that it is better to let symbols stand primarily for propositions. For, as will be noticed later, the propositions of mathematics which the newer Symbolic Logic has been shown to be able to manipulate consist of implications between propositional functions, and the "molecule" referred to in the latter is a proposition, not a class. 


\section{Symbols for Terms and Propositions i I}

in the third place, the opinion may be maintained that only one of the two should be symbolized-on this view it is generally to designate propositions that symbols are exclusively utilised.

(I) As regards the question of expediency, it has been affirmed that we should commence with the symbolization of propositions, for then, firstly, our procedure throughout will be analytical; and, secondly, we shall avoid the "confusion" that is introduced through the identification of the "physical" combination of propositions into a system with the "chemical" combination of subject and predication into a proposition.*

The former of these reasons is undoubtedly a strong one, but I am inclined to think that the common method of beginning with the consideration of classes, and the operations that may be performed upon them, is the better one to employ. For one thing, the latter procedure is of a

$$
\text { * Mind, vol. i. N.S. p. } 6 \text {. }
$$


simpler character than the other. But a stronger reason than this is that, during the process of considering the manner in which the analysis of propositions modifies the form of the synthesis, it is necessary to point out that the letters representing predications obey the simple laws of propositional synthesis; ${ }^{*}$ it is, therefore, desirable to be able to refer to an earlier discussion of terms and the operations that may be performed upon them.

With respect to the confusion that it is alleged is likely to arise from our allowing letters originally to represent terms, it is, I think, apt to be exaggerated; indeed, a careful analysis of what really happens during the employment of literal symbols in the two spheres will show that there is no good reason for confusion in any degree. The fact that contradictories are not the same in both regions has been declared to be a likely source of error. Now it is certainly true that the contradictories in the

$$
\text { * Mind, vol. i. N.S. p. } 352 \text {. }
$$


Symbols for Terms and Propositions i 3

two cases are different, but this should not involve any uncertainty in the application of the old formulæ to the new use. All that is necessary is that we make allowance for the change in the character of the contradictory, i.e., we must not admit that propositions are sometimes true and sometimes false.

Again, it has been said that those who utilise the old rules for the new subjectmatter will be led actually to confuse a class with a proposition, inasmuch as on the class view the contradictory of $x$ is the class $\bar{x}$, but on the propositional theory the contradictory of the proposition $x$ is the affirmation " $\bar{x}$ is true." * But this criticism loses its force if the distinction is drawn between the truth of a proposition and the statement that the proposition is true. When the old formulæ are applied to the new case, the correct procedure is to make the letter symbol represent the truth of a proposition, while such an expression as

$$
\text { * Mind, vol. i. N.S. p. } 17 .
$$


$x=1$ is used to denote that such a proposition is true. Hence the contradictory of the truth of $x$ does not leave us with a proposition, but simply with the truth of $\bar{x}$. There is thus a perfect analogy between this case and the case where the letters represent classes. And, just as the class $\bar{x}$ may be declared to exhaust the universe, so it is possible to state that the truth of the proposition $\bar{x}$ is the only possibility. In other words, in both cases we may say that $\bar{x}=1$.

When writers, who start by making letters stand for classes, come to make such letters stand for the truth of propositions, there is no serious alteration involved, except the one already noticed, in the logical rules that have been established: there is merely another method of interpretation put upon the literal symbols. Such logicians argue that the logical machinery may be put to uses other than those for which it was originally intended. For instance, the symbol 1 from meaning the totality of compartments comes to denote 
Symbols for Terms and Propositions i 5 the only possibility, and 0 receives the meaning of no possibility.

Where the symbolic framework, as elaborated from the point of view of the class, does not apply to the new case, the fact is due, as Venn shows, to the circumstance that we have no longer any place in the contradictory for the word "some." In dealing with classes, when it is said that $x+\bar{x}=1$, it is meant that both $x$ and $\bar{x}$ contribute to the total, but on the proposition interpretation, the admission of $x$ excludes absolutely the admission of $\bar{x}$. Hence, if $x y$ is declared false, we can only say that one of the three $x \bar{y}, \bar{x} y, \bar{x} \bar{y}$ is true, while, if $x y$ is declared true, then $x \bar{y}, \bar{x} y, \bar{x} \bar{y}$ must all be false. That is to say, of the formally possible propositional alternants only one can be true.

(2) But there are some writers who maintain that it makes no difference whether symbols stand for terms or for propositions. These logicians have to attempt to show that the characters of the contradictories 
do not vary in the fundamental way that I have just mentioned. Mrs. LaddFranklin, for instance, endeavours to deal with this question by asserting that a proposition may be true at one time while it is false at another; * but, as Mr. Johnson remarks, propositions that relate to different times are different propositions. Mrs. LaddFranklin asks, "Why exclude from an Algebra which is intended to cover all possible instances of (non-relative) reasoning such propositions as 'sometimes when it rains $I$ am pleased and sometimes when it rains I am indifferent ?" " But I am not aware that any symbolist wishes to exclude such propositions. Supposing we regard this statement as consisting of two propositions-in contradistinction for the moment to the way in which Mr. Johnson argues, namely, that the particle " and" implies that we have really only one-then the symbolist will, of course, say, "Let $x$ equal the proposition 'sometimes when it rains I * Mind, vol. i. N.S. p. I 29 . 
Symbols for Terms and Propositions i 7 am pleased,' and $y$ equal the proposition 'sometimes when it rains I am indifferent."' Here, if these two propositions are true, we shall have $x=1$ and $y=1$ respectively; while, if $x$ is not true, i.e., if $x=0$, the verbal rendering will be, "It is not true that sometimes when it rains I am pleased," and similarly with the rendering of $y=0$. Mrs. Ladd-Franklin argues as though $x$ were made by the symbolist to stand only for such a proposition as "I am always pleased," but, of course, the symbol may stand for any proposition (or rather, truth of any proposition) whatever.

But though the symbolist can deal with such propositions he will not in consequence proceed along the lines that Mrs. Ladd-Franklin thinks Schröder should have followed. She argues that it is not justifiable to regard $x-<y+z$ as requiring fundamentally different treatment according as $x, y$, and $z$ stand for terms or for propositions. Schröder had maintained that, when the letters represent pro- 
positions, it is not possible, as it is on the view that we are dealing with classes, for $x$ to be divided up between $y$ and $z$. To this his critic says that in material consequences, such as "if it rains, either I stay in or else I take an umbrella," the proposition is satisfied if there are some instances in which I stay in and some in which I take my umbrella. She fails to observe that the introduction of the word "instances" does away with the special character of the sequence, and reduces the problem to one of class implication. So long as propositions as such are retained, Schröder is undoubtedly correct in saying that $x$ cannot be divided up between $y$ and $z$.

Again, Mrs. Ladd-Franklin points out that there is a close resemblance between what she terms logical sequence and the case where the left-hand member of the subsumption stands for a singular subject. But this is not any reason for regarding the question whether we allow literal 


\section{Symbols for Terms and Propositions i 9}

symbols to stand for terms or for propositions as one of indifference. Such a statement as "she is either a queen or a fairy" is one of those limiting cases, for whose investigation in general we are so much indebted to Dr. Venn. It is quite correct to say that "there seems, in fact, to be a close relationship between the logical sequence between propositions, and the sequence between terms when the subject is singular," but Schröder's general argument is not thereby invalidated: the original formulæ must be modified to suit the case of the proposition with singular subject and disjunctive predicate, just as there must be modification to meet the case where terms stand for propositions. Mrs. Ladd-Franklin's answer to Schröder, when he asks what can possibly be meant by $(a-<b)=\bar{a}+b$ on the supposition that the letters stand for terms instead of for propositions, appears to me to be quite sound. She says that the verbal rendering will naturally be as follows: "All 
$a$ is $b$ " is-the-same-thing-as " everything is either non- $a$ or else $b . "$ But all that is hereby demonstrated is that the letters in a certain equation may have two different readings: there is here no argument to prove that it is a matter of indifference, so far as rules of application are concerned, whether our letters in a problem stand for terms or for propositions.

In stating the facts of the case we have, therefore, to avoid two extremes. On the one hand it is incorrect to say that all the rules apply equally well for both classes and propositions, and on the other hand we need not go so far as to state that the rules are different in the two regions. The former statement is erroneous; the latter suggests more disparity between the two procedures than actually exists.

(3) It has been mentioned also that sometimes it is maintained that symbols should be employed exclusively to repre- 
Symbols for Terms and Propositions 2 I sent propositions. Mr. MacColl takes this view of the case. But I can see no valid reason why symbols may not designate now classes and now propositions. The only thing to be remembered is that the rules of procedure are not quite the same in the two cases. If we are to be restricted to one only of the two uses, then I think that Venn is justified in saying that symbols should stand for classes rather than for propositions. As regards the question of economy of space in the solution of problems, the evidence seems to show that the class interpretation is to be preferred. Certainly this is the case so far as the representation of the syllogism -after all an important form of reasoning-is concerned. I do not lay much stress upon the argument based on spaceeconomy. At any rate, we ought not to judge systems by the amount of working that has been offered when the exponents were dealing with certain well-known problems, because as a rule the symbolist 
could, if he had so chosen, have made his solution much more compact than he did. Still, seeing that symbolism may at times assist rather than act as a substitute for thought, we need not despise brevity, if thought is thereby rendered the greater assistance.

I think, then, that it is correct to hold that our letters may represent either classes or propositions, but that we must be careful to notice that the rules to be adopted in working our problems are not the same in the two cases. This view has been adopted by Boole, Venn, and Schröder, who, so far as the point in question is concerned, are thus seen to have been proceeding in the right direction.

II. A variety of letter symbols has been suggested by these three writers for representing the class or the proposition, and the contradictory of each, namely, $x \bar{x}$ (Venn), $x x_{1}$ (Schröder), $\mathrm{X} x$ (Jevons). The selection of different sets of symbols 
Symbols for Terms and Propositions 23 for the class and its contradictory is one of those matters that depend on the logician's individual preferences, and is not of vital importance in marking off one exposition from another. A very clear distinction must of course be drawn between real and superficial differences existing among the so-called systems. It is to be regretted that the same symbols are not used by different writers in those cases where no principle is involved, for there is no doubt that beginners in the subject are often unnecessarily puzzled on account of the variety that is to be found. The reason that such variety exists is, I think it must be said, that symbolists have frequently not been sufficiently acquainted with the writings of their predecessors. Boole, as we have noticed, was unfamiliar with anything that had been done in Symbolic Logic; and Mr. MacColl in his earlier work furnishes according to Venn " another instance of results independently worked 
out, without knowledge of what had been already effected in the same way." Mr. MacColl's later papers have, however, been prepared with a clear apprehension of what has been engaging the attention of other writers.* This want of historical information on the part of symbolists, besides causing students unnecessary difficulties, has resulted in a good deal of wasted effort, for each logician instead of starting where his predecessor left off, has had to work out all the elementary notions of the subject for himself.

III. In close connexion with the subject as to whether Symbolic Logic deals primarily or exclusively with propositions is the question as to the kind of propositions to which in any case it must confine itself. The symbolist can deal with assertorics only. It has, however, sometimes * See particularly his article in Mind, N.S. No. 47, p. 355, and his discussions with Mr. Russell and myself with respect to logical existence, Mind, N.S. Nos. 55 and 56. 
Symbols for Terms and Propositions 25

been held that certain other propositions fall within the scope of his treatment. For instance, he is said to be able to manipulate propositions that are "probably true." I think he has nothing to do with such material, for the simple reason that it does not exist. Mrs. Bryant, in her suggestive paper on "The Relation of Mathematics to General Formal Logic," * still holds to the view that it is a legitimate subject of inquiry when we ask concerning a proposition "how often is it true relative to the total number of cases its occurrence in every one of which would constitute its unconditional truth?" Two considerations show that this question is not an intelligible one. In the first place, it is a mistake to speak of a proposition as being often true, for on each supposed occasion of its truth there would be a new proposition. In the second place, though unconditional truth may well be established from certain true propositions,

$$
\text { * Proc. Arist. Soc., vol. ii. N.S. p. I } 2 \text { I. }
$$


this establishment is due simply to the fact that such propositions are true, and not to the fact that they are always true. Mrs. Bryant escapes the mistake of speaking of degrees of truth, but she falls into an equally serious error in holding that a proposition may more or less frequently be true. She is quite correct in saying that "a proposition is the assertion of a joint event," but when this assertion is once made it is either true or it is false : it cannot be probably true. It may be more or less probable that the events ought to be joined in the way asserted by the proposition, but such probability is a matter to be taken into consideration before the assertion is made. The error in question arises apparently through the confusion of proposition with event. The probability of an event is certainly measured "by the ratio of the number of cases in which it occurs to the whole number of cases considered," but the probability of the truth of a proposition has no meaning. We 


\section{Symbols for Terms and Propositions 27}

may not, as she would allow us, write "proposition" for "event" and "is true" for "occurs."

Nor can the symbolist manipulate propositions respecting probabilities, unless he recognises that he is dealing with an affirmation of the relation in which a thinker stands to a certain statement. That is to say, the symbolist will still be engaged upon assertoric propositions. Mr. Johnson has made this quite clear. As he expresses it, these assertions about the probability that a predicate is to be attached to a subject relate to a different plane from the one with which pure Logic is concerned. They refer to the obligation under which the thinker finds himself to accept a statement of an assertoric kind, but the propositions that engage the attention of the logician are these assertorics themselves.

And in the same way that the symbolist cannot without the use of new terms deal with propositions asserting probabilities, so, unless the same procedure is adopted, he 
must consider as outside his province many of the kinds of propositions that are mentioned in the very ingenious system that has been elaborated by $\mathrm{Mr}$. MacColl. This logician holds that the symbolist, besides classifying propositions into true and false, may make other classifications according to the necessities of the problem. Thus, in addition to the probable, improbable, and even propositions already mentioned, there are those that are certain, impossible, and variable, those that are known to be true, known to be false, and neither known to be true nor known to be false, and so on. The objection to this procedure is based on the fact that the considerations according to which such classifications are reached all refer to the relation in which the thinker stands to the proposition, and not to the proposition itself. All such facts as Mr. MacColl has in view can be dealt with in Symbolic Logic, but it is in their case necessary to introduce new terms. Thus, take the case of a proposition A, 
Symbols for Terms and Propositions 29 which we will suppose to be false. We have then symbolically $A=0$. Now, suppose we introduce the conception involved in the words "it is known," the proposition that we shall have to deal with will be "that it is known that A is false is true." It will still be a case of truth or falsehood, but the propositions that we have in mind are not the same. Mr. MacColl is, therefore, incorrect in stating that his $\mathrm{A}: \mathrm{B}$ is stronger than $\mathrm{A}-<\mathrm{B}$ : it is not a matter of strength, it is a matter of an entirely different proposition.

It will be seen from these considerations why it is that the same writer's recent explanations of his views are unsatisfactory.* He maintains, for instance, that his formula $(\mathrm{A}: x)+(\mathrm{B}: x):(\mathrm{AB}: x)$ is true, but that he could not use the formula $(\mathrm{A}: x)+(\mathrm{B}: x)=(\mathrm{AB}: x)$. He grants that the latter is true when $\mathrm{A}: x$ means $(\overline{\mathrm{A}}+x)$, but not when we have the meaning that he assigns to $\mathrm{A}: x$, viz., $(\overline{\mathrm{A}}+x)^{\text {e }}$, i.e., " it * Mind, N.S. No. 47 , p. 355 . 
is certain that A implies $x$." In unfolding his view, Mr. MacColl takes an illustration, in which the chances that $\mathrm{A}$ is $x$ are 3 to 5 , that $\mathrm{B}$ is $x$ are 3 to 5 , and that $\mathrm{AB}$ is $x$ are 1 , and his demonstration that under these circumstances the former of the above formulæ alone holds good is doubtless sound. But he is not justified in constructing formulæ upon this plane. At any rate, those that he here constructs form no part of pure Logic, for in this the force of the proposition consists in the definite erasion or salvation of certain compartments. If Mr. MacColl wishes to deal with the data he mentions he should introduce new terms. Pure Logic can take account of the uncertainties that such data occasion, but the propositions dealt with will then denote not the relation of the respective letters to $x$, but the relation of the thinker to each implication. 


\section{CHAPTER II}

\section{SYMBOLS OF OPERATION}

I. Next as regards the method of connecting the term-symbols. For a long time it was thought to be absolutely necessary to use symbols of operation, but Dr. Keynes has shown that the most complicated problems may be solved with the greatest ease without such use. The words "and" and "or" are amply sufficient in his hands for the connexion of the term-symbols, while to connect the subject-group with the predicategroup he does not depart from the customary "is." Still, as Mr. Johnson points out, Keynes has hardly developed a logical calculus, for this is characterized by the mechanical application of a few logical rules. 
But I may say that there is a difference of opinion among logicians as to the best manner in which to describe the advanced work that has been done by Dr. Keynes. On the one hand it is said that he has hardly developed a calculus, and on the other hand the question is asked whether his methods can fairly claim to belong to the Common Logic.* Venn thinks that these methods would never have been reached without a training in the earlier symbolic systems, for "the spirit of the methods is throughout of the mathematical type." And Venn, in the second edition of his Symbolic Logic, which appeared after the publication of Keynes' work, repeats the statement made in the first edition to the effect that the want of symmetry in the predication view of the proposition forbids its extension and generalisation. $\dagger$ Thus, if Keynes' work is not a calculus and does not belong to the Common Logic, it is a little

* See Venn, in Mind, vol. ix. p. 304.

$\dagger$ Symbolic Logic, 2nd ed. p. 29. 
difficult to know how to classify it. My own view is that it is what he claims it to be, a generalisation of (common) logical processes. There are no symbols that are suggestive of Mathematics except the bracket, and none suggestive of earlier symbolic work except $x$ for not- $X$. The distinction between subject and predicate is observed, and the use of the copula is retained. There is generalisation of the various forms of immediate inference commonly recognised, as well as of mediate arguments involving three or more terms. Whether the processes can be readily described as a calculus is perhaps doubtful. Certainly Keynes does not reach his conclusions from the mechanical application of a very few fundamental laws, but the rules that he does employ are after all not very numerous, and with a little practice can be applied with almost mechanical facility. I agree with Venn that it is difficult to suppose that such methods would have been reached without study of existing symbolic systems, 


\section{Symbolic Logic}

and there is a distinct resemblance between certain parts of Keynes' treatment of the subject and that given in Schröder's Operationskreis, to which work frequent reference is made in the notes of the Formal Logic. Still, whatever may have been the history of the growth of the subject in the writer's mind, now that the methods are thus presented I think that they should be regarded as a generalisation of the common logical processes.

II. Most writers on the subject of Symbolic Logic have undoubtedly introduced symbols of operation, and the four following, as is well known, have frequently been used :,,$+- \times, \div$, to denote respectively aggregation, subduction, restriction, and the discovery of a class which on restriction by a denominator yields the corresponding numerator. Of course, other symbols might have been used to designate precisely these operations, and it may be well to ask whether, seeing that these symbols 
are employed in another region of thought, it is well to have them employed in both regions. If they had first been used by the class logician, would the thinker who deals with numbers have done wisely in adopting them in his science? There is no reason, of course, in the nature of things why they should not have been employed in Logic first of all, but they were in use long before the logician began to look around him for some symbols suitable for the operations he had to perform. Did Boole, therefore, act wisely in making use of these symbols in his solutions? In some respects he did wisely, and in some he did not. He did wisely because there is some analogy between certain processes of Mathematics and those of Logic; for instance, the commutative and associative laws are applicable in both regions. And, even in cases where most of all it may be said that the adoption of mathematical symbols is likely to mislead, there is little risk of error if we regard the symbols as 
"representing the operation, and merely denoting the result." * Thus, $\frac{0}{a}$, which in Mathematics denotes zero, might, regarded solely as a result, be taken in Logic to stand for "nothing"; but, when we remember that the symbol also points to an operation, no confusion need arise. It becomes obvious, that is to say, that we here have the process of finding a class which upon restriction by $a$ gives 0 , which class is immediately seen to be $\bar{a}$. Boole did wisely also-though perhaps somewhat unconsciously-in that by employing these symbols he directed, as Mr. Johnson has remarked, far more attention to the study of Symbolic Logic than the subject would otherwise have received.

On the other hand, it may be doubted whether the analogy between the two sets of processes is sufficient to justify the application of the same symbols; the formula

* Mrs. Bryant, Proc. Arist. Soc., vol. ii. N.S. p. 108. 


\section{Symbols of Operation}

$x x=x$, for instance, may always be used in the logical region while being almost entirely inapplicable in Mathematics. Moreover, had Boole not adopted these symbols there would have been avoided the many disputes concerning the propriety of using them. Without doubt, out of all the controversy on the subject some truth has emerged, but it is probable that, had the relations of classes or of propositions received the attention that the disputants gave to a comparison of the mathematical and logical processes, Symbolic Logic would have made more rapid strides than it has done. The wonderful mathematical structure was erected without reference to what the logician was doing, or whether he was doing anything, and it may be that the logical structure would have been more imposing if the builder had concentrated his thought upon his own work, instead of casting side glances to see what was occupying the attention of the mathematician. 
III. Much discussion has arisen concerning three of these four symbols of operation, and it is stimulating to thought to weigh the arguments that have been advanced in connexion with them.

(I) First, with regard to the sign + . Boole always used this sign on the understanding that the terms so joined are exclusives. It was his special merit, so it has been affirmed, to improve on the common vagueness. That is to say, if "or" on the popular view means anything from absolute exclusion to identity, then the logician is called upon to improve on the ordinary view when he states his premises in symbolic language. It has also been maintained that there is a very great advantage in adopting the exclusive notation, inasmuch as there is then rendered possible the introduction of inverse operations. That is, before $a b$ can be subtracted from an aggregate of terms, it must be known that the aggregate contains $a b$-if the matter were left open there could be no 
subtraction. Similarly with division. If a class is to be found which on restriction by a denominator is to yield the numerator, then there must be no indefiniteness as to what this numerator is.

On the other hand, it is maintained that in the process of expressing the premises in symbolic form much economy of space and time is effected if the non-exclusive method is adopted. Further, on this plan it is possible to arrive at the contradictory by a very simple process. The demonstration of this occupies a prominent position in Schröder's work.* He proves in the Operationskreis that the contradictory of $(a b)_{1}$ is $\left(a_{1}+b_{1}\right)$, and that of $(a+b)_{1}$ is $a_{1} b_{1}$-in the Vorlesungen the proposition appears as No. $3^{6}$. Of course, Jevons had previously argued that the individual does often think in the non-exclusive fashion, but this is no reason why such notation should be adopted in the logical calculus.

* See Adamson's excellent critical notice in Mind, vol. x. p. 252, where, however, Schröder is erroneously said to have originated the theorem. 
It was for Schröder to point out that by the adoption of the method in the calculus problems could be solved more easily than on the Boolian plan; and not only would the process be easier, but, what Schröder thinks to be still more important, each step would be intuitively obvious, and justifiable on purely logical grounds. As a result of the long debate, the non-exclusive notation has undoubtedly found favour, and Venn in his second edition adopts it, having come, as he says, to recognise its "brevity and symmetry," but still holding to the view that the question is one of method rather than one of principle. Having thus changed his opinion, Venn has, of course, either to reject all inverse processes, or else to revert to the exclusive notation when dealing with them.

The confusion which has been stirred up by many of those who have discussed this question is greater, perhaps, than is to be found in any other part of Logic. It is very common to find no distinction made 
between (I) what actually takes place in disjunctive thinking, (2) what is the treatment of the disjunctive judgment in the text-books that discuss the elementary rules of formal Logic, and (3) what way of dealing with the disjunctive is the most serviceable for a generalised Logic. These three points of view were made clear by Dr. Venn long ago, but they are quite neglected even now in some discussions. For instance, Mr. Ross set out recently * " to try to determine the import of the disjunctive judgment, and to find out the exact place which it occupies in the connected whole of logical thought." $\mathrm{He}$ then proceeds to criticize Mr. Bradley and Mr. Bosanquet (who are, let it be observed, talking about the manner in which we are thinking when we are thinking disjunctively) by appealing to considerations based on common logical usages. But obviously the practices of the logician can never define the actual form of the judgment. Somewhat later, when

$$
\text { * Mind, N.S. No. } 48 \text {, p. } 489 \text {. }
$$


Mr. Ross advances "other considerations which go to show how inexpedient it is to treat the disjunctive judgment as necessarily exclusive," it becomes particularly noticeable that he fails to distinguish between two entirely different questions, one of fact and one of convenience. He actually proposes to show how inexpedient it is that alternatives are (in Bradley's view) exclusive of each other!

To put the matter in the simplest possible form, when Boole meets with some premises involving alternatives, he asks whether he is to regard the alternatives as exclusives or not. Then, if the answer is in the negative, Boole will write down $x \bar{y}+\bar{x} y+x y$, where $x$ and $y$ were the original non-exclusive alternatives. If Schröder meets with the same premises, he will, of course, also want to know if the alternatives are exclusives, and, when informed that they are not, he will write down $x+y$. Then each symbolist may go to work with his special rules, and each may obtain the 
correct solution. Thus it is the person supplying the problem who places the symbolist in a position to commence the solution. I should not have put the matter in such an elementary form as this were not the many confusions that still exist a sufficient justification. The word "should" has misled Mr. Ross. It may mean, "How ought I to describe the actual facts in the mind of the individual who is thinking a disjunctive judgment?" Or it may mean, "How ought I to put down in words or other symbols the facts that constitute the disjunctive thought?"

It is relevant here to notice also $\mathrm{Mr}$. Bradley's treatment of the subject of alternatives. He wishes to show that alternatives are exclusives, and his procedure is to refer to the state of things when they are not exclusives.* Evidently, therefore, alternatives can as a matter of fact be either. To put the same thing in other 


\section{4 \\ Symbolic Logic}

words, Mr. Bradley says that when alternatives are not exclusives we are thinking slovenly. But slovenly thinking is still thinking, though we may readily grant that it is not "always safe." Mr. Bradley seems to have been led to this argument through a confusion of the kind we have just mentioned. $\mathrm{He}$ sees difficulties in the way of reasoning if we state the premises symbolically in the non-exclusive manner, and so he argues that those premises must have been given in the exclusive manner. But obviously they may have been given in either form, though we must know which before we can put them down in symbols. When information upon the subject is forthcoming, we can adopt either the exclusive or the nonexclusive method of representation. It has been pointed out that Mr. Ross attempts to show the inexpediency of the fact that alternatives are (in Mr. Bradley's view) exclusives. We now see that Mr. Bradley was led to regard alternatives as exclusives 


\section{Symbols of Operation}

by reflecting how inexpedient it would be if they are not.

(2) Concerning the employment of the sign (-) some difference of opinion has also arisen. In the first place, it has been pointed out that the sign is not absolutely necessary, since subduction may always be expressed symbolically as restriction. But, though this is true, the reply has reasonably been made that it is frequently more convenient to employ the minus sign, and that no logical considerations render such employment illegitimate. But it is to be noted that only as denoting subduction is the use of the sign appropriate. If the attempt is made to designate negative terms by prefixing $(-)$ to the positive, only error can result. For, as Venn points out, the tendency then becomes almost irresistible to transfer a term with changed sign to the other side of the equation, and this will mean that a statement is made concerning a class about which the premises give no information. 
So far all is clear concerning the use of the minus. But sometimes it is employed where the calculus is based on the intensive rendering of propositions, and the use in this way deserves some consideration. Castillon has carried out more consistently than any other writer the development of Symbolic Logic on intensive lines, and I shall restrict my remarks here to his treatment of the sign in question. What he means by (-) becomes evident when we observe his symbolic representation of the universal negative and of its converse. This proposition appears as $\mathrm{S}=-\mathrm{A}+\mathrm{M}$, by which he means that the attributes embraced under $\mathrm{S}$ are not co-existent with those embraced under A, but are co-existent with those embraced under M.* Then he affirms that such proposition may be converted thus: $A=-S+M$. Clearly, then, what Castillon means-and he says as much -by the (-) is the mental act of keeping apart, of analysis. But, as he has thus far

* Sur un nouvel algoritbm logique, pp. 9, 10. 
been criticized, ${ }^{*}$ he is supposed in the original proposition to assign to $\mathrm{S}$ two aggregates, consisting respectively of negative and positive attributes. But this is what he distinctly avoids doing. When such infinite judgment, as he calls it, is to be designated, he employs the form $\mathrm{S}=(-\mathrm{A})+\mathrm{M}$. Moreover, if he had meant what Venn thinks he did, the converse of the universal negative would, of course, have been $(-\mathrm{A})=\mathrm{S}-\mathrm{M}$. Is, then, Castillon justified in converting in the way he does? Obviously not. For to proceed from $S=-A+M$ to $A=-S+M$ is to conclude that $\mathrm{A}$ is co-existent with $M$, a statement which is at variance with the original proposition. So that on intensive lines, as these are laid down by Castillon, it is not in general allowable, any more than it is in extensive Logic, to transfer letters with changed sign to the other side of the $(=) . \dagger$

* Venn, Symbolic Logic, 2nd ed. p. 466.

$\dagger$ Castillon's doctrine on this and other questions is examined in detail in chapter iv. 
(3) The last sign that need claim our attention is the one corresponding to the $(\div)$ of the mathematics of quantity. Has this inverse process any rightful place in Symbolic Logic, or is it a survival of merely historical interest? I hold that for two reasons the process ought without hesitation to be retained. In the first place, the mental exercise involved in arriving at the comprehension of what is implied in the performance of such inverse operation is, as Venn maintains, of the greatest utility. And, in the second place, the operation is capable of yielding absolutely reliable results. It may be stated in reply to this that, in the performance of the so-called logical division, we utilise symbols that are from the logical standpoint quite meaningless, and that such a procedure is not warrantable; that, in other words, we should follow on the lines which Schröder has laid down, who makes all intermediate processes intelligible. But in answer to this it is to be noted that a 
calculus is a mechanical contrivance for arriving at results that cannot be intuitively reached. Having given our premises we state them in symbolic language, then manipulate this in accordance with a few simple logical laws, and so reach our conclusion. Whether or not the intermediate results are intelligible is of no importance whatever. Thus, even if the intermediate processes in Logic were unintelligible, as is often affirmed, the inverse operations quite reasonably find their place in the calculus.

But, as a matter of fact, the stages between the statement of the premises and the arrival at the conclusion are not meaningless. Certainly Boole never attempted to assign them a meaning, but Venn has carefully examined all the various forms that arise as a result of "division," and he has shown that they have a perfectly intelligible logical signification. The words of explanation that are given by Mrs. Bryant as to how imaginary results arise 
are not therefore required in the strictly logical realm. She says, "Whenever a subject is reduced to symbolic expression, imaginary results may be expected to appear, and this happens because the operations of thought which the combining symbols represent extend in application beyond the possibilities of the subjectmatter." * No doubt that sentence throws light on a difficult question. But as Boole's forms have all been assigned a strictly logical explanation by Venn, it cannot be asserted that in Logic there are unintelligible expressions that call for consideration. There appeared to be such when Boole published his results, but that was only because he did not perform the task of explicitly stating the logical significance of the forms in question.

To reject inverse processes, as does Mrs. Ladd-Franklin, for instance, is deliberately to throw away useful instruments for solving problems. At the same time, she is

$$
\text { * Proc. Arist. Soc., vol. ii. N.S. p. } \mathrm{I} 3 \mathrm{I} .
$$


unquestionably correct in showing how important is that interpretation of alternatives which will allow of our reaching the contradictory with ease. The most satisfactory conclusion of the whole matter is that which Venn has formed, namely, to adopt as a rule the non-exclusive rendering, so as to profit by the simple rule for contradiction; but to change to the exclusive notation at times, in order that the advantages to be derived from the employment of inverse operations may not be lost.

IV. We may proceed now to consider certain other symbols of operation that have been suggested as serviceable in the expressions of our premises. When the propositions to be dealt with are of the universal affirmative description there is an indefinite element involved, and there have been various proposals for dealing with this. Venn considers that the symbol $\frac{0}{0}$ is in every way suitable for the purpose of expressing that the subject is contained some- 
where in the predicate. The signification of the symbol may extend from the value 0 to the value 1 ; that is to say, there may be no things existing which are represented by the subject-term of the premise, or those things may constitute a portion of the universe of discourse, or they may be co-extensive with what is denoted by the predicate. Boole introduced this symbol into Logic, and with entire appropriateness, since in Mathematics $\frac{0}{0}$ denotes complete indefiniteness. But Boole is not consistent in his use of the symbol, for, though when he is dealing with universals it means with him anything from 0 to 1 , he uses it in his representation of particular propositions, and in their case the signification 0 is excluded. The same inconsistency applies to Boole's use of $v$, which is merely his alternative for $\frac{0}{0}$.

Leibnitz, to designate the indefiniteness in question, employs the equation $x=x y$,

$$
\text { * See Venn, Symbolic Logic, p. I } 76 .
$$


and Jevons prefers this. But, as Venn shows, this is precisely the same as $x=\frac{0}{0} y$. For the latter may be expressed as $x \bar{y}=0$, or $x(1-y)=0$, or $x=x y$. Again, starting with the form $x=x y$, and expressing $x$ in terms of $y$ only, i.e., eliminating $x$ trom $x y$, we get $x=\frac{0}{0} y$.

Other writers, in order to denote that there is not necessarily identity between the subject and the predicate, but possibly only subsumption, employ a different form of expression. For instance, C. S. Peirce makes use of $-<$, which sign suggests by its form the relation involved. It may be said in favour of such symbols that they are nearer to the predicative interpretation of the proposition. Of course, Keynes, who works with the term "is," does not depart at all from the predication point of view, i.e., his method is less artificial than any others.

As regards these various ways of expressing the universal affirmative, it may 
be said that, with the exception of Jevons' form, there is not much difference between them in the matter of suggestiveness and usefulness. It is quite clear, however, that $\frac{0}{0}$ must not be employed, if it is also to be employed in representing particular propositions. Jevons' form had better as a rule be discarded, for it introduces the thing defined into the definition.

It is to be noticed that, if for the universal affirmative we accept the symbolism of Venn and Boole, the import of this proposition is to be regarded as of a negative character. The import of this universal negative is to be similarly interpreted. The positive $x=\frac{0}{0} y$ and the negative $x=\frac{0}{0} \bar{y}$ are equivalent, that is to say, to $x \bar{y}=0$ and $x y=0$ respectively. The significance of this negative rendering was realised by Boole, but was first made conspicuous in the writings of Venn.

To denote equivalence the symbol $(=)$ is, as we have seen, often used. It is to be 
observed that this represents equivalence of results, not of operations. I think Mrs. Bryant has brought out this fact more clearly than any one else. She makes it very evident that the signs,,$+- \times, \div$, represent the operation and denote the result.*

Once more, in the statement of the premises it is frequently necessary to make use of the bracket. Every system has need at times for the bracket. $\dagger$ Even Keynes here makes use of a symbol of operation, as, for instance, in his statement of the Law of Distribution.t Boole was the first to employ brackets in Logic on an extensive scale, but the use of the bracket in logical work was not uncommon among earlier writers. For instance, Lambert employs it, especially in his Logische und Philosophische Abhandlungen, and Castillon realises its force in his essays before the Berlin Academy.

$$
\begin{aligned}
& \text { * See p. } 36 . \\
& \dagger \text { Mind, N.S. No. I, pp. } 4,5 . \\
& \ddagger \text { Formal Logic, } 3 \text { rd ed. p. } 385 .
\end{aligned}
$$


V. We have discussed the best methods of symbolizing premises where these are universals. But it may be that we have to deal with particulars. How are these to be stated? And to whom are we indebted for suggesting the best method of stating them? It has more than once been attempted to express them in much the same way as universals. Thus Boole says that the particular may be represented by the equation $v x=v y$. Here there appears to be an identity resembling such an expression as $x=y$. Similarly Jevons says we may adopt the form $A B=A C$. But clearly Boole cannot introduce such expressions to a treatment resembling that which he employs when dealing with universals, for $v$ in the case of particulars is made by him to exclude the value 0 . And Jevons' rendering supposes that the members found in both $\mathrm{B}$ and $\mathrm{C}$ have more attributes in common than the one of being such 
common members, and this supposition is not justifiable.**

The best way of dealing with particulars is that expounded by Venn in both editions of his work, namely, to take these propositions as denoting the existence of individuals that are found in each of two classes. In his first edition he took the symbol $v$ to designate this existence, so that the particular appeared as $x y=v$. In the second edition he employs sometimes a form of symbolic procedure closely resembling that proposed by Mrs. Ladd-Franklin in the Johns Hopkins Studies. Thus to represent "some $x$ is $y$ " he writes $x y>0$, i.e., $x y$ is not nothing. Mrs. Ladd-Franklin's own procedure is the following. She preferred to discard the symbol 0 , and to retain only the symbol for denoting everything, viz., $\infty$. Then as this occurred in every proposition it might be neglected. Thus to say "all $x$ is $y$ " she wrote $x \bar{y} \bar{v}$, and to denote "some $x$ is $y$ " she wrote $x y$ v. $\dagger$

* Venn, Symbolic Logic, p. 392.

$\dagger$ Johns Hopkins Studies in Logic, p. 25. 
Here $\infty$ is understood on the right of the copula, which is a complete or an incomplete wedge according as the proposition is universal or particular. Mrs. LaddFranklin's originality with regard to the treatment of particular propositions consists not in the fact that she represented these as denoting "something," for such an interpretation had already been suggested by Venn, but in her attempt to grapple with the problem of dealing with particulars in a general manner. Her aim was to give formulæ that would deal with them with as much ease as the formulæ that Boole proposed for universals deal with these. But though she realised the full significance of the difficulties, and attempted to surmount them, she cannot be said to have succeeded in the attempt. As will presently be shown, the formula that she proposed for elimination in the case of particulars involves error. Venn, it may then be said, was the first to recognise the existential character of particulars, while Mrs. Ladd- 


\section{Symbols of Operation}

Franklin devised a very convenient notation for expressing, and in some respects for dealing with such propositions, but she did not succeed in presenting a general treatment of the subject.

VI. But, supposing, in the next place, that the premises are not stated in categorical form, and appear as hypotheticals or disjunctives, the question arises if they can be expressed in symbolic language. Venn was undoubtedly the first symbolist who went at all fully into this question. He maintained that hypotheticals and disjunctives may without difficulty be expressed symbolically, for they are to be regarded as denoting a certain amount of compartmental destruction. The symbolist is not interested in the causes that led to the formation of these types of propositions. He does not, that is to say, emphasize the relations in which the individual stands to the environment, and which lead to the utterance of the hypothetical or the dis- 
junctive. As in the case of categoricals the only information that we here get is as to what compartments are destroyed, what are saved, and what cannot be said either to be destroyed or to be saved. Venn goes carefully into the consideration of the three kinds of hypotheticals, those involving two, three, and four elements respectively, and in each case he determines what effect the proposition has upon the compartmental scheme. In short, according to Venn, it makes no difference whether the premises are stated in categorical, disjunctive, or hypothetical form.

But Mr. Johnson in his discussion of this subject has shown that Venn's investigation is not exhaustive, and that to stay at the point reached by Venn would involve us in error. In the first place, Mr. Johnson distinguishes between conditionals and pure hypotheticals.* For one thing, in the case of the former, but not in the case of the latter, an equivalent categorical may be

$$
\text { * Mind, N.S. No. I, p. } 17 .
$$


obtained whose subject and predicate correspond respectively to the hypothesis and consequent.* That is to say, when we have conditionals, the hypothesis and the consequent refer to certain cases of a phenomenon in time or in space, while in a pure hypothetical we have presented an implication between two propositions of independent import. But, further, the pure hypothetical receives minute examination at Mr. Johnson's hands, and he demonstrates that there is no equivalence of any kind between this proposition and a categorical, except in one particular case, namely, where there is a universal antecedent and a particular consequent. In the other three cases it can only be said that a categorical implies, or that it is implied by, a pure hypothetical. $†$ From these considerations it is clear, therefore, that Venn and Boole cannot in their class Logic deal generally with the pure hypothetical, for their pro-

* Keynes, Formal Logic, $3^{\text {rd ed. p. } 213 .}$

$\dagger$ Mind, N.S. No. 2, p. 242. 
cedure is to express the premises of an argument as though these in every case denoted class relationship. But if we follow the course adopted by certain other logicians-MacColl, Johnson, and Russell, for instance-and allow symbols to represent propositions rather than classes, the pure hypothetical can receive adequate treatment. It is to be noted that Keynes asserts * that, though pure hypotheticals cannot be expressed as categoricals, in which the subject and predicate correspond respectively to the hypothesis and consequent, it is always possible to turn the former propositions into categoricals of some sort or other. But if Mr. Johnson's analysis is correct, as it certainly is, this statement of Keynes cannot be accepted :

* Formal Logic, 2nd ed., note on p. 165. Keynes omits this note in the third edition, where he does not refer to the question whether the hypothetical may always be expressed as a categorical of some kind or other. He restricts himself to the remark (p. 213) that reduction to a categorical " is not possible at all (with terms corresponding to the original antecedent and consequent) in the case of hypotheticals." 


\section{Symbols of Operation}

the change may sometimes, but not in every case, be effected.

Where the premises contain a disjunction it is important to observe whether this occurs in the subject or in the predicate. Venn, Keynes, and Schröder all call attention to this point. Only is there a true disjunctive proposition when the disjunction is found in the predicate. " $A$ or $B$ is $C$ or $D$," therefore, means " $A$ and B (each of them) is either C or D." 


\section{CHAPTER III}

\section{THE PROCESS OF SOLUTION}

\section{I. (I) Analytical Method. - Having}

then stated our premises in the way that has been described, the question next arises as to the best method of proceeding with our symbolic expressions. Our object is to determine what is said about one of the letters, or about a combination of them, in terms of the remaining letters, or of a portion of them. The propositions must obviously in some way be combined, so that it may be seen what is the totality of the force they possess. Boole would proceed to bring over all the terms to the left-hand side, and equate to zero. Then, if in each case the left-hand member is an expression that is equal to its square, all such members may be added together, and the result be put equal to 0 . 
But, should it happen in any case that a left-hand member is not equal to its square, the process of squaring must be performed before the terms are added to those of the other equations. We thus obtain a single class expression that is equal to zero. The squaring just referred to is necessary in order to obtain co-efficients that are positive, for only in this case will the same constituents appear in the resulting equation that occurred in the separate equations.*

The characteristic method of Venn, on the other hand, is the following. Supposing the premise appears in the form $x=\frac{0}{0} y$, he restricts the left-hand member by the contradictory of $y$, and then equates to zero. In the case of $x=y$ it is necessary both to do this and to equate to zero the result of restricting $y$ by the contradictory of $x$. The addition of these two equations is a full statement of the information given, i.e., each of the left-hand members being equal to 0 , the sum of them will also equal 0 . * Laws of Thought, chap. viii. props. 2 and 3. 
This applies, of course, to universals only. With regard to particulars it has been shown above that Boole cannot utilise his rules in their behalf. Venn, however, by interpreting them as denoting existence, is able to express them in relation to 0 . $\mathrm{He}$ can show not only what compartments the universals destroy, but what compartments the particulars save. Venn thus shows an advance upon Boole both in dealing with universals in a simpler manner, and in bringing out the full force of particular propositions.

The process of manipulating the symbolized premises having thus begun, it will be well to mention here two formulæ that are sometimes useful in effecting a simplification. One of them is due to Boole and the other to Peirce. Boole's is given among his methods of abbreviation, and is $(A+x)(B+x)=A B+x$. The one for which we are indebted to Peirce is as follows: $(\mathrm{A}+x)(\mathrm{B}+\bar{x})=\mathrm{A} \bar{x}+\mathrm{B} x$. $^{*}$

* See Venn, Symbolic Logic, pp. 69, 70. 
It may be well also to call attention to the advantages which Schröder's methods of solution have over those of Boole. In the Operationskreis, and with more elaboration in the Vorlesungen, Schröder is careful to take no step that is not justifiable on purely logical grounds. All his intermediate processes are intelligible. Jevons was going too far in stating that Boole's methods were "fundamentally false," * for Venn has pointed out that they are justifiable, but their justification requires a good deal more than a simple act of intuition. Boole, for instance, applied his rule of development to fractional forms, and it is quite true that the results of that application may be shown to have a definite meaning, a meaning, too, which the symbols employed may be said to suggest. But the suggestion is by no means immediate. It needed Venn's careful analysis to bring to light the logical meaning underlying these symbols. The forms of Boole did not suggest to Jevons their logical in* The Principles of Science, p. II 3 . 
terpretation, but they suggest this at the present day, now that Venn has gone exhaustively into the subject.

In the case of Schröder, on the other hand, each step is intuitively obvious, and this obviousness has its advantages. For one thing, the beginner is saved the labour -though this salvation is by no means altogether an advantage-that would have to be spent in tracing out the admissibility of the various steps in the solution. The one method is as logically intelligible as the other, but there is more for the understanding to do in the one case than in the other, in order to grasp the significance of the process.* Another point in which Schröder excels is that his solutions are

* I think that Adamson hardly states the case correctly when he says that "the superiority in logical intelligibility of Schröder's solution must be admitted" (Mind, No. x. p. 254). His remark, moreover, seems to suggest that all the intermediate processes in a solution ought to be intelligible; but this is not so, because a calculus is a means of reaching correct conclusions by means of the mecbanical application of a few logical rules, and it is quite possible that in the application of such rules unintelligible elements may temporarily appear. 
effected with more compactness. Judging the two symbolists by the number of lines or pages that they occupy in the solution of the same problem, there is certainly little difference to be noted in this respect, $\%$ and it was probably from such an examination that Adamson was led to state that it is doubtful whether Schröder's methods are so much more compact than Boole's. But on the whole, I think, Schröder in this matter shows an advance upon Boole, while Keynes' methods, which in many respects resemble Schröder's, are neatness itself.

When the equations have been put into the form of a single sum of terms equated to zero, it is possible to eliminate one or more letters which are not wanted in the result. The first writer to show how elimination in these complicated problems may be effected was Boole. He gave the well-known formula $f(1) f(0)=0$. That is to say, he developed the expression

* Lawus of Thought, pp. 146-149; Der Operationskreis des Logikkalkuls, pp. 25-28. 
with respect to the term to be eliminated, and then multiplied together the coefficient of the term and that of its contradictory. He also showed that the formula may be extended to the case of the elimination of two or more terms.

This is undoubtedly one method of eliminating, and one that may frequently be employed. But it is to be noted that it is not the only method, and that it applies only to universals. Venn and Schröder have described other methods for dealing with this problem. Schröder points out that, the equation having been expressed as a sum of terms equated to zero, we may obtain the elimination of a letter if we take all the terms that do not contain the letter, and to them add those which when taken together do not involve it. In the expression $\mathrm{A} x+\mathrm{B} \bar{x}+\mathrm{C}=0$, that is to say, the elimination of $x$ will be given by $\mathrm{AB}+\mathrm{C}=0$. And Venn shows how elimination may be effected without bringing over all the terms to the left-hand 
side. When, for instance, such an equation as $w=x y \bar{z}+x \bar{y} z+\bar{x} y z$ is given, and we want to eliminate $y$, what we do is to substitute the indefinite symbol $\frac{0}{0}$ for $y$ and $\bar{y}$ in the equation.

It is important to observe that in dealing with the problem of elimination the amount of work required in carrying out the method of Boole is greater than that involved if we follow Schröder. In the case of the earlier logician it is necessary to develop the expression on the left hand with regard to the letters to be eliminated, but in Schröder's method those terms that are free from the letters to be eliminated may be set down at once as part of the required result. As a matter of fact, however, Boole, though he does not in his statement of the rule mention this simplification, avails himself of the shorter method when he comes to work examples.*

* See the problem at the bottom of p. I44 in the Laws of Thought, and his mode of eliminating $a$. 
Coming now to the case of particulars, the process of elimination was first correctly described by Venn. He shows that the elimination of $x$ from the inequation $\mathrm{A} x+\mathrm{B} \bar{x}+\mathrm{C}>0$ can only yield $\mathrm{A}+\mathrm{B}+\mathrm{C}>0$, and that in more general symbolic language this result may appear as $f(1) \quad f(0)>0$.

And lastly, suppose that one of the premises is universal, and one is particular. Venn also shows how elimination may be effected in this case. From $\mathrm{D} x+\mathrm{E} \bar{x}+\mathrm{F}=0$ and $\mathrm{A} x+\mathrm{B} \bar{x}+\mathrm{C}>0$, since $\bar{x}$ is $\overline{\mathrm{E}}$ and $x$ is $\overline{\mathrm{D}}$, we may substitute in the inequation and get $A \bar{D}+B \bar{E}+C>0$. This, together with $\mathrm{DE}+\mathrm{F}=0$ from the universal, gives the elimination of $x$. And Venn here too states in general form the method of dealing with the problem of elimination. His formula appears as follows :-

$$
\left\{\begin{array}{l}
f(1) f(0)=0 \\
\phi(1) \cdot \overline{f(1)}+\phi(0) \cdot \overline{f(0)}>0 . *
\end{array}\right.
$$

Another formula, one which may be

* Evidently there is a misprint in Venn's statement of his formula : instead of $\overline{f(1)}$ he has $\overline{f(x)}$. (Symbolic Logic, p. $3^{88 .}$ ) 


\section{The Process of Solution}

shown to be equivalent to this, has been suggested by Mr. Johnson in an examination question in the Moral Science Tripos.* This formula runs as follows: If everything is $f(x)$ and something is $\phi(x)$, the elimination of $x$ is given by-

$$
\left\{\begin{array}{l}
\text { Everything is } f(1) \text { or } f(0), \\
\text { Something is } \phi(1) f(1) \text { or } \phi(0) f(0) .
\end{array}\right.
$$

This problem of dealing with elimination, when there is a combination of universals and particulars, had been attacked by Mrs. Ladd-Franklin, but in her statement of the rule she made a mistake. She says "if the premises include an alternation of particular propositions, the conclusion consists of the partial inclusion of the total co-efficient of $x$ in the particular propositions by the negative of that of $x$ in the universal propositions, added to the included combinations which are free from $x$ as given." $\dagger$ Such a rule would lead us when dealing

* Cambridge University Examination Papers, vol. xvi. p. 536 .

$\dagger$ Johns Hopkins Studies in Logic, p. 45. 
with the equation $A x+B \bar{x}+C \bar{v}$ and the inequation $\mathrm{E} x+\mathrm{F} \bar{x}+\mathrm{G} \vee$ to the conclusion $\mathrm{EA}+\mathrm{C} \quad \mathrm{G} \vee$. But here we have evidently committed error, for we have concluded that $\mathrm{C}$ is something, whereas in the universal it was declared to be nothing.*

In tracing to their sources and criticizing the methods that have been suggested for the performance of the process of elimination, it has been necessary to refer to the question of development or expansion. This question has been adequately discussed by all three of the logicians who have done most for the earlier Symbolic Logic, i.e., by Boole, Venn, and Schröder. The last of the three was, I believe, the first to give a geometrical justification of the process, $f$ but the analytical treatment of the subject was well treated by Boole at the outset. It was in the Laws of Thought that the now well-known formula $f(x)=f(1) x+f(0) \bar{x}$ first appeared. A companion formula to

* See the critical notice in Mind for October, 1883.

$\uparrow$ Der Operationskreis des Logikkalkuls, p. I 4. 


\section{The Process of Solution}

this has been proposed by Peirce, viz., $f(x)=\{f(1)+\bar{x}\}\{f(0)+x\}$. This formula may be used when we prefer to have the development as a product of sums rather than as a sum of products.*

In order to bring out one or two other points where later logicians show an improvement on Boole, it may be well to describe somewhat fully one of his solutions. We may take the problem that is worked out on pages 138 and 139 of the Laws of Thought. In the first place, he put the premises in the form $V_{1}=0, V_{2}=0$, and so on, i.e., in each case he brought over with changed signs all terms that were originally on the right-hand side of the symbol of equality. These equations were then added together, unless $V_{1}$ or $V_{2}$ needed squaring, in which case he squared before performing the process of addition. His next step was to make any necessary eliminations,

* See Venn, Symb. Log. p. 388 ; Peirce in the Amır. Journ. of Math. vol. iii. p. $3^{8}$. In Peirce's formula $f(\infty)$ is used instead of $f(1)$, but the meaning is the same as that of $f(1)$. 


\section{6 \\ Symbolic Logic}

and to effect these he proceeded to develop the resulting equation with reference to the letter or letters about which information was not required: the desired elimination was obtained either by multiplying together the resulting co-efficients, or by constructing the equation $E y+E^{1}(1-y)=0$, where $E$ is derived by changing into 1 in the original equation the letter about which information is asked, and then eliminating the letters not required, and where $E^{1}$ comes from changing into 0 the same letter, and making the same elimination. We thus arrive at an equation from which, by means of the application of the principle of expansion to fractional forms, the desired information may be obtained.

In this process of solution there are several drawbacks, which the more modern methods are able to avoid. We have already noticed certain modes of eliminating which are sometimes more convenient than that proposed by Boole. The 
necessity of squaring may be escaped by adopting Venn's plan of restricting the lefthand member by the contradictory of the right-hand member, and equating the result to zero. Sometimes, again, a resort to diagrams is easier than the plan laid down by Boole, who, strange to say, never appeals in his work to a diagram. And, once more, when in the course of our solution we arrive at a fractional expression with a complicated numerator and denominator, we may, so long as real class terms are involved, employ the formula $\frac{x}{y}=x y+\frac{0}{0} \bar{x} \bar{y}$, and thus avoid the liability to error from the 1 and 0 substitution.

The fact that there is abundance of opportunity of falling into mistakes on the Boolian plan of making this substitution needs perhaps but little emphasis. Those who have worked through several examples by his method will fully realise the liability. Boole himself has not always escaped falling into mistake. His solution, for in- 
stance, for $s(1-t)$ on p. I 45 of the Laws of Thought is certainly wrong, as may easily be shown by working the problem in two or three of the available ways. The answer should be irn $+\frac{0}{0}(i \bar{r}+\bar{i})$. But, though Boole's method is long, it has one marked advantage over those proposed by later logicians. That is to say, when the process that he describes has at last been completed, the whole solution that can be asked for with regard to the relation of certain letters to certain others has been obtained. For instance, on p. 397 of his Symbolic Logic, Venn reaches a conclusion $x z=\frac{0}{0} a c+\frac{0}{0} \bar{a} \bar{c}$. Now this gives assurance that $x z$ is found somewhere within $a c$ or $\bar{a} \bar{c}$, but does not tell us whether ac or $\bar{a} \bar{c}$ is more extensive than $x z$. To find out whether this is so, two operations, similar to that by which information concerning $x z$ was obtained, would have to be performed. But, when Boole had once worked out the conclusion concerning 


\section{The Process of Solution}

$x z$, there would be no doubt in what way the constituents of the other member ought to be expressed in terms of $x z$, for the coefficient 1 or $\frac{0}{0}$ would be decisive upon the point. In other words, when $\frac{0}{0}$ appears as a co-efficient in Venn's solution, the question arises whether the symbol may possibly be equal to 1 , and a new piece of work is necessary in order to determine if this is so; but, when the symbol is found at the conclusion of Boole's process, no such doubt arises, for if a term is there to have the co-efficient 1 this fact will be brought out in the original solution.

When the method referred to above of obtaining all the denials is employed, it will as a rule be necessary to combine a set of terms with the contradictory of another set of terms. Hence it is desirable to have a simple means of finding the contradictory of a complicated expression. Here De Morgan was the first to make the way plain. His rule, ex- 
tended by Venn, is as follows: For every elementary term substitute the contradictory, interchanging at the same time the symbols of addition and multiplication. This rule is mentioned by Schröder on p. I 8 of the Operationskreis, but he does not refer to De Morgan. It is also given, without employment of expressions that imply symbols of operation, by Keynes, who alludes to this early work of Schröder. To this rule Venn adds another. He gathers up the expression to be contradicted into the form $A x+B \bar{x}$, and then contradicts $A$ and $B$, thus arriving at $\bar{A} x+\bar{B} \bar{x}$. This procedure is often a simpler one either than applying De Morgan's rule, or than fully expanding the original expression, and then finding the contradictory on the principle that the contradictory of $x$ is $1-x$.

(2) Diagrammatic Method. - We have now somewhat fully discussed the simplifications that have been effected in the analytical methods of solving complicated problems. We have next to remark 
that pari passu with this simplification there has gone a marked advance in the employment of diagrams, both for the purpose of representation and for the purpose of solution. Boole, as we noticed above, never appealed to diagrams. The Eulerian method is entirely unsuitable in the case of complex propositions-is, indeed, not accurate for simple ones. Dr. Keynes has shown the unsuitability of the Eulerian diagrams, and himself has employed a diagrammatic method that is quite accurate. But Keynes' procedure, though accurate, is much too cumbrous to be of any use except in the case of propositions of the very simplest description.

Venn set himself as one of his tasks to invent a suitable diagrammatic representation of propositions, and within certain limits he was very successful. He suggested the intersection of circles, ellipses, or other closed figures to denote compartments, some of which are destroyed or saved by the premises. This plan works well up 
to five terms, and it is possible to use it for six terms. Theoretically, though not practically, it may also be used for any number of terms. It was left for Dr. Marquand to suggest an elegant method of dealing diagrammatically with those cases that involve a very large number of terms. In the case of seven terms, for instance, he forms sixteen rows of squares, eight deep. The rows are alternately (say) $d$ and $\bar{d}$. These are marked off in pairs, which are $c$ and $\bar{c}$, such pairs into other pairs $b$ and $\bar{b}$, and these, again, into the pairs $a$ and $\bar{a}$. Then those squares that constitute the depth of the figure may be marked off similarly with reference to the letters $y \bar{y}, x \bar{x}$, and $z \bar{z}$. A diagram on this plan for even ten terms would occupy only a page.

As we remarked a few pages back, diagrams may sometimes be made of service in the solution of direct problems. Such is the case when the problem is to show that a certain compartment has been en- 
tirely erased. A diagram constructed on Venn's plan decides at once whether the premises have effected such an erasion. And, where the problem is one of elimination, Dr. Marquand's diagrammatic method is serviceable in reaching the desired conclusion. To eliminate $y$, for instance, in the problem with seven terms, all that is necessary is to take those groups which involve any of the four pairs of $y$ and $\bar{y}$, add such groups together, and equate the sum to zero.* It may be remarked, however, that, if we adopt Dr. Marquand's diagrammatic scheme, the process of effecting the erasions is rather a slow one. This arises from the fact that the squares to be erased by each section of the premises do not lie together.

But, though diagrams are to this extent of service, direct problems are as a rule much more expeditiously worked by literal methods. A diagram takes some time to construct, and often when completed does * Venn, Symbolic Logic, p. 374. 
84

not yield at all easily the information we require. In fact, if the symbolist employs diagrams, he is guilty of a somewhat retrograde movement. For in the case of a figure we have to a certain extent to think out the answer, whereas a genuine calculus supplies us with a mechanical contrivance by which results may be reached with no other thought than that which is required by a person who manipulates a machine.* On the whole it must be said that, with the exception of the two cases above mentioned, diagrams in relation to the solution of direct problems are mainly of interest as giving a pictorial representation of conclusions that have been reached by the analytical method.

II. So far we have considered the method of finding the description of a letter or letters, mentioned in the premises, in terms of all or of certain only of the remaining letters. But there is also the

$$
\text { * Mind, N.S. vol. i. p. } 3 \text {. }
$$




\section{The Process of Solution}

inverse problem, and, as in the case of the direct problem, there have been here, during the period that Symbolic Logic has been studied, many improvements suggested in the methods for effecting a solution.

Boole does not attempt to deal with the Inverse Problem. Jevons realised what is the nature of the problem, but he did not suggest any general method of obtaining a solution. He drew up a table which applies to three terms, and he showed what types of proposition will result in the given destructions.* But he does not demonstrate how to arrive at a proposition that will occasion the destructions, and he does not attempt to deal with more than three terms.

It was one of the important contributions of Keynes to the development of Symbolic Logic to suggest three methods by which a solution to this problem can always be obtained. As Venn points out, it cannot be said that there is one and only one solution

$$
\text { * The Principles of Science, p. } 140 .
$$


of these problems; in other words, each of several solutions will occasion the given destructions. Keynes discovers what terms are saved, and then he throws the proposition into the form: "Everything is $\mathrm{X}$ or $\mathrm{Y}$ or $\mathrm{Z}$ or $\mathrm{W}$," where these letters represent complex terms. Hence "What is not either $\mathrm{Z}$ or $\mathrm{W}$ is $\mathrm{X}$ or $\mathrm{Y}$." Then, if the subject is thrown into the affirmative form, a series of simple propositions may be obtained that are together equivalent to the original proposition. Another method is to employ the process of obversion and reach the negative form: "Nothing is . . ." This proposition then splits up immediately into a set of simple propositions. A third method is to put the proposition into the form "Everything is ..." Then select (say) the A and the a members, and form two propositions, " $\mathrm{A}$ is . . .," " $a$ is . . ." Next, in both cases take the B and $b$ members, so obtaining four propositions. And so proceed until the propositions have no disjunctives in the predicate. 
A fourth method of dealing with the inverse problem is suggested by Schröder's third corollary to his 36 th Proposition,* namely, the method of double negation. This amounts to taking the saved terms and equating them to 1 , then contradicting both sides and getting an expression, composed of factors, which is equal to 0 . This expression may then be multiplied out. Then, if both sides are contradicted again, there will be another expression composed of factors equal to 1 . Each factor will consequently be equal to 1 , and we arrive at a series of simple propositions. This rule is not given in so many words by Schröder, but it follows immediately from the above-mentioned corollary.

A considerable advance in simplicity in connexion with this part of the subject was made when Mr. Johnson showed how Keynes' third method may be employed in a semi-diagrammatic manner. Mr. Johnson first of all shows clearly that, by a process

$$
\text { *Vorlesungen, pp. 356-357. }
$$


of multiplying out, the Inverse Problem may be solved by a direct process, and that we are not, as Jevons maintained we are, here limited to a series of guesses. But the process of multiplying out is long, and the same solution may be obtained if we "represent and by horizontal juxtaposition, and or by vertical juxtaposition." * That is to say, commencing with the given expression, Mr. Johnson finds what terms are equated to unity. He then takes two lines at right angles to one another, and lets opposite squares represent (say) $a$ and $\bar{a}$. Each of these regions may then be divided into similar portions to represent other letters and their contradictories, and so we may proceed until all the letters find their suitable place. Then, if the columns are read downwards, and the letters joined by + , and if all such sums are multiplied together, an expression will be reached equal to the original one. Hence each one of the factors of this product is equal to 1 ,

$$
\text { * Mind, N.S. No. 3, p. } 350 .
$$


and thus simple propositions are at once obtained. Mr. Johnson's originality here consists in his perceiving that the formula $(a c+\bar{a} d)=(a+d)(\bar{a}+c)$ could be expressed in this useful way, and in showing in a particularly convincing manner wherein Jevons' error consists in identifying Induction with the Inverse Problem. The fact that this problem can be solved by a direct process was also made very evident in Mr. Johnson's discussion, but of course Keynes had already practically settled this matter when he proposed the three methods of solution given above.

It will be noticed that at the end of $\mathrm{Mr}$. Johnson's solution there is an assumption that if the product is equal to 1 , then each of the factors is also equal to 1 . That this assumption is perfectly justifiable is made clear by reference to one of the truths that was established in the Johns Hopkins Studies by Dr. Mitchell.* He showed that if we have "All $x$ is $y$ " and "All $y$ is $x$," i.e.,

* See Venn's detailed critical notice in Mind, October, 1883. 


\section{0}

$x \bar{y}=0$ and $\bar{x} y=0$, the compound expression of these propositions may be given just as well by $(x y+\bar{x} y+\bar{x} \bar{y})(x y+x \bar{y}+\bar{x} \bar{y})=1$ as by $x \bar{y}+\bar{x} y=0$. He was the first logician, that is to say, to bring out the fact that the process of multiplication in the former case is equivalent to the process of addition in the latter. Obviously, therefore, to get back to the separate statement of the premises as equations, with 0 for one of the members, it is necessary that each of the factors $(x y+\bar{x} y+\bar{x} \bar{y})$ and $(x y+x \bar{y}+\bar{x} \bar{y})$ should be equal to 1 . 


\section{CHAPTER IV}

CONCERNING A CALCULUS BASED ON INTENSION*

In the critical history, which we have now concluded, of the earlier Symbolic Logic, we have had occasion to note one point on which logicians have been separated into well-marked divisions, viz., the point as to whether symbols should primarily or exclusively be employed to denote classes or to denote propositions. Boole, and Venn after him, used symbols primarily to denote classes or individuals, and secondarily to stand for propositions.

* By the expression "a Calculus based on Intension" I mean a Logic based on attributes rather than on classes. The term "intension" here is used in a general sense, not in Keynes' special sense of attributes "mentally associated" with a name. On the other hand, "connotation" and "comprehension" throughout this chapter are taken in the sense that Keynes has assigned to them. 
Schröder and the contributors to the Johns Hopkins Studies have advanced the subject on the same lines. Mr. Johnson in his presentation of the Calculus has used symbols in the first place to denote unanalyzed propositions, and, subsequently, when he treats of the synthesis of singly-quantified and of multiply-quantified propositions that follows their analysis, he points out that predications obey the same laws that were originally enumerated as necessary and sufficient for the synthesis of unanalyzed propositions. That is to say, symbols here stand primarily for propositions and secondarily for terms. Mr. MacColl also holds that propositions and implication are more fundamental than classes and inclusion.*

We have now to take note of a subject on which all these logicians are in agreement : they all hold that Symbolic Logic should adopt an extensive interpretation of the proposition. I think they are un-

* Mind, No. 17, pp. 49, 51; B. Russell, The Principles of Matbematics, p. 12. 
On a Calculus Based on Intension 93 doubtedly correct in holding this view, but the matter, which is one of great importance, calls for careful argument. In the present chapter I shall endeavour to prove that labour is not wisely spent in attempting to elaborate a calculus on intensive lines. My method of proof will be to take the work of the most consistent logician who has proceeded from the intensive standpoint, i.e., Castillon, and to show in detail the errors into which he fell in constructing the various portions of his symbolic structure. It will become evident, I think, as the investigation advances, that a calculus cannot be elaborated on the lines he laid down. Then, having demonstrated where his errors lie, I shall refer to the treatment of the subject given by Venn, with whose conclusions I am in agreement, viz., that, when we confine our attention to the attributes that are commonly denoted by the name, a calculus based on intension is impossible, but that, when we take all the attributes common to 
the members of the class, * it is possible to reach a calculus, but that this would be unnecessarily long and artificial. That is to say, the logicians mentioned above will be shown to have advanced in the right direction, inasmuch as failure or unnecessary difficulty is to be met with in the attempt to work out problems by reference to nothing but attributes.

I. Of the various logicians, whose work is based on an intensive interpretation of the proposition, Lambert is perhaps the most distinguished, but Castillon is the only thinker who, setting out from this point of view, has attempted to be rigorously consistent. The memoir, Sur un nouvel algorithme logique, which Castillon presented to the Berlin Academy in I803, is in many respects a remarkable production. In connexion with the attempt that the writer made to utilise symbols to represent the intension of terms, he * What Keynes means by "comprehension," 
On a Calculus Based on Intension 95 treated of logical problems which have not until quite recently received the attention they deserve, and some of his speculations appear even now almost unknown to the general student of Logic.

(I) Castillon's Fundamental Notions.-And first of all it will be useful to notice what is Castillon's conception of the nature of Symbolic Logic, * for he is here to a very large extent unquestionably upon the right lines. Symbolic Logic means a generalised Logic, i.e., it is a general treatment of that aspect of thought which receives a limited treatment in ordinary Formal Logic. The consideration of deduction from this higher point of view renders clear many processes that are necessarily described inadequately in the ordinary text-books of Formal Logic; and, what is still more important, actual errors that have arisen in attempts to treat exclusive portions of deductive reasoning are

* He does not, of course, use this term, which is not, I believe, to be found before the publication of Venn's book in $188 \mathrm{I}$. 
exposed. But the idea of Symbolic Logic also implies the notion of a calculus. That is to say, there is implied such a manipulation of symbols that conclusions are reached that would be quite unattainable by intellectual intuition. Symbols of some sort are essential in fully conscious reasoning. But as employed in a calculus symbols take on an additional function. They no longer merely help the mind to reach a judgment : they obtain a judgment for a mind that has in the meantime been engaged upon an operation quite different from that of reflecting upon their meaning. As $\mathrm{Mr}$. Johnson has clearly shown, there is in a calculus the intelligent manipulation of symbols by means of which results are unintelligently reached. This view implies, of course, that a calculus is very different from being merely a symbolical illustration of logical doctrines. Castillon had a clear idea of all these truths. Where he went wrong on this subject-and he has had successors who have fallen into the same mistake- 
On a Calculus Based on Intension 97 was in the following particular. He was of opinion that symbols can in some way discover the forms of judgment, can, for instance, indicate that the infinite judgment is not of the essence of Logic, or that naturally all judgment is apodeictic. But symbols can never discover the forms of judgment, but can only proceed according to their own laws, after the import of the judgment has been unfolded.

We will proceed to consider the precise description Castillon gives of the nature of the proposition, and to observe the primary use he makes of symbols. Each object that we meet with in the course of our experience forms a mental image, which, though made up of sensations, is at first not recognised as so composed. Subsequently, however, by means of imagination, the individual sensations may be detached from the whole, and a symbol may be employed both for the original complex and for the sensations so separated. Other sensations may 


\section{$9^{8}$

be similarly abstracted, and we thus arrive at such an equation as $\mathrm{O}-\mathrm{A}-\mathrm{B}=\mathrm{C}+\mathrm{D}$. Here $\mathrm{O}$ is a congeries of attributes, and the right-hand member represents the attributes that remain when $A$ and $B$ have been abstracted from $\mathrm{O}$. We are in this way, it will be seen, dealing with nothing but attributes, and the symbol that is chosen to denote a combination of attributes in a whole is correctly said to be $(+)$, while the symbol $(-)$ is employed to denote that attributes are abstracted from the whole with which we start. The signs $(+)$ and $(-)$, that is to say, indicate respectively the combination and the abstraction of attributes. It must here be allowed, then, both that there is sound psychological doctrine, in that growth of perception is seen to consist in progress from the obscure to the definite, and that there is appropriateness in the signs that are used to represent the elements and progress of thinking, when this has once commenced.

But it is necessary to inquire whether 
On a Calculus Based on Intension 99 it is justifiable to use in this way the symbol for equivalence. Venn argues that on the intensive interpretation of propositions such use is inappropriate, since, if a group of attributes is equivalent to another group, there are no means of distinguishing the one from the other.* This criticism appears to me to be true, but only within narrow limits, namely, when the two members consist of one group each, and all the attributes of each group are explicitly recognised. But then in the case of most equations there is nothing of this kind. For instance, $\mathrm{S}=\mathrm{P}+\mathrm{M}$, the form for the universal affirmative in Castillon's symbolism, denotes that $\mathrm{S}$ consists of a definite attribute, or group of attributes $\mathrm{P}$, and another group $M$. Here both $S$ and $M$ stand for groups, whose elements are not, as a rule, present before the mind. It is, therefore, surely permissible to say that the group denoted by $\mathrm{S}$ is identical with one that is specifically mentioned, together with * Symbolic Logic, p. 456 . 
another group denoted by $M$. And not only is there the fact that the attributes denoted by $\mathrm{S}$ and by $\mathrm{M}$ are not enumerated, but it is obvious that $\mathrm{S}$ is regarded as one group, while the right-hand member is composed of two groups: the sign $(=)$ is, therefore, quite as appropriate as it is in class Logic if we say that $x=x \bar{y}+x y$, where, of course, one class is declared to be identical with its two composing classes. Venn, in urging his conclusion, appears to have confined himself to the consideration of two simple conceptions that are declared to be equivalent. He is correct in saying that many logicians have thought that they were equating attributes, when really. they were merely equating classes whose extension happens to coincide. Of course, any such reference to classes involves inconsistency of treatment. But, when it is said that the attributes designated by $S$ are equivalent to the attributes designated by $\mathrm{P}$, together with those designated by $M$, there is no more re- 
On a Calculus Based on Intension io I flection required concerning classes than there is concerning attributes in extension Logic.

In the next place, we may notice the description that Castillon gives of the laws that lie at the back of formal reasoning. Some logicians have endeavoured to deduce the Law of Contradiction from the Law of Identity, or vice versa, but he says that, if judgments denote respectively the synthesis and the separation of attributes, then every judgment implies both principles. I think that those who deduce one principle from the other can only do so by some arbitrary assumption that one is "more natural" than the other.* But in Logic we are not justified in thus acting according to our preferences. We have to state the actual facts of the case, and in this particular those facts are that the Laws of Tautology and Reciprocity $\dagger$ are equally fundamental:

* Proc. of the Arist. Soc. N.S. vol. ii. p. I I 5.

$\dagger$ This term includes the Law of Contradiction and the Law of Excluded Middle. 
the former denotes that it is immaterial to thought whether a thinker duplicates a conception, and the latter that a predication consists, and consists exclusively, of what is left when the conflicting ideal that is involved in every judgment has been rejected.*

Having maintained to the above extent the independent character of the Laws of Identity and Contradiction, Castillon somewhat spoils matters by suggesting that, after all, one of the two principles may be more fundamental than the other. His proposal is to regard the principle of Contradiction as expressing the fact of the composition of a concept, while the principle of Identity denotes the reminiscence of a concept; for in positing a concept one thinks the presence and not the absence of attributes (Contradiction), but in recalling a concept the intelligence has to retrace the attributes, for otherwise the earlier concept would not be reinstated (Identity). This statement of * Mind, N.S. No. i. pp. 1 о-12. 


\section{On a Calculus Based on Intension 103}

what is involved in the principle of Contradiction is practically the same as the statement given at the end of the last paragraph. But Castillon's account here of the principle of Identity is very unsatisfactory. For the act of recalling certain attributes, if such recall is occasioned merely by the unconscious fusion of certain fresh presentational elements with a portion of the memory train, is certainly not what is meant by the principle of Identity; while, if the recall is deliberate, then there is contemporaneously a rejection of certain attributes, and the principle of Contradiction is involved.

The important question now arises whether on this intensive view of Logic it is possible to deal with other than essential attributes, and Castillon has received Venn's approval for consistency in not considering attributes that are accidental. Castillon's universal affirmative is, as we have said, $S=A+M$, and the universal negative appears as $S=-A+M$. The former means 
that the object $S$ is the sensation $A$, plus a group of other sensations $M$, which remain indeterminate, while the symbols for the universal negative denote that the object $S$ does not comprehend $A$, that the object $S$ is an indeterminate $M$ without $A$. Now, at first sight, it does appear that we must confine ourselves here to essential attributes, for in the case of the universal affimative, at any rate, we just unfold the nature of $\mathrm{S}$, state the group of attributes of which it is composed. But then it seems quite possible to do as Venn hints, * namely, to regard the essence as consisting of what is usually designated by that term, together with a limited number of other attributes. If Castillon's methods are valid on the narrower interpretation of the word essence they are valid on the wider interpretation. He suggests that, by means of small letters, it is possible to represent accidental attributes - thus $\mathrm{O}=\mathrm{A}+\mathrm{B}+\mathrm{C}+\mathrm{D}+e+f$-and, though he certainly does not recur to * Symbolic Logic, p. 463 . 
On a Calculus Based on Intension io5

this method of symbolism, I do not think his reason for not doing so was because he felt that there would be anything unsound about such a procedure. In admitting, however, this extended signification of the term essence, it is to be noted that the number of attributes is limited, for otherwise we should not have an equation, since $\infty$ is not necessarily equal to $\infty$. M, whatever it denotes, is indefinite only, not infinite.

In close connexion with this discussion is the consideration of the precise interpretation to be put upon Castillon's representation of the universal negative. His procedure here has, I think, been to some extent misunderstood. But it will be better to postpone for a moment the examination of his symbols, and to notice the classification of judgments that he prefers to adopt. The Critical School had admitted infinite terms, so that it could at once throw a universal negative into the form of a universal affirmative. Hence 
that school, Castillon says, tended to regard judgment exclusively as synthesis: the attribute comprehended by the subject could be either affirmative or negative. But he urges that it is preferable to divide judgments into affirmative and negative, and to reject the class of infinite judgments.* Castillon's position is rendered the more precise, inasmuch as he states that the classification he adopts, and which he describes as excelling others in both truth and generality, is based upon the definition of judgment given by Wolf: that is to say, judgment is "the act by which the intelligence perceives that two concepts, that are present to it, can be joined or ought to remain separate." Castillon is thus definite enough upon this matter, and it is absolutely essential to remember this, if one is to understand clearly his treatment of the universal negative.

When, then, it is observed that judgment is made to consist of synthesis or of * Mémoire, p. I I. 


\section{On a Calculus Based on Intension io7} analysis, and not of the former only, the explanation that Venn offers of Castillon's universal negative is seen to be misleading.* Venn asserts that the expression $\mathrm{S}=-\mathrm{A}+\mathrm{M}$ indicates that $\mathrm{S}$ is composed of two groups of attributes, of which the first is negative and the second is positive. That is to say, he writes the symbols as though the minus sign and the A were bracketed. But this view of the case must be wrong. If such transformation is effected, then we shall be dealing with a universal affirmative, and all judgment will be reducible to synthesis. To get at Castillon's meaning we must do as he says, namely, take the minus sign in conjunction with the sign of equality. The expression will then be read thus: " $\mathrm{S}$ does not contain A but does contain an indeterminate M." I do not mean to argue that Castillon is always consistent in his treatment of this universal negative, for he certainly does sometimes deal with the proposition as though the bracket had been

$$
\text { * Symbolic Logic, p. } 466 \text {. }
$$


inserted. Moreover, he admits in so many words that the infinite affirmative judgment may be reduced to a universal negative, and that the latter may be expressed as the former. But, generally speaking, he does not adopt the method of making a change to the affirmative: he proceeds on the understanding that a proposition which is expressed like the above is to be interpreted as denoting a separation of A from S. In short, I admit that Castillon is uncertain in his treatment of the universal negative, but think that his intention was always to regard this proposition as a case of decomposition rather than as one of composition. The sign (=-) with him signifies " is not."

What Castillon wishes to be understood by the minus sign is well brought out when we look into his treatment of conversion and of syllogism. In some cases of these processes he is able to adhere rigorously to his idea of the import of proposition. For instance, take Celarent, 
On a Calculus Based on Intension iog which appears thus: " $\mathrm{M}=-\mathrm{A}+\mathrm{N}$," " $\mathrm{S}=\mathrm{M}+\mathrm{P}, " \therefore \mathrm{S}=-\mathrm{A}+\mathrm{N}+\mathrm{P}$." Here $S$ in the conclusion comprehends $P$, just as was the case in the premise, but does not comprehend $A$, and yet comprehends $\mathrm{N}$, since these were the characteristics of $M$ in the premise. There is not the slightest need in such a case to change the major premise into a universal affirmative infinite judgment. Again, take Cesare: "A $=-\mathrm{M}+\mathrm{N}$ " $(\therefore$ " $\mathrm{M}=-\mathrm{A}+\mathrm{N}$ "), " $\mathrm{S}=\mathrm{M}+\mathrm{P}$," $\therefore$ " $\mathrm{S}=-\mathrm{A}+\mathrm{N}+\mathrm{P}$."

Just noticing in passing that Castillon gives " $\mathrm{M}=\mathrm{A}+\mathrm{N}$ " as the converse of the major-one of his many accidental mistakes in the use of his symbols-we see that he argues that, since no $A$ is $M$, but is an indeterminate $\mathrm{N}$, therefore no $\mathrm{M}$ is $\mathrm{A}$, but is an indeterminate N. Now, though this attempt at conversion is altogether unjustifiable, as I shall presently show, it helps to bring out the way in which Castillon regarded the meaning of the minus sign. For his conclusion is not 
" $(-\mathrm{M})=\mathrm{A}-\mathrm{N}$," which would be the converse of the universal affirmative, and which would be read "some $(-M)$ is A," but it is "no $M$ is A." On the other hand, for an instance where, in the treatment of the universal negative, he sacrifices principle, take the following: " $M=-A+N$," " $M=S+P$," therefore " $S+P=-A+N$," and hence " $\mathrm{S}=-\mathrm{A}+\mathrm{N}-\mathrm{P}$." Here it is obvious that two things are conceived as identical with $M$, and are hence concluded to be identical with one another. That is to say, he here interprets the universal negative with the minus sign attached to the A.

It follows from these considerations that the minus sign in Castillon's calculus is used in two quite different senses. Take his representation of the particular negative, namely, $S=-A-M$. This denotes that the $S$ attributes are not the $A$ attributes, when the $M$ attributes have been abstracted from the latter. That such must be the 
On a Calculus Based on Intension 1 i I

correct interpretation is seen from regarding the particular positive, $\mathrm{A}=\mathrm{S}-\mathrm{M}$ (the converse of the universal affirmative), where the $A$ attributes are equivalent to the $S$ attributes, when the $M$ attributes have been abstracted from those denoted by $\mathrm{S}$. Such, then, being the appropriate interpretation of the expression for the particular negative, it is obvious that the minus sign is used with a double signification. In the first place it is coupled with the $(=)$ to signify "is not," i.e., " is to be kept separate from," and in the other case the sign denotes abstraction: the attributes denoted by $M$ are to be eliminated from those denoted by A.

(2) Illusory Particulars.-We may now pass to an examination of Castillon's peculiar doctrine of the subdivision of particulars. $\mathrm{He}$ distinguishes between the real and the illusory particular proposition. The former is the converse of a universal, the latter is true because it is a subaltern. If, that is to say, " $S=A+M$ " represents the universal 
affirmative, it follows that $\mathrm{A}$ will be equal to $\mathrm{S}$ minus $\mathrm{M}$, and this in Castillon's view will represent what in class Logic is termed the accidental converse. On the other hand, when a particular is said to be true because it is a subaltern, we are stating less than the truth, for we might adhere to the universal. Hence our symbols must bring out this fact, and we shall have such a form as $S=A \mp M$. This means that we affirm "some $S$ is $A$ " $(\mathrm{S}=\mathrm{A}-\mathrm{M})$, whereas it is allowable to say "all $S$ is $A$ " $(S=A+M)$.

But this conception of the illusory, instead of introducing considerations that involve less than the truth, involves positive error, and must, I think, be definitely rejected. In discussing the matter, the fact that the calculus is being considered from the intensive point of view is to be kept always in mind. Of course, on the class view of the proposition, it is quite allowable, provided that subjects exist, to proceed from A to its subaltern. But 


\section{On a Calculus Based on Intension i i 3}

the same course is not allowable when we are arguing intensively. If the attributes denoted by $\mathrm{S}$ consist of those denoted by $A+M$, to state that the attributes denoted by $\mathrm{S}$ consist of those denoted by A - M is palpably false. We do not, in taking such a step, arrive at something less than the whole truth: we arrive at a falsity.

In deciding the fate of this illusory particular the fact has to be noticed that there is no question here of an alternative rendering. The symbol $(\mp)$ may at first sight suggest that the proposition is to be read either as a particular or as a universal. But this is not what Castillon says. His doctrine is that the particular is as a matter of fact taken, where the universal might be. So that an incorrect statement is accepted in place of the correct one. Nor is it a case where the alternative sign is used because the element of doubt enters, because we know that one proposition is to be accepted, but we do not know 
which. The illusory neither offers us an alternative nor involves an element of doubt: it compels us to accept a false statement. The attempt, therefore, to get at subalterns in the way adopted by Castillon must be relinquished.

Hence many of the proofs that Castillon offers for various logical doctrines must be regarded as resting on a false foundation. Take, for instance, his method of representing the proof of the convertibility of particulars affirmative and real. The form for this particular is, as we have seen, $\mathrm{A}=\mathrm{S}-\mathrm{M}$. Now, he says, since this proposition implies the universal $\mathrm{S}=\mathrm{A}+\mathrm{M}$-which, however, is not the case, as I shall show presently-and the latter implies the subaltern $S=A \mp M$, we reach the desired demonstration. My criticism of this is that he has proceeded from a proposition that is true to one that is false, and that therefore the desired result has not been established.

After having given this question of 
On a Calculus Based on Intension i I 5

Castillon's particulars a good deal of consideration, I thought that perhaps illusories correspond to propositions in which in class Logic the "some" means "some, it may be all," while in real particulars the "some" means "some only." And had this been the correct view of the case there would also have been no possibility of making use of illusory particulars, for the same system cannot be worked out where there is ambiguity about the meaning of "some": as Venn would say, the fourfold scheme cannot be made to correspond with the fivefold scheme. But further reflexion upon the matter has led me to dismiss the illusory particular on other grounds, namely, those given above. That "some" in the particular real denotes "some only" there is no doubt whatever. If "all" in it might be substituted for "some," then the converse of $\mathrm{S}=\mathrm{A}+\mathrm{M}$ might be $\mathrm{A}=\mathrm{S}+\mathrm{M}$, which obviously involves a falsity, since, if the components of $S$ are $A$ and $M$, it 
is absurd to conclude that A only can be composed of the attributes denoted by $\mathrm{S}$ together with those denoted by $M$. Such being the case, we have not a converse similar to that which is found in ordinary Logic, where, of course, "some" means "some, it may be all." Castillon does not notice this, but thinks that he has performed the operation that in common Logic is known as accidental conversion. $\mathrm{He}$ could arrive at a converse statement concerning " all "-supposing for the moment that the symbol $(=)$ would then have a meaning-if $M$ were equal to nothing. But he does not give the slightest hint that he had contemplated this possibility. Always in speaking of $\mathrm{M}$ as an indeterminate number of attributes, he means that there actually are attributes denoted by this letter. And, as these points are clear enough, it is, I think, equally clear that the illusory particular makes no statement about "some, it may be all": this proposition is incom- 
On a Calculus Based on Intension i I7 patible with the universal, with which Castillon's Logic can ill afford to dispense.

Castillon certainly has a very ingenious argument by which he attempts to show that subalterns should be allowed a place in his calculus. He takes the description of an object to be symbolized thus: $\mathrm{O}=\mathrm{A}+\mathrm{B}+\mathrm{C}+\mathrm{D}$. Then he says that from this we may conclude that $\mathrm{O}-\mathrm{A}=\mathrm{B}+\mathrm{C}+\mathrm{D}$. Here $\mathrm{O}-\mathrm{A}$ will denote the species under which the object $\mathrm{O}$ is comprised. This is quite reasonable. But he then proceeds to say that since $B+C+D$ are marks of the species, much more will they be the marks of the object $O$. Hence, if a universal is true, so is the subaltern. The error into which he here falls is obvious. There is no more reason that $\mathrm{B}+\mathrm{C}+\mathrm{D}$ should be among the attributes that are equated to $O$ than that these attributes should be equated to $\mathrm{O}-\mathrm{A}$. When it is said that $\mathrm{O}-\mathrm{A}=\mathrm{B}+\mathrm{C}+\mathrm{D}$, all that is meant is that if $\mathrm{A}$ be taken from the congeries $\mathrm{O}$ the 
remainder will be the right-hand member. If then the attribute $A$ is put back again, the three attributes will be no more characteristic of $\mathrm{O}$ than they were of $\mathrm{O}-\mathrm{A}$. To argue on a fortiori lines, as does Castillon, is to introduce other than formal considerations.

It may be noted in passing that on the assumption that in intensive Logic we have only universals and real particulars, and that the latter may be converted in the way Castillon lays down, two important results will follow with respect to arguments involving three or more terms. The first result will be that we shall be able to include inferences that have nothing corresponding to them in the ordinary class Logic, and the second will be that many arguments, which in the latter find a place, can no longer be regarded as valid. As an instance of one of the inferences that would be admitted, take that which is quoted by Venn, and which was exhibited by Castillon in a previous memoir: "some A 


\section{On a Calculus Based on Intension i 9}

is $\mathrm{B}$, some $\mathrm{B}$ is $\mathrm{C}$, therefore some $\mathrm{A}$ is C." This, it will be observed, is given in the language of class Logic, but is not, of course, valid in that Logic. According to Castillon, however, the conclusion is quite justifiable, for each of the three propositions may be expressed by means of conversion as a universal, and then we have " $B=A+M$, $\mathrm{C}=\mathrm{B}+\mathrm{P}, \therefore \mathrm{C}=\mathrm{A}+\mathrm{M}+\mathrm{P}$." $\mathrm{As}$ an instance of a demonstration that Castillon believes may be admitted, but which must be rejected, take the following: " $M=A \mp N$, $\mathrm{M}=\mathrm{S}+\mathrm{P}$ (or $\mathrm{S}=\mathrm{M}-\mathrm{P}$ ), $\therefore \mathrm{S}=\mathrm{A} \mp \mathrm{N}-\mathrm{P}$ : i.e., making $\mp \mathrm{N}-\mathrm{P}=\mp \mathrm{Q}$, we conclude $\mathrm{S}=\mathrm{A} \mp \mathrm{Q}$." The illusory particulars here being inadmissible, this form of argument must be regarded as untenable.

In drawing inferences involving illusory particulars, Castillon, it may be remarked, is sometimes led by the associations of quantitative mathematics into further error. For instance, he does not hesitate to change the sign $\mp$ into \pm . It is true he does not mean anything by the change: in present- 
ing the sixth mood of the third figure, he says that the subaltern of $\mathrm{M}=\mathrm{S}+\mathrm{P}$ is $\mathrm{M}=\mathrm{S} \pm \mathrm{P}$, so that he clearly makes no distinction between this and $\mathrm{M}=\mathrm{S} \mp \mathrm{P}$. But he ought not to make such a change, for what his reversed symbols must actually be taken to mean, when strictly interpreted, is that he is using a universal proposition where he is warranted in using a particular, a course that is obviously unjustifiable.

I have attempted to prove that Castillon's illusory particular must be entirely rejected, for it cannot be retained without involving the logician in self-contradiction. But it is necessary here to observe that Dr. Venn has expressed the opinion that Castillon did actually reject these propositions. Dr. Venn, soon after the publication of the first edition of his Symbolic Logic, was able to obtain a copy of Castillon's memoir, and sent a short account of the system to Mind.* The account is substantially the same as

$$
\text { * Vol. vi. p. } 448 \text {. }
$$


On a Calculus Based on Intension i 2 I that given in Venn's second edition, but contains a statement to the effect that in the memoir particulars are divided into two kinds, one of which Castillon "rejects" as "illusoires." But in what sense can such rejection be said to have been made? Illusories are used in all arguments, just as much as are particulars real. When the demonstration of the validity of the conversion of real particulars is offered, no hesitation is felt in making use, as we have seen, of illusories; and constantly in the proofs of the syllogistic moods illusory particulars occupy an important place. In several cases we are told that precisely the same results are reached if for an illusory a real is substituted. I think it must be concluded that Castillon admitted both kinds of particulars. The illusories were not rejected, as Venn affirms they were, and, as I have attempted to show, they ought to have been. They were certainly regarded as never making the best of themselves; but the fact that they might have developed 
into universals and did not do so was not considered a reason why they should not be employed in logical proofs, when it was found convenient to resort to them.

(3) Inconvertibility of Real Particulars and of Universal Negatives.-I said a few pages back that Castillon is not justified in drawing an inference from $\mathrm{A}=\mathrm{S}-\mathrm{M}$ to $\mathrm{S}=\mathrm{A}+\mathrm{M}$ * Of course he is quite justified, as we have seen, in proceeding from the latter to the former, but if he commences with the former he may not proceed to the latter. To attempt to draw this second inference is equivalent to the attempt to get an A proposition by the conversion of an I proposition. Had Castillon been arguing in class language he would never, of course, have attempted to draw such a conclusion, but, as when he started with the intensive representation of a universal affirmative he obtained the form for the particular by taking over the letters

* I am indebted to Mr. Johnson for directing my attention to this important point. 
On a Calculus Based on Intension I 23 with changed sign, he thought he might start with the form for the particular affirmative, and then transfer letters with changed signs. We shall see in the next paragraph that he is not justified in performing the process corresponding to conversion of the universal negative, so that not in general, but only in a special instance, is he justified in changing signs and transferring terms to the other side of the sign of equality.

Castillon's universal negative need not detain us long. The main thing to notice in addition to what has already been mentioned is the reason for its inconvertibility. The proposition is symbolized thus:$\mathrm{S}=-\mathrm{A}+\mathrm{M}$, which means, as we have explained, that the attributes denoted by $S$ are to be separated from those denoted by $\mathrm{A}$, but are to be regarded as co-existing with those denoted by M. Now, such being the case, it is quite unwarrantable to conclude that the attributes denoted by $\mathrm{A}$ may consist of those denoted by $M$. But 
this would be asserted if we were to admit the converse $A=-S+M$, a procedure that Castillon considers to be valid.

From the above discussions it will be seen that Castillon is not justified in making use in his calculus of more than the following: universal affirmatives, real particulars (in which "some" means "some only"), and universal negatives, of which the second and third are inconvertible.

(4) Castillon's Treatment of Hypothetical and of Problematical Fudgments.-It is necessary finally to consider two questions with which the logician arguing on intensive lines, as much as he who proceeds from the point of view of the class or of the proposition, is concerned, namely, the questions as to the relation of hypothetical and problematical judgments to categorical, and the possibility of there really being any quantitative element involved in a proposition.

To commence with the former subject. Venn remarks that it need hardly be said 
On a Calculus Based on Intension I 25 that the distinction between hypothetical and categorical is, on the intensive view, rejected. And this is undoubtedly Castillon's view of the case. But I should like to point out that, though it is attempted in this way to get rid of the purely hypothetical element, Castillon evidently feels that there is something wrong in the procedure, and it is interesting to watch the device that he adopts in order to escape from the difficulty. "In the case of the hypothetical judgment it is evidently necessary that the intelligence has the perception that, if the attribute A belongs to the subject, the attribute $\mathrm{B}$ also belongs to it, and the intelligence can only have this perception in so far as it perceives that the concept of the subject comprehends, or can comprehend, that of the attribute $A$, and the latter the concept of the attribute B." I have italicized the words by means of which this conceptualist logician escapes from the difficulty of the situation. His introduction of these few words shows that he 


\section{26 Symbolic Logic}

recognises that in a hypothetical what we really have is, as Venn would say, a known conjunction of two phenomena, but we are not sure whether there is an instance of the pair before us.

In proceeding to consider the facts relating to problematical judgments, we cannot but be struck by the circumstance that, though Castillon had not arrived at an adequate account of these judgments, his efforts were being made in the right direction. Maimon had been willing to accept the problematical judgment, but Castillon holds that this should not be considered as part of the material that is manipulated by the logician,* for the so-called judgment has reference to the state of the mind previous to the formation of a judgment, to the preliminary indecision as to whether an attribute does or does not belong to a subject. Castillon was here quite faithful to his principles. For he could, strictly speaking, only make a categorical statement * Hc means, of course, the person who treats of "pure" Logic. 
On a Calculus Based on Intension i 27 concerning the subject and its attributes, and if feeling prevented his doing this there would be, of course, no proposition. There was with him no alternative but to form a certain subject-predicate combination and to refuse to form it. Where he failed to come up to modern thought upon the subject was in not perceiving that, besides having an implication, we may have a statement as to the relation in which the thinker stands to that implication. The statement of this relation would supply material upon which the pure logician could work. Sometimes the facts occasioning the thinker's mental attitude may be such that they admit of being stated in quantitative terms, sometimes such that they can be stated only by means of such vague terms as "probable," "possible." When numerical elements enter, the statement must be handed over to the mathematician, but, when nonquantitative terms are retained, the proposition can be dealt with in Logic, where it will be necessary to symbolize the relation 
in which the thinker stands to the implication with which he is confronted.

(5) Derivation of the Notion of Quantity.We now come to what is perhaps the most striking of the proposed changes in logical doctrine that are involved in the course of treating the proposition from the intensive standpoint. In all ordinary presentations of Logic the division of propositions into universal and particular is regarded as obviously justifiable. And the same division is made in the common notations with which the symbolist is familiar. It is true that, with this classification, the singular proposition gives rise to some discussion, but the symbolist does not hesitate to regard such proposition as a special case of the universal, i.e., the class may shrink down to an individual. Further, the classification is not invalidated when, in dealing with multiply-quantified propositions, a distinction has to be made between "some or other" and "a certain some." This limitation and this subdivision, in fact, only 
On a Calculus Based on Intension i 29

bring out more prominently the apparently indispensable character of the distinction between the universal and the particular. It is, therefore, strange to hear Castillon denying that propositions can be divided up in this way. The equation $\mathrm{S}=\mathrm{A}+\mathrm{M}$ carries with it, he says, no information either of universality or of particularity : what we have is merely a statement that the subject $\mathrm{S}$ comprehends the attributes $\mathrm{A}$ together with those denoted by $M$. In order to join to this statement the idea of universality or of particularity some other act is required than this act of synthesis. And of course he would argue that the converse $A=S-M$ has similarly no notion of quantity attaching to it.

It must be confessed that, in arguing in this manner, Castillon is proceeding in accordance with his principles. But, when he comes to justify his opinion that the notion of quantity is derived from a syllogistic process, it is at once seen that his reasoning involves the very quantitative 


\section{$130 \quad$ Symbolic Logic}

element, the origin of the idea of which he wishes to explain. He agrees-with certain reservations-to the syllogism by which Maimon endeavours to make the desired deduction. The notion of universality, for instance, is derived from such an argument as the following: the concept "man" comprehends the attribute " animal," the representation of such and such an individual, say Caius, Titius, \&c., comprehends the concept "man," hence the representation of any individual whatever comprehends the concept " animal" ; i.e., all men are animals. Castillon objects to regard this reasoning as containing no notion of quantity, for he considers that at least the second premise contains the notion of unity. He is inclined, moreover, to believe that every judgment carries with it the notion of "one" and "two," since there is supposed the concept of the subject and the concept of the attribute. But with this qualification of the statement of Maimon, who had maintained that the 
On a Calculus Based on Intension i 3 I above reasoning contains no notion whatever of quantity, Castillon agrees that it is possible thus to arrive at the conception of universality. But it is obvious, when we consider his argument, that it involves a petitio principii, for, unless every attribute of $\mathrm{B}$ were among those of $\mathrm{A}$, we could not infer that the $C$ attributes, which are some of the B attributes, are among those of A. Directly a three-term argument of this description is analyzed we see that there is no longer any rigid rejection of the notions of universality and particularity. Even when we perform such a simple process as that of conversion it is obvious that the notion of a part is implied. Indeed, Castillon says as much :" $\mathrm{S}=\mathrm{A}+\mathrm{M}$ gives $\mathrm{A}=\mathrm{S}-\mathrm{M}$, which indicates that $A$ does not comprehend $S$, but a part of $S$, that which remains when from S one abstracts $M$."

(6) Comparison of Castillon's Symbolism with Mrs. Bryant's.-Before proceeding to more general considerations, I may here call 
attention to the points of correspondence between Castillon's symbolism and that briefly sketched by Mrs. Bryant.* For the A proposition, when read intensively, Mrs. Bryant gives $e^{-a-\infty+\beta}=e^{-\infty}$, and hence $a+(\infty-\beta)=\infty$, which may be interpreted the act of comprehension predicates $\alpha$ and not- $\beta$ of a class, and thus reaches the same result as if $\infty$ were predicated of the class. That is to say, the class $a \vec{b}$ does not exist. Castillon's form is $\mathrm{S}=\mathrm{A}+\mathrm{M}$. This is evidently the same as $\alpha+(\infty-\beta)=\infty$, for the latter may be written thus : $a=\beta+\infty-\infty$, where, as Mrs. Bryant shows, the $\infty-\infty$ is either zero or positive; but Castillon, as we have pointed out, regards only the positive value. Mrs. Bryant's form for the universal negative is $e^{-a-\beta}=e^{-\infty}$, and this when written $a=-\beta+\infty$ is also clearly the same as $S=-A+M$, except that I do not think, for the reasons $I$ have mentioned, that Castillon's $M$ did or could mean an infinite

$$
\text { * Loc. cit., p. } 130 .
$$




\section{On a Calculus Based on Intension I 33}

number of attributes: the $M$ is only indefinite. As Castillon, when critically examined, has nothing corresponding to the $\mathrm{I}$ and $\mathrm{O}$ of the ordinary Logic, it is not possible to institute a comparison between the two symbolisms as regards particular propositions. So far as one can tell from the matter of her paper, and from the fact that she quotes the first edition of Venn's Symbolic Logic, Mrs. Bryant, when writing, was not aware of the work done by Castillon; but, in any case, her treatment of the subject is original. To the extent, however, that there is identity between the conclusions of the two logicians, it is of course impossible - supposing my criticisms of Castillon to be valid-to proceed on the lines suggested by Mrs. Bryant.

II. We have now examined somewhat fully the principles underlying Castillon's procedure, and the investigation shows that a calculus is not workable on the plan he unfolded. He proposed a system where 
the notions of universality and particularity could be reached only by means of a petitio principii, where universal negatives could not be converted, where on conversion of a particular affirmative we reach a universal affirmative, where "some" is inaccurately employed, and where it is not possible consistently to deal with hypotheticals. Such a system is certainly one that cannot lay claim to general acceptance.

(I) A Logic based on Connotation.-But it will be well to look for a moment at the question of an intensive Logic without reference to Castillon's work. My view on the general question is in close agreement with that which Venn reached in his chapter on this subject.* That is to say, where the attributes are taken that are denoted by the name, the available stock of propositions is too limited to make it worth while to attempt to elaborate a calculus. The only proposition in the ordinary Logic that would find a counterpart in this inten* Symbolic Logic, p. 453. 
On a Calculus Based on Intension i 35 sive scheme is the universal affirmative. To represent the universal negative it would not do to refer to two different groups of attributes, and to represent the particular propositions it would not do to have two groups of attributes, of which some were found in both groups.

This is the meaning of intension that Couturat has in mind when he holds that Symbolic Logic can only be built up from the standpoint of extension, and $\mathrm{Mr}$. Russell adopts the same meaning when he asserts that though, if we must choose either pure intension or pure extension as a starting-point, Couturat's view is correct, we may commence by assuming an intermediate position, and that this course is necessary if we wish to avoid self-contradiction, and if we wish to deal with infinite classes.* That it is this meaning of intension which these logicians tacitly adopt is made clear from considering Couturat's statement that an examination of the * The Principles of Matbematics, p. 66 , 


\section{36 Symbolic Logic}

system of Leibnitz "proves that algorithmic Logic-i.e., exact and rigorous Logic - cannot be founded on the confused and vague * consideration of comprehension; it has only succeeded in being constituted by Boole because he made it rest on the exclusive consideration of extension." $\dagger$

Now intension can be confused and vague only when it is said to embrace the conventionally fixed attributes, $₫$ and not when the totality of the attributes is held to constitute the intension. In the case of some names there may be always uncertainty what is the conventionally fixed number of attributes, and in the case of others, even though at one period the intension is well known, there will gene-

* Italics mine.

$\dagger$ La Logique de Leibnitz, p. $3^{87}$.

\$ These two adjectives might indeed be applied to that conception of intension which includes the attributes "that are mentally associated with a name, whether or not they are actually implied by it," i.e., to the conception of intension as Keynes uses this word; but that Leibnitz-and so Couturatwas not thinking of such attributes is clear, I think, from the example which is quoted immediately in the text. 


\section{On a Calculus Based on Intension i 37}

rally soon be uncertainty, owing to the changes that scientific researches effect on popular thought; but the totality of the attributes, positive and negative, known and unknown, is obviously a fixed quantity.

Another way of showing that Couturat has in mind the view of intension here ascribed to him is to consider the expressions of Leibnitz, for we shall thus see what precisely it is that Couturat thinks cannot be made the basis of a generalised Logic. Now Leibnitz says if A represents "triangle," and B represents "equilateral," then $A+B$ represents the concept "equilateral triangle," * i.e., the attributes denoted by this term are conceived of as two in number, viz., triangularity and equilateralness. But this is the conventional idea of an equilateral triangle: the totality of the attributes embraces many more attributes than these, e.g., the quality of being equiangular, and the quality of having each angle equal to sixty degrees.

* La Logique de Leibnitz, p. 376. 
Thus Couturat is thinking of the number of attributes implied by the name, or of the connotation in the sense that this word is used by Mill and Keynes. And this must be the meaning that Mr. Russell adopts, since in stating that Couturat's is the correct position, were there not an intermediate one available, he is evidently thinking of extension and intension in the same sense as is Couturat.*

(2) A Logic based on Comprehension.-The only way to reach an intensive Logic would be, as Venn says, to take all the attributes that are common to the members of a class. It would then be possible to draw a diagram that would be similar to the one used in compartmental Logic,

* I may here remark that, though with Mr. Russell I should hold that it is useful for the symbolist for the purpose of defining infinite classes to retain the conception of intension, I think it is somewhat misleading to say that Symbolic Logic has its lair in a position intermediate between pure intension and pure extension. When the calculus comes to be worked, it is necessary definitely to take up either the one position or the other, and, as the reasoning of this chapter shows, the extensive interpretation is the appropriate one to be adopted. 
On a Calculus Based on Intension i 39

but whose compartments would represent combinations of attributes instead of groups of individuals.

But, in order that such a calculus could be developed, it is to be noted that certain important assumptions would have to be made, and that even with the help of these it would not be possible to deal with all the processes corresponding to those which are found in class Logic. The assumptions in question are that negative attributes may be freely admitted, and that every combination of attributes mentioned in our scheme does not necessarily exist.* The process that cannot be symbolized on intensive lines is that of class subtraction. Even for addition no intensive logician has suggested any symbolism, but Venn has pointed out that this operation can be represented by means of a symbol denoting alternation, for instance by the symbol $\sim$. In case of subtraction no symbol could be correctly used, for, though we might place a symbol

$$
\text { * Venn, Symbolic Logic, pp. 469-473. }
$$


between two groups of attributes, we should not be dealing with an operation that affected attributes, but with one that affected the corresponding classes. I presume, however, that class subtraction could be dealt with by means of the following device. Supposing that the premises are given in a form that involves the subtraction of classes, we could turn this expression into one denoting multiplication, inasmuch as $x-x y=x \bar{y}$. Then this product could be symbolized by the addition of positive and negative attributes.

Now, if the rules of class Logic have reference to the four processes of addition, subtraction, multiplication, and division, and if these processes can either directly or indirectly be represented by symbols that stand for attributes, it seems to me to be demonstrated that the rules of class Logic can be adapted to deal with the respective groups of attributes. M. Couturat affirms that a Logic based wholly on intension is impossible, and Mr. Russell agrees with 


\section{On a Calculus Based on Intension i 4 I}

him.* But though, when the narrower conception of the word intension is taken, this impossibility may certainly be established, I do not think, for the reasons that I have given, that there cannot be a calculus on the adoption of the wider interpretation. I am here only discussing the possibility of the case, not the naturalness or simplicity of such a calculus. In both of these qualities such an intensive Logic as the one described would be far inferior to that which deals with classes in a direct manner.

To sum up the results of this chapter. We have shown that the most consistent reasoner from the intensive standpoint was led into many and serious errors, and that a calculus cannot be elaborated in the way that he described. Then we observed that, if our attention is confined exclusively to the attributes that are commonly denoted by the name, we can deal only with universal affirmatives, so that nothing of the * The Principles of Mathematics, p. 66. 
nature of a calculus can be reached on this view of intension. And, finally, we have seen that, when all the attributes common to the members of the class denoted by the name are taken as our starting-point, it would be possible to reach correct conclusions, but that the process would be long and artificial, when compared with the one in which it is classes or propositions that are symbolized. 


\section{H A P TER V}

THE DOCTRINES OF JEVONS AND OF MR. MACCOLL

IT was explained in the Introduction that the object of this work is to show that during the last fifty years there has been a distinct advance made in Symbolic Logic. In the first three chapters we were occupied in tracing the earlier portion of this development. In the fourth chapter we demonstrated that the logicians who have effected the advance were justified in taking an extensive view of the import of the proposition. The present chapter will be occupied with an examination of the work of two logicians, viz., Jevons and Mr. MacColl, who have proceeded by way of extension, but who have, I think, fallen into several serious errors. 
Of these two writers the former unquestionably exercised in England, at any rate, a greater influence than any other logician of his time, while the latter has in all his work shown an ability and inventiveness of a very high order. In spite of these facts, however, I cannot but think that Jevons and Mr. MacColl have not assisted to any great extent in erecting the symbolic structure that is at present available. In the case of Jevons the reason of this seems to be that he was wanting in the power of originating important logical generalisations, and that he failed to appreciate the full significance of the work done by other logicians. The smallness in the number of $\mathrm{Mr}$. MacColl's contributions to the creation of a useful calculus is apparently due to his conviction that it is impossible for him to co-operate with other symbolists, since their procedure involves, in his opinion, many limitations and errors. It becomes necessary, therefore, for us to look at the work of 


\section{The Doctrines of Jevons}

these two logicians, and to make evident, in the first place, that the reputation of Jevons must not be based upon the fact that he contributed in any important degree to the creation of a Symbolic Logic, and, secondly, that Mr. MacColl's processes have not the advantage that he claims for them, but that they are based on views that imply errors from which the ordinary symbolic logician is free.

I. To begin then with Jevons. It will not be necessary in his case to go into very great detail, since most of his deficiencies have been sufficiently examined in various parts of Venn's Symbolic Logic. But I have drawn up as full a statement of the case as I have been able to reach.

Jevons' doctrine of the superiority of the equation $x=x y$ to represent the universal affirmative is erroneous, for this form is immediately reducible to $x=\frac{0}{0} y$ or $x=v y$. It is impossible to adopt his method of 


\section{6

denoting particular propositions, for, though he avoids the difficulty apparent in the Boolian system, where $\frac{0}{0}$ is taken to denote complete indefiniteness, such escape is effected by employing the postulate that no term whatever shall be equivalent to 0 . This would exclude the possibility of a calculus, for a collection of consistent propositions may eventually be found to have established the entire destruction of a certain term.* I should agree with this criticism of Venn's, but I do not think that Jevons would have done so; he would probably have replied that if such collections of propositions resulted in such a destruction then the group was not perfectly consistent. Again, we have already seen that Jevons' argument against using the exclusive notation in Logic is not valid, though, since his time, this method of dealing with alternatives has been largely adopted: his point was that we do often think in the non- 
exclusive manner, but this is no reason why we should do so in our symbolic reasoning. He certainly drew up a table by which a type of proposition may be reached for the solution of the inverse problem in the case of three terms, but he did not assist in removing the difficulty involved in solving the inverse problem in general. Moreover, his doctrine that Induction is to be identified with this inverse method is quite erroneous, for, as Mr. Johnson has most perspicuously shown, the series of propositions that Jevons desires to reach are only determinants of the data-are, that is to say, neither more general nor more conjectural than the data. Jevons' conception of Boole's idea of the scope of Mathematics was, previous to the second edition of the Principles of Science, altogether mistaken, and hence the attempts in the earlier edition to "divest his (Boole's) system of a mathematical dress" could not result in much that is useful.* But even in the * G. B. Halsted, in Mind, No. 9, p. 134. 


\section{Symbolic Logic}

second edition the inaccurate notion has only partially disappeared. Boole's is now a quasi-mathematical system : it still requires " the manipulation of mathematical symbols in a very intricate and perplexing manner." Jevons, in holding the view that the process of subtraction is useless because the same operation can be represented as one of restriction, passes over the fact that each may be useful at times. His objection that, because he admits the Law of Unity into his system, it was necessary for Boole to do the same is without force, since Boole was not guilty of any inconsistency in the omission. Jevons declared that $\frac{0}{0}$ cannot be understood without reference to the mathematics of quantity, an assertion which is refuted from the simplest logical considerations : the expression represents "the class of which if we take 'no part' we obtain 'nothing.' " I do not profess that this list is complete, but it must be confessed that, though Jevons stimulated 


\section{The Doctrines of Mr. MacColl 149}

logical thought much more extensively than most men are enabled to do, his actual contributions to the development of Symbolic Logic were few and relatively unimportant. His great powers were, in short, less successfully occupied in the logical than in the mathematical realm. In pure economic theory and in currency investigations, where in both cases the argument is almost entirely concerning quantities, his work is of the utmost value, and has placed him in the very first rank of thinkers upon such subjects.

II. Coming now to Mr. MacColl, I wish to point out wherein I think he falls into error. My object in considering his work is to get at the truth on certain debated questions, so that I proceed at once to these. I readily admit that there are several points in which Mr. MacColland the same remark applies to Jevonsagrees with the other writers to whom we have had occasion in previous chapters 


\section{50

to refer. Of course, if Mr. MacColl had been the first to give prominence to these points, in which there is agreement, it would have been necessary for us to dwell upon them here in some detail, but with one exception they had been well considered by other symbolic logicians.

\section{(I) Mr. MacColl's Employment of Literal} Symbols. - The question that Mr. MacColl was the first to bring to the front is that respecting the use of literal symbols to denote propositions rather than to denote classes. In his papers published in the Proceedings of the London Mathematical Society, and in his contribution to Mind in I880, he clearly showed that symbols may be employed in this way.* And, inasmuch as the newer Symbolic Logic regards the process of symbolizing pro-

* Mr. MacColl was not the first person to utilise symbols in this manner, for sometimes letters are made to stand for propositions by Boole, De Morgan, and others, but he undoubtedly gave prominence to such employment, and, moreover, as stated immediately in the text, he considered that symbols should always stand for propositions. 
The Doctrines of Mr. MacColl i 5 I positions as more fundamental than that of symbolizing classes, we are indebted to Mr. MacColl for emphasizing the less usual application of symbols.

At the same time, even on this point I think that Mr. MacColl goes astray. In the first place, his view is that symbols should be restricted to the propositional use.* But, so far as the earlier Symbolic Logic is concerned, no such restriction is necessary. I have already argued this point. $\dagger$ Provided we employ the appropriate rules, it makes no difference whether the problems solved by Venn, for instance, are treated in the one way or in the other. And, in the second place, Mr. MacColl allows his symbols indiscriminately to represent propositions and propositional functions; + but, in so far as he has done so, he has not assisted in producing the newer Symbolic Logic, for in this it is a matter

* Mind, No. 17, p. 49 ; Venn, Symbolic Logic, p. $49^{2}$.

$\dagger$ pp. 10-22.

\pm Russell, The Principles of Mathematics, pp. 12, 22. 
of fundamental importance to draw a clear line of distinction between the two uses. Mr. MacColl's view, therefore, of the propositional use of symbols is both unnecessarily at variance with the older, and does not fit in with the more recent doctrine.

(2) Mr. MacColl's Treatment of Modal Propositions.- Mr. MacColl's two chief errors consist in his treatment of modal and kindred propositions, and in his doctrine of logical existence. Each of these questions may now be carefully discussed.*

The subject of modals is constantly turning up in Mr. MacColl's writings, but perhaps he has nowhere more clearly stated his view as to the treatment of such propositions than in his second and fifth papers in Mind, $†$ and to these we may give our chief attention. In his second paper he

* The former was referred to in the first chapter, and my general opinion upon the subject was stated, but Mr. MacColl's work claims more detailed examination than was possible in that place.

$\dagger$ N.S. Nos. 24 and 47. 
The Doctrines of Mr. MacColl i 53 asserts that "sometimes we have data or premises $\mathrm{P}$ which are not always certain or admitted to be true." But this conception of certainty implies a relation that Mr. MacColl has not observed. It implies an obligation on the part of a thinker to accept the truth of an assertoric proposition. Pure Logic cannot deal separately with these certain propositions: it can only deal with the relation in which a thinker stands towards the statement that is certain. Similar remarks apply to the treatment of propositions that $\mathrm{Mr}$. MacColl classes as variable or as impossible. We do not in the case of these employ special rules. As an instance of the way in which statements described by these three terms are to be dealt with, take the following: "It is impossible that $x$ is $y . "$ This would appear in such a form as "A thinker who can believe that $x$ is $y$ does not exist." That is to say, statements that are certainties, impossibilities, or variables may all appear in the form $A B=0$. 


\section{I54 Symbolic Logic}

It is because he has not perceived the method of dealing with these statements respecting probabilities that $\mathrm{Mr}$. MacColl frequently falls into the mistake of speaking of propositions as sometimes true and sometimes false. It may sometimes be the case that the phenomenon $a$ is followed by the phenomenon $b$, but it is not the case that the proposition $p$ is sometimes true and sometimes false. Like Mrs. Ladd-Franklin and Mrs. Bryant, Mr. MacColl confuses events with statements. That this is so is made very clear from his interpretation of $\frac{a}{\bar{\beta}}$. Here each of these letters represents a statement, and the expression is "called a causal implication, as it indicates some causal connexion between $\alpha$ and $\beta$." * But a statement cannot be the cause of another statement : the term "cause" has reference to two phenomena, not to two propositions about phenomena.

The same considerations show why $\mathrm{Mr}$.

$$
\text { * Mind, N.S. No. } 24 \text {, p. } 498 .
$$


The Doctrines of Mr. MacColl i 55 MacColl's use of the term "strength," when applied to propositions, is decidedly inappropriate. When $a$ implies $\beta$, but $\beta$ does not imply $\alpha, \alpha$ is said to be stronger than $\beta$. Of course the distinction between what implies and what is implied by is of fundamental importance. But the difference is one of kind, not of strength. The latter term suggests that an entity which is under consideration possesses different amounts of force at different times. But an argument containing the so-called weaker proposition would be an entirely different argument from one containing the stronger. The same statement cannot be said at one time to reach the strength of an impossibility, and at another to sink down to the weakness of a certainty.*

It will now be apparent what was meant by saying that Mr. MacColl confuses propositions with propositional functions. The variable " $\alpha$ implies $\beta$," which he calls a proposition, is, as $\mathrm{Mr}$. Russell points out,

$$
\text { * Mind, N.S. No. 24, p. } 499 .
$$




\section{56 Symbolic Logic}

a propositional function: the statement does not affirm truth or falsehood, but when special values are given to the $x$ in $a$ and $\beta$ we get a proposition. Mr. MacColl maintains that " $\alpha$ implies $\beta$ " is true under certain circumstances. The two views are, therefore, radically distinct. In one it is held that " $\alpha$ implies $\beta$ " may on certain occasions be spoken of as being true, while in the other it is held that this implication is neither true nor false. And, since the newer Symbolic Logic proceeds on the understanding that the distinction between propositions and propositional functions must be constantly observed, it follows that Mr. MacColl cannot be said to have definitely assisted in the advance that has recently been made.

It cannot be said that Mr. MacColl in his fifth paper has made his position on this question more tenable. $\mathrm{He}$ there institutes a comparison between his views and those of other symbolists, in the course of which he says: "I divide propositions 
The Doctrines of Mr. MacColl 157 not only into true and false, but into various other classes according to the necessities of the problem treated; as, for example, into certain, impossible, variable; or into known to be true, known to be false, neither known to be true nor known to be false; or into formal certainties, formal impossibilities, formal variables (i.e., those which are neither); or into probable, improbable, even (i.e., with chance even); and so on ad libitum." But reflexion shows that every proposition which he has in view, when taken in conjunction with the fact that it occurs in the respective class, gives rise to a true or a false statement, since what is in each case stated is the relation in which a thinker stands to an assertion, and the statement of this relation is an assertoric proposition. Hence all Mr. MacColl's propositions can be dealt with by the rules of ordinary Symbolic Logic.

Mr. MacColl thinks that other symbolists make no difference between the 
true and the certain, and between the false and the impossible. But it is quite clear that the assertorics in each pair are different. For instance, taking a true and taking a certain proposition, these would assume forms such as "All the angles of a triangle are equal to two right angles," and "A thinker is so constituted that he must believe that the angles of a triangle are equal to two right angles." Variable propositions are not overlooked by the ordinary symbolist, but he cannot accept the view that they "are possible, but uncertain, propositions whose chance of being true is some proper fraction between 0 and 1." While there is a meaning in speaking of the chance that a phenomenon will occur, there is no meaning in saying that the chance that a proposition is true is greater or less. At least the only meaning that such an expression could have would be where an individual was known to be a partial deceiver: we could then of course speak of the chance that some 


\section{The Doctrines of Mr. MacColl I 59} assertion of his would be true. But this is not what Mr. MacColl means.

From these arguments it will be clear that it is not correct to say "that the whole world of new ideas opened up by this exponential or predicative system of notation is a world with which they (ordinary symbolists) are utterly unable to deal ; the bare attempt on the part of logicians would lead to a general break-up of all the systems now taught, and a recasting of the whole of logic on different principles." I hope that I have made it evident, in the first place, that it is inexpedient to speak of many antagonistic systems rather than of a calculus that has evolved as a result of efforts in different directions, and, secondly, that this calculus can deal with all the statements that $\mathrm{Mr}$. MacColl has in view.

Mr. MacColl attributes the non-adoption of his doctrines to the perversity of human nature in general and of professional logicians in particular.* But this

$$
\text { * Mind, N.S. No. } 47 \text {, p. } 356 \text {. }
$$


cannot be the true cause. One has only to study the writings of such men as Venn, Johnson, Keynes, and Russell, to see that every really valuable logical truth is readily welcomed. For instance, Venn long held to the view that it is better to draw up rules on the understanding that symbols joined by $(t)$ are exclusives. He thought it highly important to keep to this rendering, because it was essential for the introduction of those inverse processes to which he attached such great value. But in spite of his preference he writes in his second edition: "I shall now adopt the other, or non-exclusive notation:-partly, I must admit, because the voting has gone this way, and in a matter of procedure there are reasons for not standing out against such a verdict.”* Then, again, Mr. Johnson readily accepts Keynes' methods of solving the Inverse Problem, and with one of them produces a still more effective way of reaching the solution. This

* Symbolic Logic, and ed. p. 46. 
The Doctrines of Mr. MacColl i6 I improvement Keynes inserts in a subsequent edition. Once more, Boole, Venn, and Schröder (in the Operationskreis) express their premises as terms equated to zero. Then Dr. Mitchell shows that it is possible, instead of equating to zero, to equate to unity, and Venn, in his review of the Johns Hopkins Studies, * and in the second edition of his Symbolic Logic, adopts this suggestion, while Mr. Johnson states that Dr. Mitchell, by the introduction of certain processes, among which comes this one of taking the affirmative form of expressing premises, has been "enabled both to simplify and to extend the range of logical symbolism in a most suggestive way." $\dagger$ If such writers reject Mr. MacColl's doctrine the cause must be found, I think, not in their prejudices, but in its untenability.

(3) Mr. MacColl's Doctrine of a Universe of Unrealities.-I will now examine the other important point on which I think $\mathrm{Mr}$.

* Mind for Oct., $1883 . \quad \dagger$ Mind, N.S. No. 2, p. $24 \mathrm{I}$. 
MacColl falls into error, viz., that respecting logical existence. His views on this question were fully stated in his sixth paper in Mind, * but he called further attention to the subject in a note in the following number of the review. $t$ In the subsequent number Mr. Russell and I gave our reasons for holding that the doctrine expounded in those places contained fundamental errors. $\mathrm{Mr}$. MacColl has replied to both criticisms, and in the last number of Mind $+\mathrm{I}$ referred to the points in this reply. The subject may, therefore, be said to have been pretty fully discussed. I shall here briefly state $\mathrm{Mr}$. MacColl's opinion, and shall then mention the two arguments, quite distinct ones, by which in my opinion it has been refuted.

We are told in the sixth paper that "we assume our Symbolic Universe (or ' Universe of Discourse') to consist of our

* N.S. No. 53 , p. 74.

$\dagger \mathrm{Mr}$. MacColl has also given a short summary of his views on this subject in his recently published Symbolic Logic and its Applications, pp. 76-78.

$\ddagger$ Jan., s 906 , p. 143 . 
The Doctrines of Mr. MacColl ${ }^{6} 63$ universe of realities, $e_{1}, e_{2}, e_{3}$, etc., together with our universe of unrealities, $0_{1}, 0_{2}, 0_{3}$, etc., when both these enter into our argument. But when our argument deals only with realities, then our Symbolic Universe $\mathrm{S}_{1}, \mathrm{~S}_{2}$, $\mathrm{S}_{3}$, etc., and our Universe of realities, $e_{1}, e_{2}, e_{3}$, etc., will be the same; there will be no universe of unrealities $0_{1}, 0_{2}, 0_{3}$, etc. Similarly, our Symbolic Universe may conceivably, but hardly ever in reality, coincide with our universe of unrealities." This statement very definitely represents $\mathrm{Mr}$. MacColl's view on the subject: there are two universes, one consisting of realities and the other of unrealities, and the Symbolic Universe may, according to the argument, consist of either or of both. Among realities will come "the man whom you see in the garden" and "my uncle," when we utter such a proposition as "The man whom you see in the garden is my uncle"; but, if we say, "The man whom you see in the garden is really a bear," we shall be speaking firstly of an unreality and then of a 
reality.* Such objects as "round squares" are unrealities.

Now here, as Mr. Russell has pointed out, $\uparrow$ two quite different things are confused, viz., the things that exist in a philosophical sense and the things that exist in a logical sense. To say that a thing exists in the former sense means that the thing has phenomenal existence, or other existence of a philosophical character, whereas " to say that A exists in a logical sense means that $A$ is a class which has at least one member." The question then arises how it is possible that two such notions of existence should ever be confounded, and the answer is to be found by considering those classes which have members, and whose members do exist in the philosophical sense. For instance, the class horse is one which has members, and these appear in the phenomenal world. But then there are some classes which have members

$$
\begin{aligned}
& \text { * Mind, N.S. No. 53, p. } 77 \\
& \dagger \text { Mind, N.S. No. } 55, \text { p. } 398 \text {. }
\end{aligned}
$$


The Doctrines of Mr. MacColl i 65 and these do not appear in such world, e.g., the class of numbers, or the class of mathematical principles. The difficulty that $\mathrm{Mr}$. MacColl raises with regard to centaurs, round squares, and so on, is solved by noticing that classes of such things are identical with the null-class, that is to say, the class that has no members.

Having thus explained the nature and origin of the confusion between the two kinds of existence, Mr. Russell is able to show that in the logical sense of the term existence (for with the other sense the logician has nothing whatever to do) the I and $\mathrm{O}$ propositions require that there should be at least one value of $x$ for which $x$ is $\mathrm{S}$, that is to say, that $\mathrm{S}$ should exist, whereas in the case of $A$ and $E$ such existence is not necessary.

Thus Mr. Russell's method of demonstrating that Mr. MacColl is involved in error amounts to making the fact indisputable that Mr. MacColl has identified two totally different things, viz., philosophical and 
logical reality. Another way of proving that Mr. MacColl's position is untenable is to show that it involves him either in selfcontradiction or in the necessity of making unjustifiable assumptions. This was the line of argument that I pursued in the discussion, and which I will here describe, but by a somewhat different method from the one previously adopted. In the first place, then, it is certainly self-contradictory to speak of two universes of discourse. The Universe of Discourse in Symbolic Logic means all the things that we are talking about, and there cannot be two such groups of "all." Within the Universe of Discourse there may certainly be two compartments, one of realities and the other of unrealities, but this is a very different thing from saying that there may be two universes. The question is one of principle, not one of mere words.

Next, consider the passages in which $\mathrm{Mr}$. MacColl has made unjustifiable assumptions. He believes that his fundamental 
The Doctrines of Mr. MacColl i 67 division into realities and unrealities supplies a method of getting rid of certain paradoxes that ordinary symbolists have to accept. He says that, whereas these thinkers are led to state "every round square (a null class) is a triangle," he can say "no round square is a triangle." But such a universal negative can be reached only by labelling some of our compartments real and some unreal, and to do this two premises are assumed, viz., "no round squares are real," and "all triangles are real." It is surely quite apparent that, having arrived at the possible compartments, which are indicated in the case of two terms, we have no right without further information to go over such compartments and state that some of them have, and some of them have not, existence in a philosophical sense.

I think these arguments are quite sufficient to show that Mr. MacColl's doctrine on the subject of existence cannot be accepted. But he accuses ordinary 
I 68

symbolists of becoming involved in error in holding their view. It is necessary, therefore, finally to prove that he is mistaken in making this assertion. In his note in Mind* Mr. MacColl holds that it cannot be right to say that the formula $0 \mathrm{~A}=0$ will apply whatever $\mathrm{A}$ may be. For, let A stand for "existent." Then we shall have "every non-existence is existent," and this, he says, is absurd. But there is no absurdity here. For with two terms 0 and "existent" the universe of discourse is necessarily divided into four compartments, namely, 0 not-existent, 0 existent, not-0 existent, not-0 not-existent. Whether the four may be expressed as less than four is not a point that we need here consider. Now, when we say "every non-existence is existent," what happens is that the first of these compartments is erased. This implies no absurdity. Where self-contradiction would come in would be if we were to say that this or * N.S. No. 54, p. 295. 
The Doctrines of Mr. MacColl i 69 any other compartment was both erased and occupied. So that, as Mr. MacColl has not shown that ordinary symbolists are guilty of self-contradiction in stating that every non-existence is existent, he has not proved that the formula $(0 \mathrm{~A}=0)$ cannot be accepted.

I may notice also in passing the argument advanced by $\mathrm{Mr}$. MacColl in his criticism of the ordinary employment of 1 and 0 in propositional Logic.* His object is to show that such usage leads to absurdity. To do this he commences by affirming that since 1 and 0 denote true and false propositions respectively, these symbols represent two mutually exclusive classes of propositions. Hence the definition $0-<1$ should assert that every false proposition is a true proposition, which is absurd. My reply to this is that it rests on a misunderstanding. For 1 and 0 never do represent true and false propositions, and consequently two

$$
\text { * Mind, N.S. No. } 47 \text {, p. } 357 .
$$


mutually exclusive classes of propositions. The symbols denote respectively the only possibility and no possibility: we do not refer to a class at all. The introduction here of the definition $0-1$ is, therefore, altogether unjustifiable.

From these considerations I think that the case against Mr. MacColl on the subject of existence must be said to have been established. On the one hand, he has been shown to have been wanting in discrimination between two totally different things, and, on the other, his statements have been demonstrated either to involve him in self-contradiction or to rest on unjustifiable assumptions. Also the charge that he brings against ordinary symbolists of unwarrantably generalising is seen to be without foundation.

But before leaving this subject I think it desirable to clear up a point on which the reader of $\mathrm{Mr}$. MacColl's reply to Mr. Russell * may still feel uncertain. 
The Doctrines of Mr. MacColl 17 I

Mr. MacColl says : " that the word existence, like many others, has various meanings is quite true; but I cannot admit that any of these 'lies wholly outside Symbolic Logic.' Symbolic Logic has a right to occupy itself with any question whatever on which it can throw any light." It would thus appear that Mr. Russell's symbolism cannot deal with certain problems with which a calculus may be expected to deal. But we may be quite sure that when Mr. Russell said that some meanings of existence lie "wholly outside Symbolic Logic" he did not mean that the logician cannot manipulate propositions that give information respecting the various kinds of existence. What was meant was that Symbolic Logic, in occupying itself "with any question whatever on which it can throw any light,"questions of existence among others-does not adopt any special meaning of existence that may be found in Philosophy. 


\section{CHAPTER VI}

\section{LATER LOGICAL DOCTRINES}

IN the present chapter I propose to deal with the following topics: (I) the doctrine of multiple quantification, (2) the impossibility of establishing a Logic of Relatives in the sense of a generalised treatment of copulæ, and (3) the new Symbolic Logic, the ideal of whose exponents is to demonstrate that there exists a logical calculus which is capable of dealing with any problems whatsoever of a deductive character. When these topics have been unfolded the arguments contained in this book will have been brought to a conclusion, i.e., we shall have demonstrated that there has been a real advance from the year I 854 to the year I903, when The Laws of Thought and The Principles of 
Mathematics were respectively published. The elucidation of the first and third topic is of obvious importance for our purpose. The discussion of the second is of indirect assistance: we shall show that modern logicians have been justified in maintaining that "no Formal Logic really treats of Relatives in general quâ Relatives." *

I. First of all, then, we will refer to the doctrine of multiple quantification. This question was taken up by $\mathrm{Mr}$. Peirce in the American Fournal of Mathematics and in the Johns Hopkins Studies in Logic, by Dr. Mitchell in the latter work, and more recently by $\mathrm{Mr}$. Johnson in Mind. The idea of multiple quantifications, as $\mathrm{Mr}$. Johnson shows, naturally follows from starting our logical investigations with the consideration of singular or molecular propositions. We may, that is to say, synthesize two of these, and get such a simple statement as that "Socrates is mortal and Greek?" Here the

$$
\text { * Mind, N.S. No. I, p. } 26 .
$$


subjects of the synthesized propositions are the same, and the predicates are different. Or we may have a set of such singular propositions with the same predicate and different subjects. These yield the propositions "Every $\mathrm{S}$ is $p$ " and "Some $\mathrm{S}$ is $p$," according as the synthesis of the singular propositions is of a determinative or of an alternative description. Then, as it is possible to have a determinative or an alternative synthesis of two universals or of two particulars, or to have either of these kinds of synthesis when one proposition is universal and one particular, there will be presented for consideration a total of six cases. Three of these, viz., the determinative syntheses, cover the ground of syllogistic reasoning. Finally, instead of having to synthesize propositions with one aggregate of subjects, it is possible that we may have to deal with two or with more than two aggregates. It is in the last case that the proposition is said to contain multiple quantifications.

One of the problems here met with, 
which Mr. Johnson has shown how to solve, concerns the method of synthesizing these multiply-quantified propositions. Another problem is where we are given such a synthesis and have to find the least determinate alternant that implies the given synthesis, or the most determinate determinant that the synthesis implies. He draws attention to the fact that in the solution of the first problem the important point to remember is that "the external quantification must be regarded primarily as quantified subject, and all that is internal to it as the predication for that subject." * For instance, the synthesis of "All $m$ 's love some it may be different $n$ 's" and "All $m$ 's serve all $n$ 's," is "All $m$ 's (love some it may be different $n$ 's and serve all $n$ 's)," and this reduces to "All $m$ 's (love and serve some it may be different $n$ 's and serve all $n$ 's)." Here the "All $m$ 's," which is the external quantification, is the subject, and what is internal to it, i.e., what is in the bracket, is the predicate. With

$$
\text { * Mind, N.S. No. 3, p. } 353 .
$$




\section{i76 Symbolic Logic}

regard to the second problem, in selecting a determinant from a synthesis of multiplyquantified propositions the expression must first be stated as a series of propositional alternants. Then each of these may be synthesized into a single proposition. In effecting this synthesis we must make the particular quantifications as far as possible external to the universal, the reason being that we want to get as determinate a determinant as we can, and it is a principle that internal synthesis has potency over external. Then, finally, we must reject unnecessary symbols, and make our selection from the resulting determinants. From this rule the rule for obtaining the least determinate alternant may be found if we interchange the words determinative and alternative, and the words universal and particular.*

It will be seen that here we are dealing with a subject upon which Boole and Venn give no hints. So that Peirce, Mitchell, and Johnson, in unfolding the doctrine, have * Mind, N.S. No. 3, pp. 347, 356, 357 . 
made distinct contributions to the Logical Calculus. But it is to be noted that, though these writers have all treated this subject, $\mathrm{Mr}$. Johnson shows an advance upon $\mathrm{Mr}$. Peirce and Dr. Mitchell in the following respects. Mr. Peirce did not make it at all plain that this doctrine of multiply-quantified propositions is a natural continuation of the doctrine of singly-quantified propositions. He first of all worked out the theory of relative addition and relative multiplication, and showed how double quantifications may be dealt with by means of these processes. Then, when he came to deal with cases where "relative and non-relative operations occur together," and with those involving plural relations, i.e., relations subsisting between three or more objects, he argued from the point of view of the singular proposition.* According to his treatment, therefore, it would appear that there is no unity running throughout the Logical Cal-

* Mind, N.S. No. 2, pp. 249, 250 ; Johns Hopkins Studies in Logic, p. 200 . 
culus: Boolian principles apply to singlyquantified propositions, and to cases of multiply-quantified propositions, but double quantifications are dealt with on different principles. Mr. Johnson, on the other hand, has shown that the Boolian principles are applicable throughout the whole treatment of the three kinds of propositions. $\mathrm{Mr}$. Peirce's relative addition and relative multiplication may be expressed in the form of ordinary Boolian addition and multiplication. For instance, " $x$ loves some benefactor of $y$ " may be read " for some $z$ that $z$ is loved by $x$ and is a benefactor of $y$," while " $x$ loves all but the benefactors of $y$ " may be read "for every $z$ that $z$ is loved by $x$ or is a benefactor of $y$." It was clearly an advance when Mr. Johnson showed that, since nothing is involved in the Calculus but pure synthesis and pure negation, there is no need for treating in any exceptional manner the cases of double quantification.

As regards Dr. Mitchell, whose treat- 


\section{Later Logical Doctrines}

ment of doubly-quantified propositions is admirable, and of whom it has justly been said that his work contains "the most important simplification of the Boolian Logic that has appeared," * the one fault to be found is that he seems always to consider that time is the secondary differentiating mark. $\dagger \mathrm{He}$ says: "Let $U$ stand for the universe of class terms, as before, and let $V$ represent the universe of time," + and in his examples $V$ in each case has this signification. But, as $\mathrm{Mr}$. Johnson holds, there is no need whatever to limit the reference in this way. We can, for instance, deal with such propositions as "every $x$ loves every $y$," just as much as we can with such propositions as "all the Browns were ill during every part of the year." Mr. Johnson in unfolding his own doctrine avoids this restriction, and treats the subject in a

$$
\begin{aligned}
& \text { * Mind, N.S. No. 2, p. } 240 . \\
& \dagger \text { Mind, N.S. No. 2, p. } 247 \text { n. } \\
& \text { Johns Hopkins Studies in Logic, p. } 87 \text {. }
\end{aligned}
$$


perfectly general way. The Calculus as presented by him is thus of a more useful character than that for which we are indebted to Dr. Mitchell.

During the discussion that has occupied this section I have not referred to the work of De Morgan. But he was undoubtedly the first to deal with the subject that we have been considering, , and it will be possible now to see how far he had advanced. $\dagger$

De Morgan was firmly of opinion that a generalised Logic ought to consider all the formal laws of relation, and that syllogism is to be considered as one particular form of relation. Having asserted this conviction, he proceeded to deal with

* See the Trans. of the Camb. Philosoph. Soc. vol. x. p. 33 I.

$\dagger$ That the work of pioneering was not easy may be inferred from his assertion: "I have had to work my way through transformations as new to my own mind, as far as the separation of form is concerned, as the common moods of syllogism to the beginner. If there be any person who can see at a glance, and with justifiable confidence, what classes of men, including women, are specified in 'the non-ancestors of all non-descendants of $z$,' I should not like to submit to his criticism the confusions and blunders through which I arrived at the following results." (Loc. cit. p. 334.) 


\section{Later Logical Doctrines i 8 I}

syllogism from the point of view of the relational proposition. First he drew up a table which shows what are the converse, the contrary, the converse of the contrary, and the contrary of the converse, of the propositions that express such compounded relations as are involved in the conclusion of a syllogism. He deals with this question of conversion and contrariety in quite the modern way. Then he affirms that the "supreme law of syllogism of three terms, the law which governs every possible case, and to which every variety of expression must be brought before inference can be made, is this: any relation of $\mathrm{X}$ to $\mathrm{Y}$ compounded with any relation of $\mathrm{Y}$ to $\mathrm{Z}$ gives a relation of $X$ to $Z$," or that " the universal and all-containing form of syllogism is seen in the statement of $X$. . LMZ is the necessary consequence of $\mathrm{X}$. . LY and Y . . MZ." * When this idea of relation is brought to bear on syllogism, he shows that Figure is important, "but

$$
\text { * Loc. cit. p. } 3+7 \text {. }
$$


not as connected with the place of the middle term. Whether we say $X$. . LY or LY . . X, the figure is the same. Change of figure can be effected only by conversion of relation." Having explained this, he exhibits in tabular form the conclusions that may be reached with two premises expressing relations. Here each figure has four "phases," determined by the quality only of the premises. And, finally, he shows how the ordinary syllogism with quantified subject is resolvable into the simple relational propositions that he has been discussing.

Thus it will be seen that De Morgan had comprehended the all-important character of singular propositions and of their synthesis, for the propositions that he combines in his second table are really the molecular propositions upon which $\mathrm{Mr}$. Johnson lays so much emphasis. And De Morgan, having shown how two of these may be synthesized, lays it down, though not in so many words, that syntheses of 


\section{Later Logical Doctrines 183}

these propositions, when consisting of different subjects and the same predicate, yield the quantified propositions with which ordinary Formal Logic is concerned. But he did not get any further than this. That is to say, he did not show that the same principles will explain how inferences may be obtained from propositions involving double or multiple quantifications. This subject was first treated by Mr. Peirce and Dr. Mitchell, but in different ways, and has been presented in a complete form by $\mathrm{Mr}$. Johnson, who, in the course of demonstrating that inferences of the kind in question rest upon the principles which we have shown De Morgan was able up to a certain point to apply, has made it clear how the writings of the two American logicians may be brought into harmony.

II. Perhaps there is no term in Logic which the reader is likely to find so perplexing as the term "Logic of Relatives." $\mathrm{He}$ not unreasonably supposes 


\section{Symbolic Logic}

when he comes to this part of the subject that he is going to consider all those expressions whose subject and predicate are not connected by the copula "is," but by the many other words or phrases that frequently join these fundamental portions of a proposition. Such general treatment of copula is certainly what the term in question suggests to the mind, and this is the extension that De Morgan at any rate had in view. But in modern logical works this investigation is given up as hopeless, and instead of it we are introduced to the subject of multiple quantifications. Of course, such alteration in the subject-matter need not have involved any confusion, and some writers have made it perfectly clear to their readers that the problem investigated is no longer the wider one. But Mr. Peirce calls the new inquiry by the old name "Logic of Relatives," and such a procedure is very misleading.*

* Johns Hopkins Studies in Logic, p. 192 ; American Jour. of Math. vol. iii. 


\section{Later Logical Doctrines i 85}

The important question at once arises whether the larger investigation is bound to be fruitless, and, if so, why such is the case. I think that a general treatment of copulæ cannot be undertaken by the logician, because we need in every case to have a piece of special information given us beyond the propositions that form the premises. Such information is necessary whether the conclusion is reached syllogistically or intuitively without the use of syllogism. That such additional proposition is required before copulæ other than "is" can be brought under the rules of syllogism is very clear. Take the case mentioned by Jevons. He says: "If I argue, for instance, that because Daniel Bernoulli was the son of John, and John the brother of James, therefore Daniel was the nephew of James, it is not possible to prove this conclusion by any simple logical process"; we need also to be informed that the son of a brother is a nephew. Again, to take a case mentioned by Venn: "If the 
distance of $\mathrm{A}$ and of $\mathrm{B}$ from $\mathrm{C}$ is exactly a mile, that of A from $B$ (the relation desired) may be anything not exceeding two miles"; here the additional proposition would have to contain information concerning the angular measurements of the triangle made by joining the points occupied by the three persons, and to declare in general terms what, under such circumstances, is the distance between two persons situated as are $\mathrm{A}$ and $\mathrm{B}$. In still more indefinite circumstances of relation we should have to possess a still more complicated piece of information along with the original statements. Now, since we must undoubtedly reject the doctrine that was once frequently held on this subject, viz., that such an argument as " $\mathrm{A}$ equals $\mathrm{B}, \mathrm{B}$ equals $\mathrm{C}$, therefore A equals C," is, when put in another form, an actual case of syllogistic reasoning,-the opponents of such a view were quite right when they argued that this putting into another form involves a petitio principii: De Morgan, for instance, 


\section{Later Logical Doctrines}

made this rejoinder, and Keynes is in agreement with him-before all possible premises of the kind in question can be dealt with syllogistically there will be needed an infinite number of such special pieces of information, and this amounts to saying that a general treatment of relatives is impossible. If, on the other hand, the validity of such arguments as we are considering is declared not to be established by means of syllogism, but to be as intuitively evident as the validity of Barbara itself, the statement means, I take it, that in each case there is involved a separate dictum, corresponding to the dictum of the syllogism. Since, however, the number of such cases is unlimited, there will be an infinite number of dicta in our Logic, which again is impossible.

The way out of the difficulty appears to be the following. It must be admitted that such propositions as the above are not susceptible of being so manipulated that they shall be put into syllogistic form. 
Also it is absurd to suppose that we have at our disposal an infinite number of major premises or of dicta. Hence the general treatment of copulæ is impossible. But what we can do is to admit an arbitrary number of general propositions other than the dictum de omni, and the propositions thus admitted allow of our dealing with a limited number of arguments like the above. There is a special group of such statements of great importance, and they occur in the region of quantitative mathematics. I refer to the axioms of Geometry. From the pre-Peanesque point of view these may be regarded either as the assumptions that are necessary in order to allow of the application of syllogistic reasoning to propositions of that science, or as of the nature of dicta, i.e., statements that allow of our drawing conclusions by reference to them, and without employment of the dictum de omni. But, inasmuch as some of the assumptions are used only occasionally, it seems decidedly better not to speak of them as 
dicta, but as propositions that are required for the employment of the syllogism to the material that is the subject of the argument.

It may indeed be said that the syllogistic treatment of relative reasoning is the appropriate one on another ground, viz., because there is between the dictum de omni and the other general propositions a difference of such a kind as to give unique importance to the former. It is sometimes asked, as by De Morgan, whether the axioms of mathematics are not " equally necessary, equally self-evident, equally incapable of demonstration out of more simple elements" with the dictum, and, if so, whether the two are not equally important? My view is that, whatever may be the character of the two kinds of axioms as regards derivation and selfevidence, they are not of equal importance. For in all reasoning concerning quantities the dictum de omni may be employed, while in reasoning concerning qualities, where, of * Trans, Camb, Pbillosoph, Soc, vol, x. p. $33^{8}$. 
course, the dictum is also needed, the axioms of quantitative mathematics afford no assistance. De Morgan in another place * endeavours to show that questions of equality and of identity are formally on an equal footing, since " the word equals is a copula in thought, and not a notion attached to a predicate," and that "logic is an analysis of the form of thought, possible and actual, and the logician has no right to declare that other than the actual is actual." The answer to this appears to be that, though the individual does actually regard the "equals" as a copula, he does so only by a process of abbreviation: the form when fully expressed is one of identity. The logician is not bound to treat as of fundamental importance each kind of abbreviation that mankind has adopted. It is enough for him to deal with the fully expressed form, and to explain, as we have done above, that in the case of arguments concerning quantities what we really have is

* Syllabus of a Proposed System of Logic, Pp. 31, 32. 


\section{Later Logical Doctrines i 9 I}

a syllogistic process plus some material assumptions.

In this discussion we have been considering cases in which only three terms are involved, and the matter has been regarded from the point of view of ordinary Formal Logic. In this narrower region the dictum is unique. But from such statements it is not to be concluded that we shall not when discussing the generalisation of logical processes reject the dictum. It will be rejected, however, not because it is not in a unique way of a formal character, but because it applies to only three terms, and we must adopt axioms that are "necessary and sufficient" for dealing with arguments of any degree of complexity.

At first sight the above statement of the case appears perhaps to agree with the view that Boole adopted. But there is really no such agreement. Boole held that general logic is quantitative mathematics with the quantity element left out, that is to say, class logic and quantitative mathematics 
participate in the nature of general logic, and have in addition their own special characteristics. It seems to me, on the other hand, that there are not two species of the genus general logic: there is one logic, and that is class or propositional logic, and all that there is in mathematics is such logic, together with some material assumptions concerning quantitative objects. No argument whatever can be carried on in quantitative mathematics without the explicit or implicit application of class or propositional logic at every step. Certainly Boole appeared to establish two species of reasoning, when he applied the symbols of mathematics to the manipulation of arguments involving classes; but what he was really doing was to show how qualitative reasoning, if we employ in it symbols analogous to those that represent quantitative objects and processes, may be extended far beyond the limits of the old syllogistic arguments. To put the matter in a word, even from the standpoint of pre-Peanesque 
notions it is better to recognise only the socalled specific logic of quality, and to regard quantitative reasoning as merely qualitative reasoning together with certain assumptions concerning the relations of quantities. As Dr. Shadworth H. Hodgson says, * formal logic " is a system wholly unrestricted in its range," or, as he adds, class Logic is " the Logic of the whole nature of any and every object of thought, of its What, $\tau^{\prime} \dot{\epsilon} \sigma \tau \iota v$, of its Quid, which includes both its Quale and its 2uantum." That is to say, class Logic has to do with the relation of classes whether qualitatively or quantitatively determined.

It need hardly be said that though Jevons speaks of the necessity of there being additional information, before the proposition that I have quoted from him can be manipulated, he does not make any general statement on the subject. And he evidently considers that all such arguments form a class distinct from the miscellaneous selection which he brings forward in

* Proc. Arist. Soc. N.S. vol. ii. pp. 135, 136. 
illustration of his principle of Substitution. My view is rather that his illustrations are special cases of relative reasoning, and that this is not in general possible except on the lines that I have endeavoured to indicate.

So long as we do not make use of the doctrines which have been unfolded by Peano, the above is, I believe, the best way to regard the reasoning that is involved in quantitative mathematics. Peano's method, as will be explained in the next section, allows of our dispensing with these arbitrary assumptions: all the material that is discussed in Mathematics is regarded as expressible in terms of variables and logical constants, and so as susceptible of being manipulated by the rules of Symbolic Logic. Such a way of approaching the subject is a great improvement. At the same time it is obviously desirable to observe what is the proper way to regard mathematical reasoning if we are confined to the prePeanesque point of view. The important 


\section{Later Logical Doctrines}

matter, however, for our present purpose is to notice that this discussion about Mathematics arose because we found that it is impossible to establish a Logic of Relatives in the sense of a general treatment of copulæ.

When it is stated, as was the case at the commencement of this section, that the expression "Logic of Relatives" as generally used refers only to the operations performed upon propositions involving multiple quantifications, it is not meant to suggest that this investigation is not important. On the contrary, as will have been gathered from the earlier portion of this chapter, I think that we have here a development of the greatest interest. An investigation of the principles, according to which results concerning multiple quantifications may be reached, naturally follows the study of the subject-matter of ordinary Symbolic Logic, in which, of course, we are concerned with singly-quantified propositions. 


\section{ig6 Symbolic Logic}

III. We have now traced the development of Symbolic Logic up to the furthest point that was reached before the work done by Frege, Peano, and Russell. I propose in this section to make clear in what way these writers have shown that the subject can deal in a direct manner with material with which it was supposed up to their time that it could deal either not at all, or only in an indirect manner. We have seen in the last section that Boole, Venn, and Schröder could not bring within the scope of their procedure the deductions of Mathematics, except by making arbitrary assumptions concerning the way certain quantities are related. That is to say, mathematical material could be dealt with by these logicians only in an indirect manner. The alternative to this procedure - so far as pre-Peanesque doctrines are concerned-is to adopt Kant's view that mathematical demonstrations owe their certainty, just as do syllogistic inferences, to special exer- 
cises of an intuitional faculty. The validity of the dictum de omni and the validity of the axioms of Mathematics must on this view be held to stand on an equal footing: each must be held to be intuitively obvious. There would thus be two branches of deductive reasoning, that concerned with qualitative and that concerned with quantitative objects.

Concerning these two views it is to be noted that they are not satisfactory. The first obviously involves us in an uncertain number of assumptions. The second may be based on a faulty philosophical analysis. For there are many philosophers who hold that the facts of experience do not justify us in asserting the existence of a faculty such as that which Kant described, and, therefore, do not permit us to declare that the validity of the truths assumed in Mathematics is intuitively obvious. Such philosophers explain the certainty felt in adopting these truths as due to the accumulated results of special experiences. 
Now both of these explanations of the mathematical axioms cannot be true, though both Kantians and their critics may continue to hold that their respective statements correctly account for the characteristics of mathematical reasoning.

In short, since the earlier Symbolic Logic could not deal in a satisfactory manner with the deductions of Mathematics, and since it may be that mathematical axioms do not really rest on intuition, the subject of the relation of Logic to Mathematics was, previous to the time of Peano, in a state that demanded careful consideration. This consideration has been given by Peano and his followers. What they have done is to take mathematical ideas and analyze them, so as to arrive at the general notions that are involved in the various parts of the science. Then these notions are all shown to be expressible in terms of variables and logical constants, the latter being notions that are all definable in terms of a specified number of indefinables. The resulting 
propositions are susceptible of being dealt with by the ordinary rules of Symbolic Logic, and in this way Mathematics is seen to derive its validity from the fact that it depends on principles of a logical character.

This view of the subject has been fully expounded by Mr. Russell in his work The Principles of Mathematics. He thinks that the analysis of mathematical conceptions. reveals the fact that there are some eight or nine of these general notions, and he maintains that the logical constants by which such notions may be expressed require only these indefinables: implication between propositions, relation of a member to a class of which it is a member, the notion of such that, the notion of relation, and the notions involved in formal implication.*

To put the matter in a slightly different form, Mr. Russell is occupied throughout his book in justifying his definition of Pure Mathematics, which runs as follows:

* The Principles of Mathematics, p. II. 
"Pure Mathematics is the class of all propositions of the form ' $p$ implies $q$,' where $p$ and $q$ are propositions containing one or more variables, the same in the two propositions, and neither $p$ nor $q$ contains any constants except logical constants." * Here the notion of implication connecting $p$ and $q$ involves some of the indefinables of Symbolic Logic, and, when we come to observe of what $p$ and $q$ are composed, we find that they are composed of variables, the same in each, and of certain logical constants that are expressible in terms of the other indefinables.

Now on this view it is clear that the relation in which Symbolic Logic stands to Mathematics is quite changed. Previous to the work of Peano the two disciplines were regarded as occupied respectively with qualitative and with quantitative objects. Symbolic Logic could not deal directly with the material upon which Mathematics is occupied, and Mathematics could

$$
\text { * Loc. cit. p. } 3 .
$$




\section{Later Logical Doctrines $20 \mathrm{I}$}

not of course solve problems with respect to qualitative objects. But on the new view Symbolic Logic can solve both kinds of problems, or, more correctly, the two kinds are reduced to one, and with this Symbolic Logic deals. Symbolic Logic may thus be regarded as synonymous with deductive reasoning.

Perhaps the most important of the notions of the new doctrine is that respecting the relation of an individual to the class of which it is a member. The older symbolist considered that there is no need to make a distinction between this relation and that of a class to a wider class; in other words, he held that the singular proposition may be treated as a special case of the universal. Venn, for instance, adopts this view, and applies it in working the example on p. 345 of his Symbolic Logic. As it happens, there is no difficulty in that problem in passing over the distinction in question, for the premises do not contain any alternatives in the predicates. But, 
when disjunctive predicates do occur, it becomes at once apparent that the contradictory of the predicate is not of the same description as the contradictory where classes are involved. When we are dealing throughout with classes the contradictory of $(x+y)$ is $\bar{x} \bar{y}$, and this may be combined with the subjectterm, and the whole be equated to zero. But when the subject-term is singular the contradictory of the predicate $(x+y)$ will not be $\bar{x} \bar{y}$, but either this combination or one of the two impossible combinations of the three $x \bar{y}, \bar{x} y, x y$; or, as Vailati puts the matter, in the case of $c \epsilon a+b$, where $a$ and $b$ are classes, it follows that one of the two, $c \in a$ or $c \in b$, is true, whereas in $c>a+b$, where $c$ is a class, there is no need for either $c>a$ or $c>b$ to be true.* Still another way of distinguishing the relation where an individual is involved from the relation of classes is to say that the relation in the latter but not in the former case is

* Revue de Métaplysique et de Morale, vol. vii. No. I, p. 97 . 


\section{Later Logical Doctrines 203}

transitive.* Peano was the first to give prominence to this unique character of the reference of an individual to a class, but Frege in the Grundgetze der Arithmetik had recognised the existence of the great difference between the two relations. $t$ The importance of making the distinction in question becomes especially observable when the attempt is made to bring mathematical conceptions within the scope of Symbolic Logic. For these conceptions are found to be equivalent to implications between propositional functions, i.e., between classes, whose elements are propositions stating the relation of an individual to a class of which it is a member.

It may here be remarked that $\mathrm{Mr}$. Whitehead holds that Mathematics is to be identified with deductive reasoning, $\neq$ and that the discipline can take the place of all intellectual exercises, except philosophy,

\footnotetext{
* The Principles of Mathematics, p. I9.

$\dagger$ Russell, loc. cit. pp. I 9, 5 I 2.

I A Treatise on Universal Algebra, vol. i. p. viii.
} 
inductive reasoning, and imaginative compositions. In the earlier portion of this statement Mr. Whitehead does not identify Symbolic Logic with deductive reasoning, but makes the former a species of the latter. It will thus be seen that he does not take up precisely the same position as Mr. Russell, who identifies deductive reasoning with Symbolic Logic, and represents this discipline as somewhat wider in character than Mathematics. The second portion of the above statement needs, I think, some elucidation. I presume Mr. Whitehead means that Symbolic Logic (when the term is used as equivalent to deductive reasoning) cannot at the same time work problems and enunciate the principles upon which it rests, and in this I should agree with him. But this hardly justifies us in stating that philosophy is excluded from Symbolic Logic. For the latter can manipulate philosophical arguments quite as much as any others. That is to say, if our premises give informa- 
tion of a philosophical character we can deal with them, and we shall arrive in our conclusion at information of a similar character.

As regards inductive reasoning, the question arises whether this is really anything different from deductive reasoning. There is a good deal to be said for Mr. Russell's view when he remarks: "What is called induction appears to me to be either disguised deduction or a mere method of making plausible guesses." * I do not myself consider that this expresses the truth of the matter, for the process of generalisation is, as Venn makes quite clear in his Empirical Logic, as important as the original insight or the subsequent verification. Mr. Russell's view, however, is that in induction we are really concerned with statements similar to those which are found in pure Mathematics. He would thus consider that the statement "If the conditions of the Method of Difference

$$
\text { * Loc. cit. p. I } 1 \text { n. }
$$


are fulfilled, the cause that will always produce the phenomenon under investigation has been discovered" is precisely similar to such a statement as: "If two sides of a triangle are equal each to each, and if the included angles are equal, the bases are equal." And just as the principles of Peano will allow of our manipulating the latter proposition by means of Symbolic Logic, so Russell would argue that by the same means may the former be manipulated.

The other doctrine, asserted by $\mathrm{Mr}$. Whitehead, namely, that Symbolic Logic cannot be of service in the production of imaginative literature, is undoubtedly true. The statement holds whether we are speaking of the earlier or of the later application of the Calculus. For imagination is most effectively employed when the faculty of pure reason is, comparatively speaking, quiescent, and, therefore, when the Calculus, which is a substitute for the exercise of pure reason, is not being 


\section{Later Logical Doctrines 207}

employed. In other words, the associative forces are more important for enabling the individual to reach conceptions of beauty, while, for reaching the true, such forces must be held in check, and there must be an observance of logical rule.

In order to make clear the way in which the school of Peano treats mathematical conceptions we may refer to the subject of integers and of their addition and multiplication. Mr. Russell demonstrates that it is possible to define numbers in such a way that they are seen to be susceptible of being manipulated by the rules of Logic. A number may be defined as a class of similar classes, i.e., of classes whose members are correlated one to one ; ${ }^{*}$ and, since classes may be logically treated, numbers are brought within the scope of Pure Logic. Thus the various arithmetical operations that are performed upon numbers may be expressed in logical language. For instance, addition is definable thus: "If $k$

* The Principles of Mathematics, pp. II 3, I 5 . 
be a class of classes no two of which have any common terms (called for short an exclusive class of classes), then the arithmetical sum of the numbers of the various classes of $k$ is the number of terms in the logical sum of $k . " * \quad M r$. Russell calls special attention to the fact that in bringing addition of numbers within the scope of Pure Logic it is essential to speak of the numbers as classes of classes. Unless there is such reference to the latter, we should never be able to take account of a repeated term. If a sum of numbers be spoken of merely as a class of numbers, then, supposing the number $\mathbf{1}$ is repeated, we cannot take account of this repetition, since in Logic $1+1=1$. On the other hand, when we have in mind a class of classes, if 1 occurs in one class, and again in another class, such number may be taken account of in each case, for all the terms of the one class are different from the terms of the other. 


\section{Later Logical Doctrines}

Just as addition of integers may be expressed as a logical sum of terms of two or more classes, so multiplication may be expressed as a sum of terms of a single class. The definition of the latter process as presented by $\mathrm{Mr}$. Russell, who follows Mr. Whitehead, is as follows: "Let $k$ be a class of classes, no two of which have any term in common. Form what is called the multiplicative class of $k$, i.e., the class each of whose terms is a class formed by choosing one and only one term from each of the classes belonging to $k$. Then the number of terms in the multiplicative class of $k$ is the product of all the numbers of the various classes composing $k$." This definition has the advantage of introducing no order among the numbers multiplied, and it applies both to finite and to infinite classes.*

It is thus seen that from the Peanesque point of view numbers may be defined as classes of a certain kind, and addition and * The Principles of Mathematics, p. I 19. 
multiplication of numbers may be expressed as logical addition of terms. In a similar way it may be shown that the other processes which are performed upon numbers may be expressed as logical processes. And, just as numbers may be dealt with by the pure logician, so, Mr. Russell shows, may be the other general mathematical notions that analysis reveals to be fundamental.

I have mentioned three writers who expound such doctrines as we have just been considering. My object has been to show the advanced position that Frege, Peano, and Russell have assumed with regard to the application of Symbolic Logic. It must not, however, be supposed that there are not considerable differences between the views of these writers. The points in which there is disagreement are numerous, and call for some consideration.

As regards the two latter writers there is a difference, in the first place, as to the 
notions that are to be taken as indefinable, and, secondly, as to the propositions that are to be taken as primitive. We have already enumerated the indefinables as given by Mr. Russell. Peano's are as follows: "Class, the relation of an individual to a class of which it is a member, the notion of a term, implication where both propositions contain the same variables, i.e., formal implication, the simultaneous affirmation of two propositions, the notion of definition, and the negation of a proposition." * These are for the most part the same as those given by Mr. Russell, but the latter writer rightly prefers to take as ultimate the simultaneous affirmation of all the propositions of a class, and maintains that formal and material implication should be both mentioned among the indefinables. Moreover, he thinks there is no need to make negation a primitive idea, since, if we start with propositions rather than with classes,

* The Principles of Mathematics, p. 27. 
it is possible to show that all propositions respecting negation are only other forms of the principle of Reduction. This principle runs thus: "If $p$ implies $p$ and $q$ implies $q$, then " " $p$ implies $q$ " implies $p$ ' implies $p$," where of course nothing is involved but implication.*

Coming to primitive propositions, $\mathrm{Mr}$. Russell urges that it is not desirable to have one merely to describe the product of two classes, but that instead of such proposition one should be stated respecting the product of a class of classes; for, unless the latter procedure be adopted, we cannot describe the product of the classes contained in an infinite class. Similarly, there is no reason to have two axioms to say respectively that $a b$ is contained in $a$ and $b$, and that $b a$ is contained in each of these : if we speak of a class of classes, then when we obtain the logical product of the contained classes, there will be no reference to the order of the terms. $f$ * On this last point see loc. cit. pp. I7, 3 I. † Loc. cit. p. 30. 
Finally, in connexion with his discussion of primitive propositions, Peano is led to define the null-class as the class which is contained in every class. Mr. Russell does not disagree with this definition, but he points out that, in order to accept it, Peano must be explicit as to what is meant by the assertion that " $x$ is an $a$ " implies " $x$ is a $b$ " for all values of $x$. Peano hesitates to say whether this implication does or does not involve that $x$ must be an $a$, but inclines to adopt the view that it does. But, if such were the case, " ' $x$ is a 0 ' implies ' $x$ is a $b$ ' for all values of $x$ " (which, following Peano, we must take as equivalent to $0-<b$ ) could not be taken as a definition of 0 , for to utter such an implication would be to say that $\mathbf{0}$ both has and has not members. On the other hand, if we adopt the view that in the implication " ' $x$ is an $a$ ' implies ' $x$ is a $b$ ' for all values of $x$ " we are not confined to the $x$ 's that actually are $a$ 's, no contradic- 
tion is involved in dealing with the nullclass.*

From these considerations I think it may safely be said that, while Peano has gone further than his predecessors, on the abovementioned points Mr. Russell occupies the correct position, and so shows an advance upon Peano.

The other logician who has seen that Symbolic Logic may deal with more problems than were contemplated by Boole, Venn and Schröder, is Frege. This writer's importance has until lately been quite overlooked. Venn, whose historical researches in Logic have usually been so productive of valuable results, passes him over with but scant attention, merely remarking that "Here again we have an instance of an ingenious man working out a scheme-in this case a very cumbrous one-in apparent ignorance that anything better of the kind had ever been attempted before. ... The obvious defect in this scheme is the inor-

$$
\text { * Loc. cit. pp. } 32,38 \text {. }
$$




\section{Later Logical Doctrines 215}

dinate amount of space demanded for its display. Nearly half a page is sometimes expended on an implication which, with any reasonable notation, could be compressed into a single line." * This observation upon Frege's cumbrousness is no doubt fully justified, but his logical doctrines, as Mr. Russell has shown, are deserving of much more attention than Venn has given to them.

Frege's chief excellence consists, I think, firstly, in recognising the importance of considering propositions and their implications as fundamental, $\dagger$ and, secondly, in perceiving that, without making arbitrary assumptions, it is possible to bring certain mathematical arguments within the scope of Symbolic Logic. In the first chapter I contended that, so far as we are concerned with the problems discussed (say) by Venn, it does not matter whether symbols repre-

* Symbolic Logic, pp. 493, 494.

$\dagger$ It should be noted that Mr. MacColl had drawn attention to this importance two years before the Begrifsschrift was published. 
sent terms or represent propositions, but I quite admit that when we attempt to extend the scope of Symbolic Logic it is preferable to let symbols represent propositions rather than classes.* Frege's propositional calculus closely resembles that adopted by Mr. Russell. There are, however, certain important differences between the two. For instance, Frege considers that if $a$ occurs in a proposition, the latter may always be resolved into $a$ and a statement about $a$, whereas Mr. Russell holds that, though such analysis is possible in the case of an expression of the form "Socrates is a man," the analysis is not possible when we have to deal with such a statement as "Socrates is a man implies Socrates is a mortal." $\dagger$

With respect to Frege's extension of the scope of Symbolic Logic it is to be observed that he made a start in the direction that Peano and Russell have pursued with such

$$
\begin{aligned}
& \text { * See note on p. } 9 . \\
& \text { † Loc. cit. pp. } 84,85
\end{aligned}
$$




\section{Later Logical Doctrines}

important results. Especially noteworthy is his treatment of cardinal numbers. These he defines very much as they are defined above, i.e., he shows that they are really classes. But he makes the strange assertion in the Grundlagen der Arithmetik that numbers cannot be applied to actually existing things, but only to class-concepts. * I think with Mr. Russell that this view is incorrect, since, in those cases where Frege says that the same set of objects may have different numbers, it is not really the same objects that are being considered.

That there are several points of difference between Frege's doctrine and that set forth by Mr. Russell is very certain, but, as the latter writer remarks, they are few as compared with the points of agreement. Of the truth of one statement of fundamental importance both writers are fully convinced, namely, that a "proposition concerning every does not necessarily result from enumeration of the entries in a catalogue."

* The Principles of Mathematics, p. 519. 
They hold as against Mill, and as against Kelly-who in attacking Frege practically takes up Mill's position-that general propositions may frequently be established by means of a procedure which does not involve previous reference to the individual cases that are covered by the universal term.**

In concluding this account of the newer doctrines, I think it important to show that their acceptance is in agreement with the view that $I$ endeavoured to unfold in the second section of this chapter. I there maintained that it has been correctly held that a Logic of Relatives is impossible. In the present section we have seen that $\mathrm{Mr}$. Russell takes as one of his indefinables the notion of relation. It may appear, therefore, that there is here involved a contradiction. But such is not the case. What was proved above to be impossible is a logic that can deal with all copulæ in a general manner, just as ordinary Formal * The Principles of Mathematics, p. 522. 
Logic can by means of the dictum deal with all propositions whose terms are connected by the copula "is." It was shown that, owing to the infinite number of different kinds of copulæ that exist, there cannot be a dictum by reference to which any two or more propositions containing any of these copulæ can be synthesized. There cannot, in other words, be a logic that rests upon what may be called a Universal Dictum. But it is quite true that the subject of relations, when by this is meant the doctrine of multiple quantifications, forms part of the material with which the symbolic logician has to deal. The notion of relation will thus for the logician be ultimate, and the propositions that contain the quantitative terms as subjects may be synthesized in the way that was described above in the first section. Thus mathematical notions may quite well involve the notion of relation, and so be treated logically, and yet a Logic of Relatives in any other sense than the doctrine of 
multiple quantifications may be an impossibility.

And, once more, there is no contradiction between Mr. Russell's view that classes, owing to the fact that they sometimes consist of an infinite number of terms, should be defined by reference to intension, and Mr. Johnson's doctrine that, when multiply-quantified propositions come to be synthesized, there is a reference to the individuals that constitute the classes.* This reference is essential whether the classes contain an infinite or a finite number of members, and whether the classes are formed by enumeration of objects or by reference to attributes.

* See on this point an important note by Mr. Johnson in Mind, N.S. No. i. p. 28. 


\section{CHAPTER VII}

\section{THE UTILITY OF SYMBOLIC LOGIC}

I PROPOSE in this concluding chapter to indicate briefly what is the utility of the Symbolic Logic whose development we have traced in the preceding pages. Of the educational advantages arising from the concentration of thought, that the discipline demands, it is impossible to speak too highly. On all sides the educational utility of mathematical * study is recognised, but I venture to state that Symbolic Logic takes no second place in this respect. Probably, also, every one would allow that the generalised treatment of thought throws much light upon problems that appear in the special or syllogistic treatment. As regards the direct utility of the discipline,

* I am here using this term in the sense in which it was understood previous to the time of Peano. 
the question is somewhat complex. It may readily be granted that natural science cannot make any direct use of Symbolic Logic. Mathematics is absolutely necessary for an insight into many of Nature's laws, but natural science is not immediately furthered by the rules of the logical calculus. Jevons seemed to think that the facts point in the other direction, for he held that science is advanced by means of the Substitution of Similars. But the truth is that science must supply the premises upon which the symbolic logician may bring to bear his mechanical contrivances.

It is, I think, quite true to assert that Jevons believed that Symbolic Logic assists in the advancement of science. His position on the subject is, however, not always perfectly clear. As Mr. E. C. Benecke points out, ${ }^{*}$ while in the former part of the Principles of Science a calculus is elaborated, there is no reference to such construction in the later parts, where the * Proc. of Arist. Soc. N.S. vol. ii. p. 141. 


\section{The Utility of Symbolic Logic 223} methods employed in the various sciences are discussed. Still, Jevons definitely asserted that "the Substitution of Similars is a phrase which seems aptly to express the capacity of mutual replacement existing in any two objects which are like or equivalent to a sufficient degree," * and "in every act of inference or scientific method we are engaged about a certain identity, sameness, similarity, likeness, resemblance, analogy, equivalence or equality apparent between two objects." $\dagger$ Nothing could be clearer than these statements. We must not, therefore, I think, regard Jevons as first developing a logical calculus, and then as proceeding to deal with scientific methods. Rather the whole of his Principles of Science has to do with the methods of science (as Croom Robertson says, "the Methods, rather than the Principles, of Science, would, perhaps, be a more appropriate title for

$$
\begin{aligned}
& \text { * The Principles of Science, p. I } 7 . \\
& \text { † Loc. cit. p. I. }
\end{aligned}
$$


the book as it stands"), and the latter portion of the volume is engaged not upon an investigation quite distinct from that which occupies the former part, but with the work of ascertaining "when and for what purposes a degree of similarity less than complete identity is sufficient to warrant substitution." This substitution is all along held to be the fundamental process.

To resume the main discussion of this section, we have said that Symbolic Logic does not directly lead us to any new truths in natural science. It is, however, by no means the case that no new truth at all, but only a recognition in another form of the information contained in the premises is reached by means of the calculus. For what is a new truth? It is an accurate subject-predicate combination that an individual forms, but which has never till then been formed in the history of the race. Now such a combination may be reached deductively or inductively. It was a new 
The Utility of Symbolic Logic 225 truth when the conclusion of Euc. I. 47 was for the first time reached, just as it was a new truth when Adams and Leverrier discovered the planet Neptune. In a second sense a truth may be said to be new when, though well known to science, the full force of the subject-predicate combination is for the first time grasped by the mind of a student. Here again the abovementioned combinations may take equal rank in their claims to be designated new. And, just as in pure Mathematics the results may constitute new truths in both of the above senses, so in Symbolic Logic we may be said in the same senses to reach a new truth. For instance, the difficult problem that was first solved by Boole* gave a result that was true and altogether new, and this solution, which is well known to all symbolists, is the occasion of the experience of a new truth in the mind of each student of the subject.

Moreover, though it be correct, as we * Boole, Laws of Thought, pp. I46-1 48 . 
have seen, to say that Symbolic Logic cannot directly assist the individual in his scientific pursuits or in his daily affairs, the indirect help of the discipline in such spheres of practice is by no means insignificant. Mankind is consciously or semiconsciously much occupied with questions that turn upon the relations of classes, so that the manner of looking at things which the logical study makes habitual cannot fail to be of service in practical concerns. Instead of confining himself to things that are seen, the logician spontaneously is led to regard the things that are not seen. It has become a custom with him to consider the $\bar{x}$ as of equal value with the $x$. The truth is not that his logically developed habits are not applicable to the affairs of practical life, but rather that he will so weigh the pros and cons of a question that his active forces will be apt to suffer from a certain paralysis. The man of strong will, who is possessed of a vivid idea of one aspect of a practical problem, is much more likely to achieve a 
The Utility of Symbolic Logic

great deal than the man who sees accurately both sides. Hence the dilemma faces us whether it is better to act vigorously, and accomplish much that has to be revised and largely undone, or to produce only a small amount, but such as needs little alteration.

Now, if the study of Symbolic Logic is thus indirectly of use in natural science and in ordinary affairs, then $\grave{a}$ fortior $i$ the study is of service to the philosopher. For I take it that we philosophize rather in order to know than in order to act, and therefore in Philosophy there is no danger whatever arising from seeing the other side of a question. I think, moreover, that the principles of Symbolic Logic point in a striking manner to the fact that in Philosophy we can reach nothing simpler than a duality, however far we press our investigations. Attempts to reduce the world to unity - to God, to Self, to Nature, for instance-appear to be doomed to fail. In this extreme case our 1 means the totality of the existent, the universe in the 
common acceptation of that term. As before, $x+\bar{x}=1$ of necessity, and with this necessity we are obliged to stop. We cannot establish the existence of $x$ only, for at the outset of an attempt at such demonstration we become involved in self-contradiction. For instance, let $x$ stand for "God," then $\bar{x}$ will stand for " not-God." Now, if we attempt to demonstrate the non-existence of $\bar{x}$, we shall be proceeding in an absurd manner, for we shall be assuming, if not ourselves, at any rate our reasoning, which evidently is a part of the $\bar{x}$. An opponent of this argument might perhaps affirm that the human proof may well be regarded as a form of Divine reasoning. God would thus be proving His own exclusive existence. But it is obvious that the circumstances under which such Divine ratiocination would be taking place would be such that a human thinker was recognising the argument as his own construction. Hence the human thinker and his thought would still be distinct from 


\section{The Utility of Symbolic Logic 229}

the Divine. And, similarly, in our other efforts to reach unity, the argument is based on the assumption of an ultimate duality.

It should be observed here that I do not maintain that the existence of this duality can be proved by logical rule, but only that the principles of Symbolic Logic point to the circumstance that we cannot demonstrate the fact of unity. That is to say, if a Calculus of the kind we have described be accepted, such acceptance involves the necessity of our being content to stop short with a philosophical duality. In other words, if we adopt the formula $x+\bar{x}=1$-as we do throughout the whole of the Calculus-then in the limit, i.e., where 1 means the totality of the existent, whatever object $x$ may represent, there will always appear along with it another object $\bar{x}$.

The remarks that we have made with respect to the utility of the ordinary Symbolic Logic apply also to the so-called Logic of Relatives. In this further study we do not arrive at anything more general or con- 
jectural than the multiply-quantified propositions with which we start. There is here, therefore, no instrument by which the problems of natural science may be solved. But the educational advantage and indirect assistance of the study, and the possibility of reaching new truths, in the sense that we have just mentioned, are the same as in the case of the Symbolic Logic that deals with singly-quantified propositions.

Up to this point Symbolic Logic cannot be said to be able to reach new scientific truths. But, when we consider the relation in which Mathematics has in recent years been shown to stand to the discipline, and when it is remembered that Mathematics is essential in many scientific investigations, it is observable that Symbolic Logic is no longer confined to the uses just mentioned. New propositions in certain sciences are now seen to be derivable by applying logical rules to propositions that represent mathematical notions. Part of Mr. White- 
The Utility of Symbolic Logic $23 \mathrm{I}$ head's object in his work, $A$ Treatise on Universal Algebra, is to demonstrate the scientific value of Symbolic Logic.* The book is occupied in exhibiting the Algebras "both as systems of symbolism, and also as engines for the investigation of the possibilities of thought and reasoning connected with the abstract general idea of space."

And just as, on the modern view of the relation of Logic to Mathematics, Symbolic Logic may reach new truths in science, so by the same means may truths that are already known to science be reached by the mind of a student. This is well brought out in a suggestive article by Mr. T. P. Nunn.† He shows that when the formula for finding the Centigrade reading from the Fahrenheit reading is regarded purely as a statement, such formula may, by means of the Logical Calculus, be transformed into another, by which,

* He does not, however, as I have pointed out (p. 204), take up quite the same position as $\mathrm{Mr}$. Russell.

$\dagger$ See the periodical School, vol. iv. No. 22. 
given the Centigrade reading, the Fahrenheit reading may be obtained. Here there is a direct application of logical rules to the verbal elements of a statement. $A$ student, therefore, by making use of these rules, is enabled in such cases to reach truths which are new to him, and which are of a scientific character. 


\section{N D E X}

Accidental attributes, Cas-|Boole, G., brackets used by, tillon's symbolization of, I04.

Adamson, R., on intermediate processes, $68 \mathrm{n}$; ; on Schröder's solutions, $68 n$.

Addition, Russell's definition of, 207 ; symbolization of, I 39.

Alternants, least determinate, I75.

Alternatives, Boole's symbolization of, 42 ; exclusive method of representing, $38 ; \mathrm{F} . \mathrm{H}$. Bradley on, 43 ; non-exclusive method of representing, 39 ; Schröder's symbolization of, 42 ; Venn's symbolization of, $5 \mathrm{I}, \mathrm{I} 60$.

"And," W. E. Johnson on particle, 16.

Assertorics, Symbolic Logic confined to, 24.

Attributes, abstraction of, 98 ; combination of, 98 ; conventionally fixed, I36; existence of, I39; intension constituted by totality of, I 36 ; negative, 139 .

Axioms, $\mathrm{De}$ Morgan on mathematical, 190.

Axioms in Geometry, prePeanesque treatment of, I 88.

BENECKE, E. C., criticism of Jevons by, 222.

55 ; calculus constructed by, 5 ; formula of simplification adopted by, 66 ; fractional forms used by, 67; inconsistency of, 52 ; Jevons' criticism of, 67, I 47 ; mathematical symbols used by, 35 ; method of elimination adopted by, 69, 7I; on logical expansion, 74; on symbolization of particulars, 56 ; problem worked by, 75 ; process of squaring adopted by, 65 ; progress since time of, 6 ; propositions symbolized by, 150 n. ; representation of premises by, I6I ; symbolists anterior to, 3,4 ; symbolization of alternatives by, 42 ; transposition of terms by, 64; Venn's explanation of forms used by, 67 ; view of general logic adopted by, I9I.

Boolian principles, Johnson on application of, 178 .

Brackets, use of, 55 .

Bradley, F. H., treatment of alternatives by, 43 .

Bryant, S., confusion of statements and events by, I54; intensive symbolism adopted by, I3I: on origin of imaginary results, 49; on propositions frequently true, $25,26$. 
CALCUlus, available logicai, 2 ; Boole's, 5 ; nature of a, $31,48,49,96$.

Castillon, G. F., brackets used by, 55 ; conception of Symbolic Logic held by, 95; consistency of, 94 ; erroneous proofs offered by, II 4 ; inconsistency of, IO2 ; invalid inferences admitted by, II 8 ; memoir by, 94 ; on classification of judgments, 105; on conversion of particulars, I22; on hypotheticals, I24; on illusory particulars, I I I ; on infinite judgments, 47 ; on logical laws, IOI; on nature of propositions, 97 ; on notion of quantity, I29; on syllogism, I08; on symbolization of accidental attributes, IO4; on symbolization of essential attributes, I03; on transposition of terms, 123; on use of minus sign, 46 ; representation of universal negative by, 46 ; $\mathrm{S}$. Bryant's symbolism compared with that of, I3I ; treatment of problematical judgments by, I26; treatment of universal negative by, 123 ; use of word "some" by, II5; Venn's criticism of, 99, I07, I 20.

"Certain," distinction between "true" and, 158.

"Certainties," common treatment of, 158; nature of MacColl's, I 53 .

Chance, propositions and, I 58.

Class-concepts, application of number to, 2 I 7.

Class of classes, number as, 208.

Classes, individuals distin- guished from, 202, 203; symbolization of, I I, I 2.

Compartment, universe distinguished from, $\mathrm{I} 66$.

Compartments, salvation of, 66.

Comprehension, Logic based on, I38; signification of term, $9 \mathrm{I}$.

Conclusions, character of Venn's, 78.

Conditionals, hypotheticals distinguished from, 6o; nature of, 6o, 6I.

Connotation, Keynes' view of, I 38 ; Logic based on, I 34 ; Mill's view of, 138 ; signification of term, $9 \mathrm{I}$.

Contradictory, De Morgan's rule for finding, 79, 80 ; symbol for, 22 ; Venn's rule for finding, 8o.

Contradictories, interpretation of symbols representing, I 3 ; two types of, 202.

Conversion, Castillon on, I08, I 22.

Copulæ, general treatment of, I 84,2 I 8.

Couturat, L., examination of Leibnitz by, 136 ; on a Logic of intension, 140; on meaning of intension, I 35 .

Critical School, infinite terms admitted by, 105.

Deductive reasoning, Whitehead on scope of, 203, 204.

De Morgan, A., advance made by, I82; notion of Figure adopted by, I8I ; on a generalised Logic, I80; on axioms of Mathematics, I 90 : on contrariety of relational propositions, I8I; on con- 
version of relational propositions, I8I ; on finding contradictories, 79, 80 ; on nature of Logic, 190; on supreme law of syllogism, I 8 I ; propositions symbolized by, I $50 n$.

Destruction, compartmental, 59.

Determinants, most determinate, 175 .

Diagrams, disadvantages of, 83 ; employment of, 77,81 ; solutions effected by, 82 .

Dicta in relative reasoning, 187.

Dictum de omni, importance of, 189; sphere of, I9I.

Disjunction, interpretation of, 63.

Disjunctive predicates, contradictories of, 202 ; Vailati on, 202.

Disjunctives, symbolization of, 59.

Division, exclusive notation and, 39 ; sign of, 48 .

Double quantifications, Mitchell on, 178, 179; Peirce on, 177.

Elimination, Boole's method of, 69, 7I ; C. LaddFranklin's formula for, 58, 73 ; diagrams useful for, 83 ; in case of particular propositions, 72 ; Johnson's formula for, 73; Schröder's method of, 70, 7I ; Venn's formula for, 70,72 .

Equations, transposition of terms in, 45 .

Equivalence, symbol for, 54, 99.

Essential attributes, I03.

Eulerian diagrams, 8I.
Event, proposition distinguished from, 26, 27.

Events, statements confused with, 154.

Existence, logical, 164 ; MacColl on, I7I ; philosophical, I64.

Existence of attributes, 139.

Existential import of universals, 54.

Expansion, analytical treatment of, 74 ; Boole's formula for, 74 ; geometrical justification of, 74 ; Peirce's formula for, 75 .

"FALSE," distinction between "impossible" and, 158.

Figure, De Morgan's notion of, I8I.

Formal Logic, S. H. Hodgson on nature of, 193.

Formulæ, modification of, 19.

Fractional forms, Boole's, 67.

Frege, G., differences between

Russell and, 216 ; on distinction between individuals and classes, 203; on formation of general propositions, 217 ; on fundamental character of implication, 215 ; on scope of Symbolic Logic, 215 ; propositional calculus of, 216 ; treatment of cardinal numbers by, 217 ; Venn's criticism of, 214 .

General Logic, Boole's view of, I9I.

General propositions, formation of, 217.

Generalised Logic, 95 ; De Morgan on a, I80.

HaBits, logically developed, 226. 
Hodgson, S. H., on nature of Formal Logic, 193.

Holland, G. J., Lambert's coadjutor, 4 .

Hypotheticals, Castillon on, I 24; conditionals distinguished from, 60 ; nature of, 61 ; symbolization of, 59 ; treatment of, 61, 62.

ILLUSORY particulars, Castillon on, III.

Imaginary results, origin of, 50.

Implication, Frege on fundamental character of, 2 I 5.

Implications, relation of thinker to, 30 .

"Impossible," distinction between "false" and, 158.

Inconsistency, Boole's, 52.

Indefinables, logical constants imply, I98; Peano's list of, 2 I I ; Russell's list of, 199.

Indefiniteness, symbol for, $5 \mathrm{I}$.

Induction, connexion of Peano's principles with, 206 ; Inverse Problem distinguished from, 89; Jevons on nature of, I47; pure Mathematics and, 205 ; Russell on nature of, 205 ; Whitehead on position of, 204.

Infinite classes, synthesis of propositions containing, 220 .

Infinite juclgments, Castillon's treatment of, 47 .

Infinite terms, Critical School admits, 105.

Integers, logical treatment of, 207.

Intension, assumptions in logic of, I39; changes produced in, I 36 ; classes determined by, 220 ; Couturat's interpretation of term, I35; Leibnitz's interpretation of term, I37; Logic based on, 140; Russell's interpretation of term, I35; signification of term, 9I.

Intensive Logic, minus sign in, 46.

Intermediate processes, intelligibility of, 48,49 .

Internal synthesis, potency of, I 76.

Inverse operations, possibility of, $3^{8}$; reliable results of, 48 ; utility of, 48 .

Inverse Problem, improvements in solution of, 85 ; induction distinguished from, 89; Jevons' treatment of, 85 , I 47 ; Johnson's solution of, 87, I60 ; Keynes' solution of, 86, I60, I6I ; Schröder's methods of dealing with, 87 ; variety of answers to, 85 .

JEVONS, W. S., criticism of Boole by, 67, I 47 ; interpretation of propositions by, $7 n$; on Inverse Problem, I 47 ; on Law of Unity, 148 ; on nature of induction, 147 ; on relative reasoning, 185 ; on symbolization of alternatives, 146 ; on Substitution of Similars, 224 ; on symbolization of particulars, 56 ; on thinking in non-exclusive manner, 39; representation of universal affirmative by, I 45 ; symbol for indefiniteness used by, 52; symbolization of particulars by, 146.

Johns Hopkins Studies, 89. 
Johnson, W. E., criticism of Peirce by, 178 ; formula for elimination given by, 73; Inverse Problem solved by, 87 ; Mitchell criticized by, I79; on application of Boolian principles, 178 ; on hypotheticals and conditionals, 6o ; on modal propositions, 27 ; on molecular propositions, I73; on nature of a calculus, $3 \mathrm{r}, 96$; on particle "and," I6; on selecting determinants, I76; on synthesis of multiplyquantified propositions, 175 . Judgment, symbols cannot discover forms of, 97; Wolf's definition of, ro6.

Judgments, Castillon's classification of, 105.

KANT, critics of, I97; view of mathematical reasoning adopted by, 196.

Keynes, J. N., compact methods of, 69; employment of diagrams by, 8I ; Formal Logic, 34 ; on connotation, 138 ; on meaning of intension, $136 \%$, predicative standpoint adopted by, 53; solution of Inverse Problem by, 85, 160, I61 ; symbols of operation not used by, 31 ; use of bracket by, 55 .

LADD-FRANKLIN, C., answer to Schröder by, I9, 20 ; confusion of statements and events by, I 54; criticism of Schröder by, I7, 18 ; formula for elimination proposed by, 58, 73; inverse processes rejected by, 50 ; on logical sequence, 18 , I9; on use of literal symbols, 16; symbolization of particulars by, 57 .

Lambert, J. H., brackets used by, 55 ; coadjutors of, 4 ; intensive system of, 94 ; work done by, 3, 4 .

Law of Unity, Jevons' view of, 148.

Laws of Thought, problem worked in, 75 .

Leibnitz, Couturat's examination of, 136 ; influence of, 4 ; on meaning of intension, I 36 n., I37; symbol for indefiniteness used by, 52.

Limiting case, instance of, I9.

Literal symbols, MacColl's use of, I50: primary use of, IO ; variety of, 22.

Logic, connotation as the basis of, I34; De Morgan on nature of, r9o; generalisation of common, 33 ; use of mathematical symbols in, 35.

Logic of intension, possibility of, I40; unnaturalness and complexity of, $14 \mathrm{r}$.

Logic of relatives, notion of relation and, 219; Peirce on, I 84 ; utility of, 229.

I_ogical calculus, problems solved by, 2 .

Logical constants, nature of, I98.

Logical existence, I64, I7I ; MacColl's views on, I62.

Logical laws, Castillon on, IOI.

Logical machinery, double use of, 14 . 
Logical processes, mathematical and, 36 .

Logical sequence, singular propositions and, 18, I9.

MACCOLL, H., criticism by, I68, I69; formula adopted by, 29; independent work of, 23 ; on classification of propositions, 28 ; on existence, I7I ; on statements and propositions, $9 n$. ; on Universe of Discourse, I62; on use of literal symbols, 2 I, I 50 ; symbolization of propositional functions by, I5 I ; treatment of modals by, I 52 .

Maimon, S., on notion of universality, 130 ; on problematical judgments, I 26.

Marquand, H., employment of diagrams by, 82 .

Material consequences, Ladd-Franklin on, $\mathbf{I} 8$.

Mathematics, Logic involved in, I92; new treatment of propositions in, $9 n$; Peano's treatment of, 194 ; relation of Symbolic Logic to, 200; Russell's analysis of conceptions of, I99 ; Russell's definition of, I99, 200 ; validity of, I99.

Mathematical conceptions, analysis of, $\mathbf{1 9 8 ,} \mathbf{1 9 9 .}$

Mathematical reasoning, Kant on, 196.

Mathematical symbols, Boole's use of, 35 .

Methods of solution compared, 76.

Mill, J. S., on connotation, I 38 .

Minus sign, 45 ; Castillon's double use of, i Io.
Mitchell, O. H., Johnson's criticism of, I79; on change of terms into factors, 89; on double quantifications, I78, I79; representation of premises by, I6I.

Modals, MacColl's treatment of, I52; Pure Logic and, I53; Johnson's treatment of, 27.

Molecular propositions, 173. Multiple quantifications, 173 .

Multiplication, Russell's definition of, 209.

Multiply-quantified propositions, synthesis of, 175 .

Negation, Russell on, 2 I I.

Negative attributes, 139.

Negative interpretation of propositions, 54 .

Negative terms, symbolization of, 45 .

New truths, nature of, 224 .

Null-class, I65; Peano's definition of, 213.

Numbers, Frege's treatment of, 2 I 7 ; Russell's definition of cardinal, 207.

Nunn, T. P., on utility of Symbolic Logic, 23x.

PARTICULAR propositions, compartments saved by, 66 ; elimination in case of, 72 ; existential character of, 57,58 ; Jevons' representation of, 146 ; symbolization of, 56 ; Venn's symbolization of, 57 .

Peano, G., connexion of induction with principles of, 206 ; indefinables enumerated by, 2 II ; null-class defined by, 2I3: on distinction between individuals and 
classes, 203 ; primitive propositions enumerated by, 212 ; Russell's criticism of, 2II, 2I2; treatment of Mathematics by, I94.

Peirce, C. S.; formula of simplification adopted by, 66 ; Johnson's criticism of, I78; on double quantifications, 177 ; on Logic of Relatives, I8t; on logical expansion, 75; on plural relations, 177 ; symbol for subsumption used by, 53.

Philosopher, Symbolic Logic useful to, 227.

Philosophy, Whitehead on relation of Symbolic Logic to, 204.

Philosophical duality, Symbolic Logic and, 227.

Philosophical existence, 164.

Ploucquet, G., Lambert's coadjutor, 4.

Plural relations, Peirce on, 177.

"Possibilities," nature of MacColl's, I 53.

Potency, syntheses vary in, I 76.

Premises, symbolic representation of, 9; Venn's treatment of, 65 .

Primitive propositions, Peano's, 2 I 2.

Probability of an event, 26 .

Probabilities, propositions respecting, 27 .

Problematical judgments, Castillon on, I 26.

Proof, Castillon's methods of, I 14.

Propositions, Castillon's description of, 97 ; chance and, 158 ; combination of, 64 ; concerning probabilities,
27 ; extensive interpreta tion of, 92; existential import of, 54; MacColl's classification of, 28 ; indefinite element in, 5 I ; negative interpretation of, 54 ; nonexistence of probably true, 25 ; physical combination of, I I; predication view of, 32: strength of, I55; symbolization of, i jo $n$.

Propositional calculus, Frege's, 216.

Propositional functions, Russell on, 155 ; symbolization of, $I ; I$.

Pure Logic, formulæe of, 30 ; modals and, $1 ; 3$.

Pure Mathematics, induction and, 205.

QUANTITY, Castillon on notion of, 129.

REALiTIEs, Universe of, 163.

Relation, mathematics and notion of, 2 I9.

Relational propositions, contrary of, ISI; converse of, I $8 \mathrm{I}$.

Relative addition, Peirce on, I 77.

Relative multiplication, Peirce on, 177 .

Relative reasoning, dicta in, I87; Jevons on, 185 ; syllogistic treatment of, I 86 ; Venn on, i 85.

Restriction, subduction may be replaced by, 45 .

Results, equivalence of, 55 .

Ross, G. R. T., on disjunctive judgments, $+\mathrm{I}$.

Rules, mechanical application of, 33 . 
Russell, B., definition of addition given by, 207 ; definition of numbers given by, 207 ; differences between Frege and, 216 ; mathematical indefinables enumerated by, I99; on analysis of mathematical conceptions, I99; on definition of multiplication, 209 ; on distinction between individuals and classes, 202, 203; on formation of general propositions, 217 ; on logical existence, I7I ; on meaning of intension, I35; on nature of induction, 205; on position occupied by Symbolic Logic, I $38 n$.; on propositions respecting existence, I7I ; on propositional functions, I55; Peano criticized by, 2II, 2 I2 ; Pure Mathematics defined by, 199, 200 ; view of negation adopted by, 2 II.

SChröDEr, E., Adamson's criticism of, $68 n$. ; C. LaddFranklin's answer to, I9, 20 ; compact methods of, 69 ; Inverse Problem solved by methods of, 87 ; method of elimination adopted by, 70, 7I; on intelligibility of intermediate processes, 40, 48 ; on logical expansion, $74 ;$ on method of finding contradictory, 39 ; on secondary use of literal symbols, I7, I 8 ; Operationskreis, 34 ; representation of premises by, I6I ; symbolization of alternatives by, 42.

Schröder's methods, advantages of, 67 .
Science, Symbolic Logic and, 230.

Self-contradiction, nature of, I 68.

Simplification, Boole's formula of, 66 ; Peirce's formula of, 66.

Singular propositions, I73; logical sequence and, i8, I9; treatment of, 201.

Solutions, diagrammatic, 82 ; space occupied by, 2I, 22.

"Some," Castillon's use of word, II 5.

Squaring, Boole's process of, 65.

Statements, events confused with, I 54 ; propositions distinguished from, 9.

Strength of propositions, 155.

Subalterns, i I2, I 17.

Subduction, restriction may replace, 45.

Substitution, liability to error in, 78 .

Substitution of Similars, science and, 222.

Subsumption, symbols for, 53.

Subtraction, exclusive notation and, 38 ; intensive treatment of, I 40 ; symbolization of, $\mathrm{r} 39$.

Syllogism, Castillon's treatment of, 108 ; supreme law of, I $8 \mathrm{I}$.

Symbols, exclusive use of, I 5 I ; primary use of literal, IO; results denoted by, 36 ; operations represented by, 36.

Symbols of operation, frequent use of, 34 ; Keynes dispenses with, $3 \mathbf{I}$.

Symbolic Logic, Castillon's notion of, 95 ; contributors 
to development of, 6 ; educational advantages of, 221 ; Frege's conception of scope of, 215 ; imaginative literature and, 206 ; indirect utility of, 226 ; Jevons on utility of, 222 ; new truths reached by, 224; Nunn on utility of, 23I ; philosophical duality and, 227 ; relation of Mathematics to, 200; Russell's view of position of, I $38 \mathrm{n}$; science and, 222, 230; use to philosopher of, 227 ; Whitehead on utility of, $230,23 \mathrm{I}$.

Symbolic Universe, MacColl on, 162.

Symbolists, pre-Boolian, 3 , 4.

Synthesis of molecular propositions, 173.

Synthesis of multiply-quantified propositions, 175 .

Systems, logical, I; real and superficial differences between, 23.

TERMS, Boole's transposition of, 64 .

Things, application of numbers to, 217.

Transposition of terms, 123.

"True," distinction between "certain" and, 158.

Truth, propositional, I 3 .

UNIVERSAL affirmative, Jevons' representation of, I 45 .

Universal dictum, non-existence of, 2 I9.

Universal negative, Castillon's representation of, 46, I05, 123.

Universe, compartment distinguished from, I66.
Universe of Discourse, MacColl on, I62.

Unrealities, Universe of, 163 .

Vailati, G., on disjunctive predicates, 202.

"Variables," common treatment of, 158 ; nature of MacColl's, I 53 .

Venn, J., Boole's forms explained by, 67; Castillon criticized by, 99 ; conclusions reached by, 78 ; criticism of Frege by, 214; employment of diagrams by, 81 ; formula for elimination given by, 72 ; interpretation of Castillon by, 47, 120; method of elimination described by, 70 ; on Boole's originality, $3 n$.; on Castillon's universal negative, $\mathrm{IO} 7$; on elimination from particulars, 72 ; on exclusive use of literal symbols, 21 ; on finding contradictories, 80 ; on hypotheticals and disjunctives, 59; on intelligibility of intermediate processes, 49 ; on interpretation of alternatives, 40, I60 ; on Keynes' methods, 32 ; on Logic based on comprehension, 138 ; on negative interpretation of universals, 54 ; on performance of inverse processes, 40 ; on relative reasoning, 185 ; on secondary use of literal symbols, 15 ; on symbolization of negative terms, 45 ; on symbolization of particulars, 57 ; on treatment of singular propositions, 20I ; treatment of premises by, 65, I61.

Whitehead, A. N., on mul- 
tiplication, 209; on position | imaginative literature, 206; of inductive reasoning, 204; on relation of Mathematics to deductive reasoning, 203 ; on relation of Philosophy to Symbolic Logic, 204 ; on relation of Symbolic Loyic to on scope of deductive reasoning, 203, 204; on utility of Symbolic Logic, 230, 231.

Wolf, Ch., influence of, 4 ; on judgment, 106.

THE END 


\section{A Catalogue}

of

\section{Williams \& Norgate's Publications}

\section{Divisions of the Catalogue}

\section{THEOLOGY}

II. PHILOSOPHY, PSYCHOLOGY . . . . . 29 III. ORIENTAL LANGUAGES, LITERATURE, AND HISTORY • 34 IV. PHILOLOGY, MODERN LANGUAGES • • • • 39 v. SCIENCE, MEDICINE, CHEMISTRY, ETC. • . . 46 VI. BIOGRAPHY, ARCHEOLOGY, LITERATURE, MISCELLANEOUS . . . . . . . . 56 FULL INDEX OVER PAGE

\section{London}

\section{Williams \& Norgate}

I 4 Henrietta Street, Covent Garden, W.C. 


\section{INDEX.}

Abyssinia, Shihab al Din, 37 .

Alcyonium, Liverpool Marine Biol. C. Memis., 50.

Algæ, Cooke, 47.

America, Creation Myths of, Curtin, 57.

Americans, The, Münsterberg, 30 .

Anarchy and Law, Brenster, 29.

Anatomy, Cleland, 47; Cunningham Memoirs, 48 ; Lockwood, $5 \mathrm{I}$.

Anthropology, Prehistoric, Avebury, 56 ; Engelhardt, 57; Laing, 59.

Evolution of Religion, Farnell, 57.

Apocalypse, Bleek, 8 ; Clark, 16.

Apostles and Apostolic Times, Dob. schiitz, 4; Hausrath, 18; Weinel, 5 ; Weizsäcker, 7 ; Zeller, 9.

Statutes of, edit. G. Horner, 26.

Apostolic Succession, Clark, I6.

Arabic, Grammar, Socin, 37.

Poetry, Faizullah Bhai, 35; Lyall, 35 ; Noldeke, 36.

Ascidia, Liverpool Marine Biol. Mems., 5o.

Assyrian, Dictionary, Muss-Arnolt, 36 ; Norris, 36.

Grammar, Delitzsch, 34 .

Language, Delitzsch, 34 .

Assyriology, Brown, 56; Delitzsch, ro, 34; Evans, 35 ; Sayce, I3; Schrader, 9.

Astigmatic Tests, Pray, 52 ; Snellen, 54. Astronomy, Cunningham Mems., V., 48 ; Memoirs of Roy. Astronom. Soc., 62.

Augustine, St., Confessions of, Harnack, 18.

Babylonia, see Assyriology.

Belief, Religious, Upton, is.

Beneficence, Negative and Positive, Bible, 16 . Spencer, Principles of Ethics, II., 3I.

See also Testament.

Beliefs about, Savage, 25.

Hebrew Texts, I9.

History of Text, Weir, 27.

Plants, Hensloze, I 9.

Problems, Cheyne, I2.

Bibliography, Bibliographical Register, 56 .

Biology, Bastian, 46; Liverpool MIarine Biol. Mems., 50; Spencer, 31.

Botany, Bentham and Hooker, 46; Church, 47; Cooke, 47; Grevillea, 49 ; Jour. of the Linnean Soc., 49 ; Prior, 52.

Brain, Cunningham Mems., VII., 48.

Buddha, Buddhism, Davids, 14 ; Hardy, 35 ; Oldenberg, 36.

Calculus, Harnack, 49.

Canons of Athanasius, Text \& Trans. Soc., 38 .

Cardium, Liverpool Marine Biol. Mems., 50.

Celtic, sec also Irish.

Stokes, 43 ; Sullivan, 44.

Heathendom, Rhys, I5.
Ceremonial Institutions, Spencer, Princ. of Sociology, II., 3I.

Chaldee, Grammar, Turpie, 38.

Lexicon, Fuerst, 35 .

Chemistry, Berzelius, 46 ; Dittmar, 48 ; Faraday, 49; Van't Hoff, 49.

Hindu, $R a y$, 52 .

Christ, Early Christian Conception of, Pfeiderer, $13,23$.

Life of, Keim, 8.

No Product of Evolution, Henslow, 19.

Study of, Robinson, 24 .

Teaching of, Harnack, 6, II.

The Universal, Beard, I6.

Christianity, Evolution of, Gill, 18.

History of, Baur, 8; Dobschiitz, 4; Harnack, 6, II, I8; Hausrath, 8, I9; Johnson, 20; Mackay, 21 ; Wernle, 3 .

in Talmud, Herford, I9.

Liberal, Reville, Ir.

Roots of, Martineau, 22.

Simplest form of, Drummond, 14.

Spread of, Harnack, 5 .

What is? Harnack, 6, II.

Church, Catholic, Renan, 14.

Christian, Baur, 8; Clark, 16 ; Dob. schïtz, 4 ; Hatch, I4; Wermle, 4.

Coming, Hunter, 20.

Civic, Apathy, Hunter, 20.

Codex Palatino-Vaticanus, Todd Lec. tures, III., 44 .

Codium, Liverpool Marine Biol.Mems., $5 \mathrm{I}$.

Coleoptera, Murray, 52.

Communion of Christian with God, Herr. $\operatorname{mann}, 19$.

Comte, Spencer, 32.

Constellations, Primitive, Brozen, $5^{6}$.

Cornish, Stokes, 43.

Creed, Christian, 16.

Crown Theological Library, ro.

Cuneiform Inscriptions, Schrader, 9.

Daniel and his Prophecies, C. H. $H$. ilright, 28.

Critical Commentary on, C. H. H. Wright, 28.

Danish Dictionary, Rosing, 43.

Darwinism, Schurman, 30.

Denmark, Engelhardt, 57.

Doctrine and Principle, Beeby, r6.

Dogma, History of, Harnack, 5. of Virgin Birth, Lobstein, ro.

Domestic Institutions, Spencer, Princ. of Sociology, I., 3r.

Duck Tribes, Morphology of, Cunningham MTems., VI., 48 .

Dutch, Cape, Oordt, 43 ; Werner, 45.

Dynamics, Cunningham Mems., IV., 48. Chemical, Van't Hoff, 49.

Ecclesiastes, Taylor, 26.

Ecclesiastical Institutions, Spencer, Princ. of Sociology, III., 3I, 32. of Holland, Wicksteed, 27.

Echinus, Liverpool Marine Biol. Mems., 50. 
INDEX - continued.

Economy, Political, Mackenzie, 30.

Education, Herbert, 57; Lodge, 42; Spencer, 32.

Educational Works, see Special Cata. logue.

Egypt, Religion of, Renouf, I5.

Egyptian Grammar, Emann, 35.

Enoch, Book of, Gill, I8.

Epidemiology, Trans. of Epidemiolog. Soc., 55 .

Epizootic Lymphangitis, Treatise on, Pallin, 52.

Ethics, and Religion, Martineau, 22.

Data of, Spencer, Principles of E., I., 31 .

Induction of, Spencer, Principles of E., I., 3 I.

Kantian, Schurman, 30.

of Evolution, Schurman, 30.

of Individual Life, Spencer, Principles of E., I., 3 I.

of Reason, Laurie, 29.

Principles of, Spencer, 3 .

Ethnology, Cunningham Mems., X., 48.

Evolution, Spencer, 31, 32. of the Idea of God, $D^{\prime}$ Alviella, ${ }^{4} 4$. of Religious Thought, $D^{\prime}$ Alviella, $\mathbf{I}_{5}$.

Exodus, Hoerning, 20.

Ezekiel, Mosheh ben Shesheth, 22.

Faith, Herrmann, I2;Rix, 24; Wim. mer, 27.

Fisheries, British, Johnstone, 49.

Flinders Petrie Papyri, Cunningham Mems., VIII., IX., $4^{8 .}$

Flora of Edinburgh, Sonntag, 54 .

French, Bö̈elle, 40; Delbos, 4 I ; Eugène, 4I; Hugo, 41, 42; Roget, 43; also Special Education Catalogue.

Literature, Roget, 43.

Novels, Army Series, 39.

Fungi, Cooke, 47 ; Grevillea, 49.

Genera Plantarum, Bentham and Hooker, 46.

Genesis, Hebrew Texts, I9, 35 ; Wright, C. H. H., 27 .

Geography, Ancient, Kicpert, 58.

Geometry, Spencer, $W$. G., 54 .

German, Literature, Nibelungenlied, 42; Phillipps, 43.

Novels, Amin Series, 39.

Germany, Marcks, 59.

God, Idea of, $D^{\prime}$ Alviella, I4.

Gospel, First, Plain Commentary, 23. Fourth, Drummond, I 7 ; Tayler, 26.

Gospels, Lost and Hostile, Gould, I8. Old and New Certainty, Robinson, 24. Greek, Modern, Zompolides, 45.

Gymnastics, Medical, Schreber, 54.

Health, Herbert, 49.

Hebrew, Biblical, Kennedy, 35.

Language, Delitzsch, 34 .

Lexicon, Fuerst, 35.

New School of Poets, Albrecht, 36 .

Scriptures, Sharpe, 25.

Story, Peters, 23.

Synonyms, Kennedy, 35.

Text of O.T., Weir, 27.

Texts, I9, 35 .
Hebrews, History of, Kittel, 6 ; Peters, I2; Shaipe, 25.

Religion of, Kuenen, 9 ; Montefiore, 14. Heterogenesis, Bastian, 46.

Hibbert Lectures, I4, I 5.

Hygiene: How to Live, Caton, 47.

Hymns, Jones, 20.

Icelandic, Lilja, 42 ; Viga Glums Saga, 44.

Dictionary, Zoega, 45 .

Grammar, Bayldon, 40.

Individualism, Spencer, Man $v$. State, 32.

Irish, Atkinson, 40; Book of Ballymote, 40 ; Book of Leinster, 4I ; Hogan, 4 I ; Leabhar Breac, 42 ; Leabhar na H.Uidhri, 42; U'Grady, 43; Stokes, 43; Todd Lectures, 44; Iellow Book of Lecan, 45.

Isaiah, Diettrich, 34 ; Hebrew Texts, I9,

Israel, History of, Kittel, 6 ; Peters, 23 ; Sharpe, 25.

Religion of, Kuene'n, 9.

in Egypt, Wright, G. H. H., 28.

Jeremiah, Mosheh ben Shesheth, 22.

Jesus, Life of, Keim, 8.

The Real, Vickers, 27.

Times of, Hausrath, 8.

See also Christ.

Job, Book of, Ewald, 8; Hebrew Text, I9, 35 ; Wright, G. H. H., 28.

Rabbinical Comment. on, Text \& Trans. Soc., 38.

Justice, Spencer, Princ. of Ethics, II., 31,32 .

Kant, Schurman, 30.

Kindergarten, Goldammer, 57.

Knowledge, Evolution of, Perrin, 30.

Labour, Harrison, 57; Schloss, 59; Vynne, 60.

Leabhar Breac, 42; Atkinson, 40; $\operatorname{Hog} a n, 4 \mathrm{I}$.

Leprosy, Abraham, 46.

Life and Matter, Lodge, 2 I.

Lives of the Saints, Hogan, 4 I.

Logarithms, Sang, 53; Schroen, 54 ; $\operatorname{Veg} a, 55$.

London Library Catalogue, 57.

Lumbar Curve, Cumningham Mems., II., 48 .

Mahabharata, Sörensen, 37.

Malaria, Annett, 46 ; Boyce, 47 ; Dutton, 43; Nems. of Liverpool School of Tropical Medicine, 5I; Ross, 55; Stephens, 54 .

Maori, Dictionary, Williams, 45.

Manual, Maori, 42.

Materialism, Martineau, 22.

Mathematics, Harnack, 49 ; Spencer, 54. See also Logarithms.

Mediæval Thought, Poole, 23.

Mesca Ulad, Todd Lectures, I., 44.

Metaphysics, Lamrie, 29.

Mexico, Religions of, Réville, I5.

Micah, Book of, Taylor, 26.

Microscopy, Journal of the Roy. Micro. Soc., 50; Journal of the Quekett Micro. Club, 50. 


\section{INDEX-continued.}

Midrash, Christianity in, Herford, 9.

Mineral Systems, Chapman, 47.

Monasticism, Harnack, is.

Mosquitoes, Mems. of Liverpool School of Trop. Medicine, $5 \mathrm{I}$.

Mythology, American, Curtin, 57 .

Greek, Brown, 56 ; St. Clair, 59.

Northern, Stephens, 60.

Myxomycetes, Cooke, 47 .

Natural Selection, Spencer, 32 .

Nautical Terms, Delbos, $4 \mathrm{I}$.

Nennius, The Irish, Hogan, 4I.

New Guinea, Cunningham Mems., X., 48.

New Testament, see Testament, 26 .

New Testament Times, Haus'ath, 8, 19.

Nitidulariæ, Nurray, 52.

Norwegian Dictionary, Larsen, 42 ; Rosing; 43.

Ophthalmic Tests, Pray, 52 ; Snellen, 54 .

Origins, Christian, Johnson, 20. of Religion, Hibbert Lectures, $14,15$.

Pali, Dipavamsa, 34 ; Milanda Panho, 36 ; Vinaya Pitakan, 38.

Handbook, Frankfurter, 35.

Miscellany, 36 .

Pathology, Inflammation Idea in, Ran. som, 52 .

Paul, St., Baur, 8; Pfeiderer, 9; Weinel, 5 .

Persian, Avesti Pahlavi, 34. Grammar, Platts, 37.

Peru, Religions of, Réville, I5.

Philo Judaus, Drmmmond, 29.

Philosophy, 29.

and Experience, Hodgson, 29.

Jewish Alexandrian, Drummond, 29.

of Religion, Pfleiderer, 9.

Reorganisation of, Hodgson, 29.

Religion of, Perrin, 22.

Synthetic, Collins, 29; Spencer, 3r.

Phyllotaxis, Church, 47 .

Plague, Boghurst, 46.

Political Institutions, Spencer, Princ. of Sociology, II., 3I.

Prayers, Common Prayer, I6; Jones, 2o; Personal, 22 ; Sadler, 24; Ten Services, 26; Vizard, 27.

Prehistoric Man, Avebury, 56; Engelhardt, 57 ; Laing, 59.

Printing at Brescia, Peddie, 59.

Professional Institutions, Spencer, Princ. of Sociology, III., 3I.

Profit-sharing, Schloss, 59.

Prophets of O.T., Ewald, 8.

Protestant Faith, Hermann, I2 ; Réville, ir.

Psalms, Hebrcu Texts, 19, 35. and Canticles, Ten Services, 26.

Commentary, Ezvald, 8.

Psychology, Mind, 3o; Scripture, 30 ; Wundt, 33 .

of Belief, Pikler, 3 .

Principles of, Spencer, 3 r.

Reconciliation, Henslow, ig.

Reformation, Beard, 14 .

Religion, Child and, 13.

History of, Kuenen, 9, 14 ; Reville, 9, 15. of Philosophy, Perrin, 23.
Religion, Philosophy of, Pfeiderer, 9. Struggle for Light, Wimmer, I .

See also Christianity, History of.

Religions, National and Universal, Kuenen, $2 \mathbf{r}$.

of Authority, Sabatier, 4.

Resurrection, Macan, $22 ;$ Marchant, 22.

Reviews and Periodical Publications, $6 \mathrm{r}$.

Rigveda, Wallis, 38 .

Rome, Renan, 15.

Runes, Stephens, 60.

Ruth, Wright, C. H. H., 27.

Sanitation, in Cape Coast Town, Taylor, 55.

in Para, Notes, 52.

Sanscrit, Abhidhanaratnamala, 34 ; Sörensen, 37 .

Self-Aid, in War, Caverhill, 47.

Sermons, Beard, I6; Broadbent, I6.

Services, Common Prayer, 16 ; Jones, 20 ; Ten Services, 26.

Silva Gadelica, O'Grady, 43 .

Social Dynamics, Mackenzie, 30. Statics, Spencer, 32.

Sociology, Lescriptive, Spencer, 32. Principles of, Spencer, 3r.

Study of, Spencer, 32 .

Solomon, Song of, Révilie, 23.

South Place Ethical Society, Conway, 17.

Spanish Dictionary, Velasquez, 44.

Spinal Cord, Bruce, 47.

Sternum, Paterson, 52.

Storms, Piddington, 52 .

Sun Heat, Cunningham Mems., III., 48.

Surgery, System of, von Bergmann, 46.

Syriac, Bernstein, 34; Diettrich, 34; Nöldeke, 36 .

Taal, Afrikander, Oorat, 42 ; Werner, 45.

Talmud, Christianity in, Herford, 19.

Tennyson, Weld, 60.

Testament, New, Commentary, Protes. tant Commentary, 9.

Textual Criticism, Nestle, 7.

Times, Hausratk, 8, 19.

See also Gospels.

Testament, Old, Cuneiform Inscriptions, Schrader, 9.

Literature of, Kautzsch, zI.

Test Types, Pray, 52 ; Snellen, 54 .

Theism, Voysey, 27.

Theological Translation Library, 3 .

Theology, Analysis of, Figg, r8.

History of, Pfeiderer, 9 .

Truth, Search for, Horton, 20.

Trypanosomiasis, Dutton, 48.

Virgil, Henry, 57.

Virgin Birth, Lobstein, 10.

Weissmann, Spencer, 32.

Woman's Labour, Englishwoman's Revieze, 57; Harrison, 57; Vynne, 6o.

Suffrage, Blackburn, 56 .

Yellow Fever, Durham, 48.

Zoology, Fasciculi Malayenses, 49; Journal of the Linnean Soc., 49; Liverpool Marine Biology Committce Mems., 50. 


\section{Williams \& Norgate's \\ Catalogue of Publications.}

\section{Theology and Religion.}

\section{THEOLOGICAL TRANSLATION LIBRARY. Hew Series.}

A Series of Tianslations by which the best results of recent Theological Investigations on the Continent, conducted without reference to doctrinal considerations, and with the sole purpose of arriving at the truth, are placed within reach of English readers.

Vols. I.-XII. were edited by the Rev. T. K. Cheyne, M.A., D.D., Oriel Professor of Interpretation in the University of Oxford, Canon of Rochester; and the late Rev. A. B. Bruce, D.D., Professor of Apologetics, Free Church College, Glasgow.

Vol. XIII. was edited by Rev. Allan Menzies, D.D., Professor of Divinity and Biblical Criticism in the University, St Andrews.

Vols. XV., XVII., XVIII., and XXI. are edited by Rev. W. D. Morrison, M.A., LL.D.

Vols. XIX. and XX. are edited by Rev. James Moffatt, B.D., D. D., St Andrews.

\section{The Price per Volume is 10s. $6 d$.}

Subscribers to the Series obtain three volumes for 21s., or 22s. 6d. carriage free, payable before publication of the volumes.

Vols. XIX. and XX.

THE EXPANSION OF CHRISTIANITY IN THE FIRST THREE CENTURIES. By Adolf Harnack, Ordinary Professor of Church History in the University, and Fellow of the Royal Academy of the Sciences, Berlin. Translated and edited by James Moffatt, B.D., D.D., St Andrews.

"On the value of such a work by such a writer, it is scarcely" necessary to enlarge. All famaliar with Professor Harnack's method expect his treatment of a theme like this to be masterly, and their expectation is more than realised." - Christian World.

"Nothing could surpass the excellent skill and taste with which these volumes have been translated, edited, and produced."-Bratish Weekly.

14 Henrietta Street, Covent Garden, London, W.C. 
THEOLOGICAL TRANSLATION LIBRARY-Continued.

\author{
Vol. XXI. Just ready. One Volume.
}

ST. PAUL: The Man and his Work. By Prof. H. Weinel of the University of Jena. Translated by Rev. G. A. Bienemann, M.A. Edited by Rev. W. D. Morrison, M.A., LL.D.

\title{
Vol. XVIII.
}

CHRISTIAN LIFE IN THE PRIMITIVE CHURCH. By Ernst von Dobschütz, D.D., Professor of New Testament Theology in the University of Strassburg. Translated by Rev. G. Bremner, and edited by the Rev. W. D. Morrison, LL.D.

"It is only in the very best English work that we meet with the scientific thoroughness and all-round competency of which this volume is a good specimen; while such splendid historical veracity and outspokenness would hardly, be possible in the present or would-be holder of an English theological chair." - Dr Rashdall in The Speaker.

"Some may think that the author's finding is too favourable to the early churches; but, at any rate, there is no volume in which material for forming a judgment is so fully collected or so attractively presented."-British Weekly.

\section{Vol. XVI.}

\section{THE RELIGIONS OF AUTHORITY AND THE RE-} LIGION OF THE SPIRIT. By the late Auguste Sabatier, Professor of the University of Paris, Dean of the Protestant Theological Faculty. With a Memoir of the Author by Jean Réville, Professor in the Protestant 'Theological Faculty of the University of Paris, and a Note by Madame Sabatier.

"Without any exaggeration, this is to be described as a great book, the finest legacy of the author to the Protestant Church of France and to the theological thought of the age. Written in the logical and lucid style which is characteristic of the best French theology, and excellently translated, it is a work which any thoughtful person, whether a professional student or not, might read without difficulty."-Glasgow Herald.

\section{Vols. XV. and XVII,}

THE BEGINNINGS OF CHRISTIANITY. By Paul Wernle, Professor Extraordinary of Modern Church History at the University of Basel. Revised by the Author, and translated by the Rev. G. A. Bienemann, M.A., and edited, with an Introduction, by the Rev. W. D. Morrison, LL.D.

\section{Vol. I. The Rise of the Religion.}

\section{Vol. II. The Development of the Church.}

\section{From some of the Reviews of the Work.}

Dr. Marcus Dods in the British Weekly-"We cannot recall any work by a foreign theologian which is likely to have a more powerful influence on the thought of this country than Wernle's Beginnings of Christianity. It is well written and well translated; it is earnest, clear, and persuasive, and above all it is well adapted to catch the large class of thinking men who are at present seeking some non-miraculous explanation of Christianity."

I4 Henrietta Street, Covent Garden, London, W.C. 


\section{THEOLOGICAL TRANSLATION LIBRARY-Continued.}

"This translation of Prof. Wernle's lectures deserves a very hearty welconie in England. The style is alive and vigorous, the thought suggestive; the whole narrative is admirably clear and simple, popular in the best sense of the term. ... It may be accepted as a companion volume to Harnack's What is Christianity? as an announcement of a liberal position of slightly differing tendency. It is quite easy and pleasant reading for the ordinary layman who may be desirous of knowing the present position of the more advanced schools, and how much of the traditional theology these are prepared to retain. One could wish that a few more English theologians would attempt a similar apologia for the edification of the perplexed lay mind."-Daily News.

"No English book covers the same ground, or is conceived with the same breadth and sanity; in few works in any language are learning and insight so happily combined."-Edinburgh Review.

"The translation is well done, and the book is full of interest."-A thenour:.

The Earlier Works included in the Library are:-

HISTORY OF DOGMA. By Adolf Harnack, Ordinary Professor of Church History in the University, and Fellow of the Royal Academy of the Sciences, Berlin. Translated from the Third German Edition. Edited by the Rev. Prof. A. B. Bruce, D.D. 7 vols. (New Series, Vols. II., VII., VIII., IX., X., XI., KII.) $8 \mathrm{vo}$, cloth, each IOs. $6 \%$; half-leather, suitable for presentation, I2s. $6 d$.

ABBREVIATED LIST OF CONTENTS :-Vol, I.: INTRODUCTORY Divisiox:-I. Prolegomena to the Study of the History of Dogma. II. The Presuppositions of the History of Dogma. Division I. - The Genesis of Ecclesiastical Dogma, or the Genesis of the Catholic Apostolic Dogmatic Theology, and the first Scientific Ecclesiastical System of Doctrine. Book I. :The Prefaration. Vol. II.: Division I. Book II. :-The Laying of the Foundation. - I. Historical Survey.-I. Fixing and gradual Secularising of Christianity as a Church.-II. Fixing and gradual Hellenising of Christianity as a System of Doctrine. Vol. III. : Division I. Book II.:-The Laying of the Foundationcontinued. Division II. - The Development of Ecclesiastical Dogma. Book I. :-The History of the Development of Dogma as the Doctrine of the God-man on the basis of Natural Theology. A. Presuppositions of Doctrine of Redemption or Natural Theology. B. The Doctrine of Redemption in the Person of the God-man in its historical development. Vol. IV. : DIvIsION II. Book I. :The History of the Development of Dogma as the Doctrine of the God-man on the basis of Natural Theology-continued. Vol. V.: Division II. Book II. :-Expansion and Remodelling of Dogma into a Doctrine of Sin, Grace, and Means of Grace on the basis of the Church. Vol. VI. : Division II. Book II.:-Expansion and Remodelling of Dogma into a Doctrine of Sin, Grace, and Means of Grace on the basis of the Church-continued. Vol. VII.: 


\section{THEOLOGICAL TRANSLATION LIBRARY-Continued.}

Division II. Book III. :-The Threefold Issue of the History of Dogma. - Full Index.

"No work on Church history in recent times has had the influence of Prof. Harnack's History of Dogma." - Times.

"A book which is admitted to be one of the most important theological works of the time."-Daily Nerws.

WHAT IS CHRISTIANITY? Sixteen Lectures delivered in the University of Berlin during the Winter Term, I899-1900. By Adolf Harnack. Translated by Thomas Bailey Saunders. (New Series, Vol. XIV.) Demy 8vo, cloth, IOs. $6 d$.; half-leather, suitable for presentation, $12 s .6 d$.

Prof. W. Sanday of Oxford, in the examination of the work, says :--"I may assume that Harnack's book, which has attracted a good deal of attention in this country as in Germany, is by this time well known, and that its merits are recognised-its fresh and vivid descriptions, its breadth of view and skilful selection of points, its frankness, its genuine enthusiasm, its persistent effort to get at the living realities of religion."

"Seldom has a treatise of the sort been at once so suggestive and so stimulating. Seldom have the results of so much learning been brought to bear on the religious problems which address themselves to the modern mind."Pilot.

"In many respects this is the most notable work of Prof. Harnack. . . . These lectures are most remarkable, both for the historical insight they display and for their elevation of tone and purpose."-Literature.

THE COMMUNION OF THE CHRISTIAN WITH GOD : A Discussion in Agreement with the View of Luther. By W. Herrmann, Dr. Theol., Professor of Dogmatic Theology in the University of Marburg. Translated from the Second thoroughly revised Edition, with Special Annotations by the Author, by J. Sandys Stanyon, M.A. (New Series, Vol. IV.) 8vo, cloth. IOS. $6 d$.

"It will be seen from what has been said that this book is a very important one. . . . The translation is also exceedingly well done."-Critical Rcviezu.

"We trust the book will be widely read, and should advise those who read it to do so twice." - Primitive Methodist Quarterly.

"Instinct with genuine religious feeling ; . . exceedingly interesting and suggestive."-Glasgow Herald.

A HISTORY OF THE HEBREWS. By R. Kittel, Ordinary Professor of Theology in the University of Breslau. In 2 vols. (New Series, Vols. III. and VI.) 8vo, cloth. Each volume, Ios. $6 d$.

Vol. I. Sources of Information and History of the Period up to the Death of Joshua. Translated by John Taylor, D.Lit., M.A. 
THEOLOGICAL TRANSLATION LIBRARY-Continued.

\section{Vol. II. Sources of Information and History of the} Period down to the Babylonian Exile. Translated by Hope W. Hogg, B.D., and E. B. Speirs, D.D.

"It is a sober and earnest reconstruction, for which every earnest student of the Old Testament should be grateful."-Christian World.

"It will be a happy day for pulpit and pew when a well-thumbed copy of the History of the Hebrize's is to be found in every manse and parsonage."Literary World.

"It is a work which cannot fail to attract the attention of thoughtful people in this country."-Pall Mall Gazette.

AN INTRODUCTION TO THE TEXTUAL CRITICISM Eberhard Nestle, of Maulbronn. Translated from the Second Edition, with Corrections and Additions by the Author, by William Edie, B.D., and edited, with a Preface, by Allan Menzies, D.D., Professor of Divinity and Biblical Criticism in the University of St. Andrews. (New Series, Vol. XIII.) With eleven reproductions of Texts. Demy 8vo, IOs. $6 d$; half-leather, I2s. $6 d$.

"We have no living scholar more capable of accomplishing the fascinating task of preparing a complete introduction on the new and acknowledged principles than Prof. Nestle. This book will stand the most rigorous scrutiny; it will surpass the highest expectation."-Expository Times.

"Nothing could be better than Dr. Nestle's account of the materials which New Testament textual criticism has to deal with." - Spectator.

"We know of no book of its size which can be recommended more cordially to the student, alike for general interest and for the clearness of its arrangement. . . In smoothness of rendering, the translation is one of the best we have come across for a considerable time."-Manchester Guardian.

THE APOSTOLIC AGE. By Prof. Carl von Weizsäcker. Translated by James Millar, B.D. 2 vols. (New Series, Vols. I. and V.) Demy 8vo, cloth. Each Ios. 6d.

"Weizsäcker is an authority of the very first rank. The present work marks an epoch in New Testament criticism. The English reader is fortunate in having a masterpiece of this kind rendered accessible to him."-Expository Times.

". . No student of theology or of the early history of Christianity can afford to leave Weizsäcker's great book unread."-Manckester Guardiast.

"In every direction in this work we find the mark of the independent thinker and investigator . . . this remarkable volume .. . this able and learned work. . "-Christian World.

"The book itself . . . is of great interest, and the work of the translation has been done in a most satisfactory way."-Critical Review.

I4 Henrietta Street, Covent Garden, London, W.C. 
THEOLOGICAL TRANSLATION FUND LIBRARY. Old \$eries.

Uniform Price per Volume, 6s.

BAUR (F. C.). CHURCH HISTORY OF THE FIRST THREE CENTURIES. Translated from the Third German Edition. Edited by Rev. Allan Menzies. 2 vols. 8vo, cloth. I $2 s$.

PAUL, THE APOSTLE OF JESUS CHRIST, HIS LIFE AND WORK, HIS EPISTLES AND DOCTRINE. A Contribution to a Critical History of Primitive Christianity. Edited by Rev. Allan Menzies. 2nd Edition. 2 vols. 8vo, cloth. I $2 s$.

BLEEK (F.). LECTURES ON THE APOCALYPSE. Translated. Edited by the Kev. Dr. S. Davidson. 8vo, cloth. $6 \mathrm{~s}$.

EWALD'S (Dr. H.) COMMENTARY ON THE PROPHETS OF THE OLD TESTAMENT. Translated by the Rev. J. F. Smith. [Vol. I. General Introduction, Yoel, Amos, Hosea, and Zakharya 9-II. Vol. II. Yesaya, Obadya, and Mikah. Vol. III. Nahûm, Ssephanya, Habaqqûq, Zakhârya, Yéremya. Vol. IV. Hezekiel, Yesaya xl.-lxvi. Vol. V. Haggai, Zakharya, Malaki, Jona, Baruc, Daniel, Appendix and Index.] 5 vols. 8vo, cloth. 30 s.

COMMENTARY ON THE PSALMS. Translated by the Rev. E. Johnson, M.A. 2 vols. 8vo, cloth. I2s.

COMMENTARY ON THE BOOK OF JOB, with Translation. Translated from the German by the Rev. J. Frederick Smith. 8vo, cloth. $6 s$.

HAUSRATH (Prof. A.). HISTORY OF THE NEW TESTAMENT TIMES. The Time of Jesus. Translated by the Revs. C. T. Poynting and P. Quenzer. 2 vols. 8vo, cloth. I $2 s$.

The second portion of this work, "The Times of the Apostles," was issued apart from the Library, but in uniform volumes; see p. 18.

KEIM'S HISTORY OF JESUS OF NAZARA : Considered in its connection with the National Life of Israel, and related in detail. Translated from the German by Arthur Ransom and the Rev. E. M. Geldart. [Vol. I. Second Edition. Introduction, Survey of Sources, Sacred and Political Groundwork. Religious Groundwork. Vol. II. The Sacred Youth, Self-recognition, Decision. Vol. III. The First Preaching, the Works of

I4 Henrietta Street, Covent Garden, London, W.C. 
THEOLOGICAL TRANSLATION FUND LIBRARY-Continued.

Jesus, the Disciples, and Apostolic Mission. Vol. IV. Conflicts and Disillusions, Strengthened Self-confidence, Last Efforts in Galilee, Signs of the Approaching Fall, Recognition of the Messiah. Vol. V. The Messianic Progress to Jerusalem, the Entry into Jerusalem, the Decisive Struggle, the Farewell, the Last Supper. Vol. VI. The Messianic Death at Jerusalem. Arrest and PseudoTrial, the Death on the Cross, Burial and Resurrection, the Messiah's Place in History, Indices.] Complete in 6 vols. 8vo. $36 s$.

(Vol. I. only to be had when a complete set of the work is ordered.)

KUENEN (Dr. A.). THE RELIGION OF ISRAEL TO THE FALL OF THE JEWISH STATE. By Dr. A. Kuenen, Professor of Theology at the University, Leyden. Translated from the Dutch by A. H. May. 3 vols. 8vo, cloth. I 8 s.

PFLEIDERER (O.). PAULINISM : A Contribution to the History of Primitive Christian Theology. Translated by E. Peters. 2nd Edition. 2 vols. 8vo, cloth. I2s.

- PHILOSOPHY OF RELIGION ON THE BASIS OF ITS HISTORY. (Vols. I. II. History of the Philosophy of Religion from Spinoza to the Present Day ; Vols. III. IV. GeneticSpeculative Philosopliy of Religion.) Translated by Prof. Allan Menzies and the Rev. Alex. Stewart. 4 vols. 8vo, cloth. $24 s$.

RÉVILLE (Dr. A.). PROLEGOMENA OF THE HIS. TORY OF RELIGIONS. With an Introduction by Prof. F. Max Miiller. 8vo, cloth. 6s.

PROTESTANT COMMENTARY ON THE NEW TESTAMENT. With General and Special Introductions. Edited by Profs. P. W. Schmidt and F. von Holzendorff. Translated from the Third German Edition by the Rev. F. H. Jones, B.A. 3 vols. 8vo, cloth. I8s.

SCHRADER (Prof. E.). THE CUNEIFORM INSCRIP. TIONS AND THE OLD TESTAMENT. Translated from the Second Enlarged Edition, with Additions by the Author, and an Introduction by the Rev. Owen C. Whitehouse, M.A. 2 vols. (Vol. I. not sold separately.) With a Map. 8vo, cloth. I $2 s$.

ZELLER (Dr. E.). THE CONTENTS AND ORIGIN OF THE ACTS OF THE APOSTLES CRITICALLY INVESTIGATED. Preceded by Dr. Fr. Overbeck's Introduction to the Acts of the Apostles from De Wette's Handbook. Translated by Joseph Dare. 2 vols. 8vo, cloth. I2s.

I4 Henrietta Street, Covent Garden, London, W.C. 


\section{THE CROWN THEOLOGICAL LIBRARY.}

Dr. John Watson, of Liverpool: "The Crown Theological Library is rendering valuable service to lay theologians in this country, as well as to ministers."

The volumes are uniform in size (crown octavo) and binding, but the price varies according to the size and importance of the work.

Vol. I. BABEL AND BIBLE. By Dr. Friedrich Delitzsch, Professor of Assyriology in the University of Berlin. Authorised Translation. Edited, with an Introduction, by Rev. C. H. W. Johns. Crown 8vo, with 77 illustrations, cloth. 5 s.

These are the two famous Lectures which were delivered before the Deutsche Orient-Gesellschaft in the presence of the German Emperor, and again before the Emperor, Empress, and the Court, and which gave rise to the Babel-Bible controversy. They set forth freshly and temperately the close relation between the results of cuneiform studies and the more familiar facts of the Old Testament, and clearly state the conclusions of European scholarship as to the compilation of the Pentateuch from many different sources, and as to its dependence on Babylonian myths for large portions of its primeval history.

"This interestingly illustrated and well-made version of the Lectures should satisfy both scholars and general readers, though no doubt scholars will know best how to appreciate the high value of its arguments."-Scotsman.

"It is written in an interesting and arresting style, and gives the best account we have seen in short compass of these most important discoveries." The Weekly Leader.

"It is long since any book on Biblical Archæology could claim to be more deeply interesting to inquiring minds than this volume must be admitted to be by any thoughtful reader. . We believe that most readers will be delighted with the book as a description, romantic in its realism, of actual dis. coveries, and their bearing on the accuracy of the Old Testament statements." Christian Commonzealth.

\section{Vol. II. THE VIRGIN BIRTH OF CHRIST: An Historical} and Critical Essay. By Paul Lobstein, Professor of Dogmatics in the University of Strassburg. Translated by Victor Leuliette, A.K.C., B. -ès-L., Paris. Edited, with an Introduction, by Rev. W. D. Morrison, LL. D. Crown Svo. 3 s.

"It should be added that Lobstein falls behind no one of those who have refined the tone of modern controversy, that bis attitude to those whose views he opposes is considerate, his own purpose constructive for faith, and his tone impressively reverent. Mr Leuliette's translation is in admirably clear and good English."-Hibbert Journal.

"Professor Lobstein handles his theme with a thoroughly reverent spirit, and the book may be recommended to all who are in doubt as to this particular dogma."-Scotsman.

"No one who reads this most scholarly and convincing volume will doubt the sincerity of the Professor's endeavour and aim ; and most readers will gratefully own the notable success he has achieved."-St Andrew.

I4 Henrietta Street, Covent Garden, London, W.C. 
THE CROWN THEOLOGICAL LIBRARY-Continued.

Vol. III. MY STRUGGLE FOR LIGHT: Confessions of a Preacher. By R. Wimmer, Pastor of Weisweil-am-Rhein in Baden. Crown 8vo, cloth. $3 s .6 d$.

Dr P. T. Forsyth, Principal of Hackney College.-" A beautiful translation of a beautiful book."

"It is a book which will appeal to ministers who are anxious to preserve intellectual sincerity, and to thoughtful laymen who are turning over in their mind the deepest problems of religion. The author's spirit throughout the book reminds one of Martineat. The tone and style of the book are admirable."Dr John Watson in Christian Commonvealth.

"Well worth translating and adding to the Crown Theological Library. It is a book of beautiful intention and most sincere aspiration."-Expository Times.

"This is a notable and vital book, full of keen thought and sweet with the fragrance of true piety."-Week's Suvey.

"This is a delightful book, for we have in it, not the result of scholarship, though that is sound and wide, but the faithful record of the victorious struggles of a religious genius with the spectres of a mind which assail every earnest and thoughtful man in this critical age. The book has one of the marks of true greatness-absolute sincerity. The entire courage, simplicity, and clearminded. ness with which Wimmer faces the difficulties of modern religious thought enforce our admiration, and win our trust and sympathy." -Exaniner.

Vol. IV. LIBERAL CHRISTIANITY: Its Origin, Nature, and Mission. By Jean Réville, Professeur adjoint à la Faculté de Théologie Protestante de l'Université de Paris. Translated and edited by Victor Leuliette, A.K.C., B.-ès-L. Crown Svo, cloth. 45 .

"The book is a powerful, lucid and interesting restatement of the position of Protestantism in regard to modern advances in philosophy and science." Scotsman.

"We commend the book for its lucid style, vigorous reasoning, and spiritual aims."-Christian Commonwealth.

"Admirably translated and edited by Victor Leuliette; is a book which will be of great value to all who are interested in the history of religious development." - St Andrew.

"An honest and earnest effort to vindicate the eternal place of religion in the life of man, and deserves all respect."-Week's Survey.

Vol. V. WHAT IS CHRISTIANITY? By Adolf Harnack, Professor of Church History in the University, Berlin. Translated by Thomas Bailey Saunders. Crown 8vo. 5 s.

Prof. W. Sanday, of Oxford, in an examination of the work, says :- "I may" assume that Harnack's book, which bas attracted a good deal of attention in this country as in Germany, is by this time well known, and that its merits are recognised-its fresh and vivid descriptions, its breadth of view and skilful selection of points, its frankness, its genuine enthusiasm, its persistent effort to get at the living realities of religion."

"In many respects this is the most notable work of Prof. Harnack. . . . These lectures are most remarkable, botb for the historical insight they display and for their elevation of tone and purpose."-Literature. 
THE CROWN THEOLOGICAL LIBRARY-Continued.

Vol. VI. FAITH AND MORALS. By W. Herrmann, Professor of Systematic Theology at the University of Marburg; Author of "The Communion of the Christian with God." Crown 8vo, cloth. 5 s.

Two of the author's shorter writings, with brief notes by the translators. One is on Ritschl, and discusses the Protestant notion of Christian Belief; the other on Romanist versus Protestant Ethics, showing the fundamentally opposite conceptions of the moral law underlying recent Jesuit and Protestant views of truth-speaking or of conscience. An Appendix written for the last German edition deals with three replies.

Vol. VII. EARLY HEBREW STORY. A Study of the Origin, the Value, and the Historical Background of the Legends of Israel. By John P. Peters, D.D., Rector of St. Michael's Church, New York ; author of "Nippur, or Explorations and Adventures on the Euphrates." Crown 8vo, cloth. 5 s.

These lectures were originally delivered as Bond Lectures before the Bangor Theological Seminary in Bangor, Me., U.S.A. Extract from a minute adopted by the Faculty of that Institution after the delivery of those lectures:- "The broad and ripe scholarship, the fresh knowledge of details, the constructive temper, and the reverent Christian spirit which were always manifest, gave these lectures exceptional worth, not only for the student body, but for the large company of thoughtful people who heard them. We earnestly hope that these lectures will be published, for, while opinions may differ about some of the conclusions arrived at, we believe that the course is adapted to promote biblical scholarship, and that their expert knowledge and positive constructive tone give them exceptional value at the present time."

"These lectures are certainly of quite exceptional worth . . . . will not only interest the general reader, but will suggest much to the expert."-British Weekly.

Vol. VIII. BIBLE PROBLEMS AND THE NEW MATERIAL FOR THEIR SOLUTION. A Plea for Thoroughness of Investigation, addressed to Churchmen and Scholars. By the Rev. T. K. Cheyne, D.Litt., D.D., Fellow of the British Academy; Oriel Professor of Interpretation in the University of Oxford, and Canon of Rochester. Crown 8vo. 5 s.

"The temper of his book is admirably gentle and restrained, and the matter is of most living interest."-Academy and Literature.

"The work is remarkably interesting and learned .... those who wish to understand what problems are likely to engage attention in the near future ought not to neglect the book." -British Friend.

Vol. IX. THE DOCTRINE OF THE ATONEMENT AND ITS HISTORICAL EVOLUTION; and RELIGION AND MODERN CULTURE. By the late Auguste Sabatier, Professor in the University of Paris. Translated by Victor Leuliette, A.K.C., B. -ès-L. Crown 8vo. $4 s .6 d$.

"The essay on the Atonement is a masterly outline sketch of the historical evolution of the doctrine."-Oxford Chronicle.

"The second portion of the volume is an admirable statement of the mental condition of the modern world, its doubts and confusions, and of the true method of resolving them. ... Both the studies in the volume are profoundly interesting; marked everywhere by the piercing insight, philosophic grasp, and and deep spirituality which are characteristic of this great and lamented Christian thinker."-The Christian World.

I4 Henrietta Street, Covent Garden, London, W.C. 
THE CROWN THEOLOGICAL LIBRARY-Continued.

Vol. X. THE EARLY CHRISTIAN CONCEPTION OF CHRIST: Its Value and Significance in the History of Religion. By Otto Pfleiderer, D.D., Professor of Practical Theology in the University, Berlin. Crown 8vo. $3 s .6 d$.

"We can heartily recommend Professor Pfleiderer's book as a solid contribution towards the solution of the question which it discusses." - St Andreze.

"It would be difficult to name any recent English work which could compare with this brilliant essay, as a concise but lucid presentation of the attitude of the more advanced school of German theologians to the Founder of the Christian religion."-Scotsman.

Vol. XI. THE CHILD AND RELIGION. Eleven Essays. By Prof. Henry Jones, M.A., LL.D., University of Glasgow ; C. F. G. Masterman, M.A. ; Prof. George T. Ladd, D.D., LL.D., University of Yale; Rev. F. R. Tennant, M.A., B.Sc., Hulsean Lecturer ; Rev. J. Cynddylan Jones, D.D, ; Rev. Canon Hensley Henson, M.A. ; Rev. Robert F. Horton, M.A., D.D. ; Rev. G. Hill, M.A., D.D. ; Rev. J. J. Thornton; Rev. Rabbi A. A. Green; Prof. Joseph Agar Beet, D.D. Edited by Thomas Stephens, B.A. Crown 8vo. 5 s.

"No fresher and more instructive book on this question has been issued for years, and the study of its pages will often prove a godsend to many perplexed minds in the church and in the Christian home."-British Weekly.

Vol. XII. THE EVOLUTION OF RELIGION : An Anthropological Study. By L. R. Farnell, D. Litt., Fellow and Tutor of Exeter College, Oxford; University Lecturer in Classical Archæology, etc., etc. Crown 8vo, cloth. $5^{s}$.

Vol. XIII. THE HISTORY OF EARLY CHRISTIAN LITERATURE. The Books of the New Testament. By H. von Soden, D.D., Professor of Theology in the University of Berlin. Translated by the Rev. J. R. Wilkinson, and edited by Rev. W. D. Morrison, LL.D. Crown 8vo, cloth. 5 s.

In Active Preparation.

Vol. XIV. JESUS. By Wilhelm Bousset, Professor of Theology in Göttingen. Translated by Janet Penrose Trevelyan, and edited by Rev. W. D. Morrison, LL.D. Crown 8vo. $4 s$.

SCIENCE AND RELIGION. A Demonstration of the Reconcilability of their Points of View. By Rudolf Otto, Professor of Theology in Göttingen.

I4 Henrietta Street, Covent Garden, London, W.C. 


\section{THE HIBBERT LECTURES.}

Library Edition, demy 8vo, IOs. 6d. per volume. Cheap Popular Edition, 3s. $6 d$. per volume.

ALVIELLA (Count GOBLET D'). EVOLUTION OF THE IDEA OF GOD, ACCORDING TO ANTHROPOLOGY AND HISTORY. Translated by the Rev. P. H. Wicksteed. (Hibbert Lectures, 189I.) Cloth. Ios. 6d. Cheap Edition, 3s. $6 d$.

BEARD (Rev. Dr. C.). LECTURES ON THE REFORMATION OF THE SIXTEENTH CENTURY IN ITS RELATION TO MODERN THOUGHT AND KNOWLEDGE. (Hibbert Lectures, I883.) 8vo, cloth. Ios. $6 d$. Cheap Edition, 3rd Edition, 3s. $6 d$.

DAVIDS (T. W. RHYS). LECTURES ON SOME POINTS IN THE HISTORY OF INDIAN BUDDHISM. (Hib. Lec., I881.) 2nd Ed. 8vo, cloth. IOs. 6d. Cheap Ed., 3s. 6d.

DRUMMOND (Dr.) VIA, VERITAS, VITA. Lectures on Christianity in its most Simple and Intelligible Form. (The Hibbert Lectures, I894.) Ios. $6 d$. Cheap Edition, 3s. $6 d$.

HATCH (Rev. Dr.). LECTURES ON THE INFLUENCE OF GREEK IDEAS AND USAGES UPON THE CHRISTIAN CHURCH. Edited by Dr. Fairbairn. (Hibbert Lectures, I888.) 3rd Edition. 8vo, cloth. Ios. 6d. Cheap Edition, $35.6 d$.

KUENEN (Dr. A.). LECTURES ON NATIONAL RELIGIONS AND UNIVERSAL RELIGION. (The Hibbert Lectures, I882.) 8vo, cloth. Ios. 6a. Cheap Edition, 3s. $6 d$.

MONTEFIORE (C. G.). ORIGIN AND GROWTH OF RELIGION AS ILLUSTRATED BY THE RELIGION OF THE ANCIENT HEBREWS. (The Hibbert Lectures, I892.) 2nd Edition. 8vo, cloth. IOs. 6d. Cheap Edition, $3 s .6 d$.

PFLEIDERER (Dr. O.). LECTURES ON THE INFLUENCE OF THE APOSTLE PAUL ON THE DEVELOPMENT OF CHRISTIANITY. Translated by the Rev. J. Frederick Smith. (Hibbert Lectures, I885.) and Edition. 8vo, cloth. IOs. $6 \%$. Cheap Edition, 3s. $6 d$.

RENAN (E.). ON THE INFLUENCE OF THE INSTITUTIONS, THOUGHT, AND CULTURE OF ROME ON CHRISTIANITY AND THE DEVELOPMENT OF THE CATHOLIC CHURCH. Translated by the Rev. Charles Beard. (Hibbert Lectures, I880.) 8vo, cloth. IOs. $6 d$.

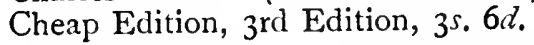

I4 Henrietta Street, Covent Garden, London, W.C. 
THE HIBBERT LECTURES-Continued.

RENOUF (P. LE PAGE). ON THE RELIGION OF ANCIENT EGYPT. (Hibbert Lectures, 1879.) 3rd Edition. 8vo, cloth. IOs. $6 d$. Cheap Edition, 3s. $6 d$.

RHYS (Prof. J.). ON THE ORIGIN AND GROWTH OF RELIGION AS ILLUSTRATED BY CELTIC HEATHENDOM. (Hibbert Lectures, I886.) 8vo, cloth. IOs. $6 d$. Cheap Edition, 3s. $6 d$.

RÉVILLE (Dr. A.). ON THE NATIVE RELIGIONS OF MEXICO AND PERU. Translated by the Rev. P. H. Wicksteed. (Hibbert Lectures, 1884.) 8vo, cloth. Ios. $6 d$. Cheap Edition, 3s. $6 d$.

SAYCE (Prof. A. H.). ON THE RELIGION OF ANCIENT ASSYRIA AND BABYLONIA. 4th Edition. (Hibbert Lectures, I887.) 8vo, cloth. IOs. 6d. Cheap Edition, 3 s. $6 d$.

UPTON (Rev. C. B.). ON THE BASES OF RELIGIOUS BELIEF. (Hibbert Lectures, I893.) Demy 8vo, cloth. Ios. 6d. Cheap Edition, 3s. 6d.

\section{ALPHABETICAL LIST.}

ALLIN (Rev. THOS.). UNIVERSALISM ASSERTED AS THE HOPE OF THE GOSPEL ON THE AUTHORITY OF REASON, THE FATHERS, AND HOLY SCRIPTURE. With a Preface by Edna Lyall, and a Letter from Canon Wilberforce. Crown 8vo. Sewed, Is. $6 d$. net ; cloth, 2s. $6 d$. net.

ALVIELLA (Count GOBLET D'). THE CONTEMPORARY EVOLUTION OF RELIGIOUS THOUGHT IN ENGLAND, AMERICA, AND INDIA. Translated from the French by the Rev. J. Moden. 8vo, cloth. Ios. $6 d$.

EVOLUTION OF THE IDEA OF GOD. See The Hibbert Lectures, p. I4.

ANNOTATED CATECHISM. A Manual of Natural Religion and Morality, with many practical details. 2nd Edition. Crown 8 vo, cloth. Is.

BAUR (F. C.). CHURCH HISTORY OF THE FIRST THREE CENTURIES. See Theological Translation Library, Old Series, p. 8.

- PAUL, THE APOSTLE OF JESUS CHRIST. See Theological Translation Library, Old Series, p. 8.

I4 Henrietta Street, Covent Garden, London, W.C. 
ALPHABETICAL LIST-Continued.

BEARD (Rev. Dr. C.). THE UNIVERSAL CHRIST, AND OTHER SERMONS. Crown 8vo, cloth. 7s. $6 d$.

- LECTURES ON THE REFORMATION OF THE SIXTEENTH CENTURY IN ITS RELATION TO MODERN THOUGHT AND KNOWLEDGE. See The Hibbert Lectures, p. I4.

BEEBY (Rev. C. E., B.D., Author of "Creed and Life"). DOCTRINE AND PRINCIPLES. Popular Lectures on Primary Questions. Demy 8vo, cloth. 4s. $6 d$.

BIBLE. Translated by Samuel Sharpe, being a Revision of the Authorised English Version. 6th Edition of the Old, roth Edition of the New Testament. 8vo, roan. 5s. See also Testament.

BLEEK (F.). LECTURES ON THE APOCALYPSE. See Theological Translation Library, Old Series, p. 8.

BROADBENT (The late Rev. T. P., B.A.). THIRTEEN SERMONS, AN ESSAY, AND A FRAGMENT. With a Prefatory Note by Rev. Prof. J. Estlin Carpenter, M.A. Crown $8 \mathrm{vo}$, cloth. $4 s$. net.

CAMPBELL (Rev. Canon COLIN). FIRST THREE GOSPELS IN GREEK. See Testament, New, p. 26.

CHANNING'S COMPLETE WORKS. Including "The Perfect Life," with a Memoir. Centennial Edition. 4to Edition. Cloth. $7 s, 6 d$.

CHEYNE, Prof. T. K. BIBLE PROBLEMS AND THE NEW MATERIAL FOR THEIR SOLUTION. See Crown Theological Library, p I2.

CHILD AND RELIGION. Edited by Thomas Stephens, B.A. See Crown Theological Library, p. I3.

CHRISTIAN CREED (OUR). 2nd and greatly Revised Edition. Crown 8vo, cloth. 3s. $6 d$.

CLARK (ARCHD. JAS.). DE SUCCESSIONE APOSTOLICA NEC NON MISSIONE ET JURISDICTIONE HIERARCHIA ANGLICANAE ET CATHOLICÆ. 8vo. (Georgetown, Guiana.) Cloth. 2Is.

- SEVEN AGES OF THE CHURCH; or, Exposition of the Apocalypse. Sewed. Is.

COMMON PRAYER FOR CHRISTIAN WORSHIP: in Ten Services for Morning and Evening. 32mo, cloth. is. $6 d$. Also in 8vo, cloth. 3 s.

14 Henrietta Street, Covent Garden, London, W.C. 
ALPHABETICAL LIST-Continued.

CONWAY (MONCURE D.). CENTENARY HISTORY OF THE SOUTH PLACE ETHICAL SOCIETY. With numerous Portraits, a facsimile of the original MS. of the hymn, "Nearer, my God, to Thee," and Appendices. Crown $8 \mathrm{vo}$, half vellum, paper sides. 5 s.

DAVIDS ( $T$. W. RHYS). LECTURES ON SOME POINTS IN THE HISTORY OF INDIAN BUDDHISM. See The Hibbert Lectures, p. I4.

DELITZSCH (F.). BABEL AND BIBLE. Two Lectures delivered before the Deutsche Orient-Gesellschaft in the presence of the German Emperor. See Crown Theological Library, p. Io. See also Harnack, A., "Letter to Preuss. Jahrbiicher," p. I8.

DOBSCHUUTZ (E. VON). CHRISTIAN LIFE IN THE PRIMITIVE CHURCH. See Theological Translation Library, New Series, p. 4.

DRIVER (S. R.). See Mosheh ben Shesheth, p. 22.

DRUMMOND (JAMES, M.A., LL.D., Hon. Litt. D., Principal of Manchester College, Oxford). AN INQUIRY INTO THE CHARACTER AND AUTHORSHIP OF THE FOURTH GOSPEL. Demy 8vo, cloth. Ios. $6 d$.

"This is a valuable book, the work of a liberal theologian of distinction and great influence."-Rev. R. J. CAMPBELL, in Christian Commonwealth.

"The book is not only learned, but also reverent and spiritual in tone, and ought to find its way into the libraries of students of all shades of belief, as a very notable attempt to solve one of the most important of New Testament problems."-Christian World.

"Of the spirit in which Dr. Drummond approaches the study of this work of a master mind, of the completeness and arrangement of the material, and of the temper in which the argument is conducted, it is impossible to speak too highly."-Scotsman.

VIA, VERITAS, VITA. See The Hibbert Lectures, p. I4.

PHILO JUDAUS. See p. 29.

ECHOES OF HOLY THOUGHTS: Arranged as Private Meditations before a First Communion. 2nd Edition, with a Preface by Rev. J. Hamilton Thom. Printed with red lines. Fcap. 8vo, cloth. Is.

EWALD (H.). COMMENTARY ON THE PROPHETS OF THE OLD TESTAMENT. See Theological Transla. tion Library, Old Series, p. 8.

COMMENTARY ON THE PSALMS. See Theological Translation Library, Old Series, p. 8.

I4 Henrietta Street, Covent Garden, London, W.C. 
ALPHABETICAL LIST-Continued.

EWALD (H.). COMMENTARY ON THE BOOK OF JOB. See Theological Translation Library, Old Series, p. 8.

FIGG (E. G.). ANALYSIS OF THEOLOGY, NATURAL AND REVEALED. Crown 8vo, cloth. $6 s$.

FOUR GOSPELS (THE) AS HISTORICAL RECORDS. 8vo, cloth. I5s.

GILL (C.). THE EVOLUTION OF CHRISTIANITY. By Charles Gill. 2nd Edition. With Dissertations in answer to Criticism. 8vo, cloth. I2s.

THE BOOK OF ENOCH THE PROPHET. Translated from an Ethiopic MS. in the Bodleian Library, by the late Richard Laurence, LL.D., Archbishop of Cashel. The Text corrected from his latest Notes by Charles Gill. Re-issue, 8vo, cloth. $5 s$.

GOULD (Rev. S. BARING). LOST AND HOSTILE GOSPELS. An Account of the Toledoth Jesher, two Hebrew Gospels circulating in the Middle Ages, and Extant Fragments of the Gospels of the first Three Centuries of Petrine and Pauline Origin. Crown 8vo, cloth. $7 s .6 d$.

HARNACK (ADOLF). MONASTICISM : Its Ideals and History; and THE CONFESSIONS OF ST. AUGUSTINE. Two Lectures by Adolf Harnack. Translated into English by E. E. Kellett, M.A., and F. H. Marseille, Ph.D., M.A. Crown 8vo, cloth. $4 s$.

"The lectures impart to these old subjects a new and vivid interest which cannot but win this faithful version many admiring readers."-Scotsman.

"One might read all the ponderous volumes of Montalembert without obtaining so clear a view or so rare a judgment of this immense subject as are offered in these luminous pages. . . The translation is excellent, and gives us Harnack in pure and vigorous English."-Christian World.

LETTER to the "Preussische Jahrbuicher" on the German Emperor's Criticism of Prof. Delitzsch's Lectures on " Babel and Bible." Translated into English by Thomas Bailey Saunders. $6 d$. net.

HISTORY OF DOGMA. See Theological Translation Library, New Series, p. 5.

WHAT IS CHRISTIANITY? See Theological Translation Library, New Series, p. 6. Also Crown Theological Library, p. I I. See Saunders (T. B.), "Professor Harnack and his Oxford Critics," p. 25.

EXPANSION OF CHRISTIANITY IN THE FIRST THREE CENTURIES. See Theological Translation Library, p. 3 .

I4 Henrietta Street, Covent Garden, London, W.C. 
ALPHABETICAL LIST-Continued.

HATCH (Rev. Dr.). LECTURES ON THE INFLUENCE OF GREEK IDEAS AND USAGES UPON THE CHRISTIAN CHURCH. See The Hitbert Lectures, p. I4.

HAUSRATH (Prof. A.). HISTORY OF THE NEW TESTAMENT TIMES. The Time of the Apostles. Translated by Leonard Huxley. With a Preface by Mrs Humphry Ward. 4 vols. 8vo, cloth. 42s. (Uniform with the Theological Translation Library, Old Series.)

NEW TESTAMENT TIMES. The Times of Jesus. Sec Theological Translation Library, Old Series, p. 8.

HEBREW TEXTS, in large type for Classes:

Genesis. 2nd Edition. I6mo, cloth. Is. $6 d$.

Psalms. I6mo, cloth. Is.

Isaiah. $16 \mathrm{mo}$, cloth. Is.

Job. I6mo, cloth. Is.

HENSLOW (Rev. G.). THE ARGUMENT OF ADAPTATION ; or, Natural Theology reconsidered. 8vo, cloth. Is.

SPIRITUAL TEACHINGS OF BIBLE PLANTS; or, The Garden of God. 8vo, cloth. Is.

- THE AT-ONE-MENT; or, The Gospel of Reconciliation. 8 vo, cloth. Is.

CHRIST NO PRODUCT OF EVOLUTION. 8vo. cloth. Is.

HERFORD (R. TRAVERS, B.A.). CHRISTIANITY IN TALMUD AND MIDRASH. Demy 8vo, cloth. I8s, net.

CON'TENTS :-Introduction. Division I. Passages from the Rabbinical Literature: A. Passages relating to Jesus. B. Passages relating to Minim, Minuth. Division II. General Results. Appen. dix containing the Original Texts of the Passages translated. Indices.

"His book (if he is right in his identification of the Minim) is a history of Judaising Christianity - the first independent and competent history written in English."-Expository Times.

"It must become at once the standard authority on its subject."-Manchester Guardian.

"It is no exaggeration to say that it will prove indispensable not only to scholars interested in Talmudic literature, but to all who study the subject of the evangelical tradition. It will introduce the reader into a new world-that of Jewish thought in the centuries after Christ."-Cambridge Review.

HERRMANN (W.). THE COMMUNION OF THE CHRISTIAN WITH GOD. See Theological Translation Library, New Series, p. 6.

I4 Henrietta Street, Covent Garden, London, W.C 


\section{ALPHABETICAL LIST-Continued.}

HERRMANN (W.). FAITH AND MORALS. See Crown Theological Library, p. I2.

HIBBERT JOURNAL: A Quarterly Review of Religion, Theology, and Philosophy. Edited by L. P. Jacks and G.' Dawes Hicks. Vol. I. Royal 8vo, 856 pp. Vol. II., 864 pp. Vol. III., 869 pp. Cloth. Each I 2s. 6d. net. Annual Subscription, IOS. post free.

HOERNING (Dr. R.). THE KARAITE MSS., BRITISH MUSEUM. The Karaite Exodus (i. to viii. 5) in Forty-two Autotype Facsimiles, with a Transcription in ordinary Arabic type. Together with Descriptions and Collation of that and five other MSS. of portions of the Hebrew Bible in Arabic characters in the same Collection. Royal 4to, cloth, gilt top. 20s.

HORTON (J.). MY SEARCH FOR TRUTH, AND WHAT I FOUND. Crown 8vo, cloth. 2s. $6 d$.

HUNTER (Rev. J., D.D.). THE COMING CHURCH. A Plea for a Church simply Christian. Cloth. Is. 6d. net.

CIVIC APATHY. A Sermon preached at Bechstein Hall, London, Sunday morning, 25th June 1905. 6d. net.

JOHNSON (EDWIN, M.A.). THE RISE OF CHRISTENDOM. Demy 8vo, cloth. 7s. 6d.

- ANTIQUA MATER: A Study of Christian Origins. Crown 8vo, cloth. 2s. $6 d$.

- THE RISE OF ENGLish CULTURE. Demy 8vo, cloth. I5s. net.

JONES (Rev. R. CROMPTON). HYMNS OF DUTY AND FAITH. Selected and Arranged. 247 pp. Fcap. 8vo, cloth. 2nd Edition. 3s. $6 d$.

CHANTS, PSALMS, AND CANTICLES. Selected and Pointed for Chanting. 18mo, cloth. 1s. $6 d$.

ANTHEMS. With Indexes and References to the Music. I 8 mo, cloth. Is. $3 d$.

- THE CHANTS AND ANTHEMS. Together in I vol., cloth. $2 s$.

A BOOK OF PRAYER. In Thirty Orders of Worship, with Additional Prayers and Thanksgivings. 18mo, cloth. 2s. $6 d$. With Chants, in I vol. $18 \mathrm{mo}$, cloth. 3 s.

14 Henrietta Street, Covent Garden, London, W.C. 
ALPHABETICAL LIST-Continued.

KAUTZSCH (E.). AN OUTLINE OF THE HISTORY OF THE LITERATURE OF THE OLD TESTAMENT. With Chronological Tables for the History of the Israelites, and other Aids to the Explanation of the Old Testament. Reprinted from the "Supplement to the Translation of the Old Testament." By E. Kautzsch, Professor of Theology at the University of Halle. Edited by the Author. Translated by John Taylor, D. Lit., M.A., etc. Demy 8vo, cloth. $6 s .6 d$.

"This English translation ... is likely to prove very acceptable to all those, students who desire to see for themselves the view taken by the "higher critics" of the growth of the Old Testament."-The Guardian.

"Dr. Taylor has rendered a great service to the English readers by his excellent translation of this important work."-British Weekly.

"As to matter, it is the work of a scholar who is not afraid of results suggested by fair research, but who never grasps at novelties merely for the sake of originality. In style and language, the book reads more like an original than a translation; an original, too, which in its terseness of expression has escaped the prolix obscurity so commonly complained of in the writings of the author's country."-Church Gazette.

"A brief yet comprehensive statement of critical opinion respecting the order and origin of the Old Testament books."-Methodist Times.

KEIM'S HISTORY OF JESUS OF NAZARA. See Theological Translation Library, Old Series, p. 8.

KENNEDY (Rev. JAS.). BIBLICAL HEBREW. See p. 35 .

KIRK (R. S.). SIDE-LIGHTS ON GREAT PROBLEMS OF HUMAN INTEREST. Crown 8vo, cloth. Is.

KITTEL (R.). HISTORY OF THE HEBREWS. See Theological Translation Library, New Series, p. 6.

KUENEN (Dr. A.). LECTURES ON NATIONAL AND UNIVERSAL RELIGIONS. See The Hibbert Lectures, p. 14 .

THE RELIGION OF ISRAEL TO THE FALL OF THE JEWISH STATE. See Theological Translation Library, Old Series, p. 9.

LOBSTEIN (P.). THE DOGMA OF THE VIRGIN BIRTH OF CHRIST. See Crown Theological Library, p. IO.

LODGE (Sir O.). LIFE AND MATTER. A Criticism of Professor Haeckel's "Riddle of the Universe." Crown 8vo, cloth. $2 s, 6 d$. net.

I4 Henrietta Street, Covent Garden, London, W.C. 
ALPHABETICAL LIST-Continued.

MACAN (R. W.). THE RESURRECTION OF JESUS CHRIST. An Essay in Three Chapters. 8vo, cloth. $5 s$.

MACKAY (R. W.). SKETCH OF THE RISE AND PROGRESS OF CHRISTIANITY. 8vo, cloth. $6 s$.

MARCHANT (JAMES). THEORIES OF THE RESURRECTION OF JESUS CHRIST. Crown 8vo, stiff covers, 2s. net ; superior cloth binding, 3 .

MARTINEAU (Rev. Dr. JAMES). THE RELATION BETWEEN ETHICS AND RELIGION. An Address. 8 vo, sewed. Is.

MODERN MATERIALISM : ITS ATTITUDE TOWARDS THEOLOGY. A Critique and Defence. 8vo, sewed. 2s. $6 d$.

MONTEFIORE (C. G.). ORIGIN AND GROWTH OF RELIGION AS ILLUSTRATED BY THE RELIGION OF THE ANCIENT HEBREWS. See The Hibbert Lectures, p. 14 .

MOSHEH BEN SHESHETH'S COMMENTARY ON JEREMIAH AND EZEKIEL. Edited fron a Bodleian MS., with a Translation and Notes, by S. R. Driver. 8vo, sewed. 3 .

MÜNSTERBERG (Prof. HUGO). THE AMERICANS. See p. 30.

NESTLE (E.). INTRODUCTION TO THE TEXTUAL CRITICISM OF THE GREEK NEW TESTAMENT. See Theological Translation Library, New Series, p. 7.

OTTO (R.). SCIENCE AND RELIGION. See Crown Theological Library, p. 13.

PERRIN (R. S.). THE EVOLUTION OF KNOWLEDGE. A Review of Philosophy. Crown 8vo, cloth. 6s.

PERSONAL AND FAMILY PRAYERS. Svo, buckram. Is. net.

I4 Henrietta Street, Covent Garden, London, W.C. 
ALPHABETICAL LIST-Continued.

PETERS (JOHN P.). EARLY HEBREW STORY. A Study of the Origin, the Value, and the Historical Background of the Legends of Israel. See Crown Theological Library, p. I2.

PFLEIDERER (Dr. O.). LECTURES ON THE IN. FLUENCE OF THE APOSTLE PAUL ON THE DEVELOPMENT OF CHRISTIANITY. See The Hibbert Lectures, p. I4.

PAULINISM : A Contribution to the History of Primitive Christianity. See Theological Translation Library, Old Series, p. 9.

PHILOSOPHY OF RELIGION ON THE BASIS OF ITS HISTORY. See Theological Translation Library, Old Series, p. 9.

- THE EARLY CHRISTIAN CONCEPTION OF CHRIST: Its Significance and Value in the History of Religion. See Crown Theological Library, p. I3.

PLAIN COMMENTARY ON THE FIRST GOSPEL. By an Agnostic. 8vo, cloth. I4s.

POOLE (REG. LANE). ILLUSTRATIONS OF THE HISTORY OF MEDI EVAL THOUGHT IN THE DEPARTMENTS OF THEOLOGY AND ECCLESI. ASTICAL POLITICS. 8vo, cloth. Ios. $6 d$.

PROTESTANT COMMENTARY ON THE NEW TESTAMENT. See Theological Translation Library, Old Series. p. 9.

RENAN (E.). ON THE INFLUENCE OF THE INSTITUTIONS, THOUGHT, AND CULTURE OF ROME ON CHRISTIANITY AND THE DEVELOPMENT OF THE CATHOLIC CHURCH. See Hibbert Lectures, p. I4.

RENOUF (P. LE PAGE). ON THE RELIGION OF ANCIENT EGYPT. See Hibbert Lectures, p. 15.

RÉVILLE (A.). THE SONG OF SONGS, Commonly called the Song of Solomon, or the Canticle. Translated from the French. Crown 8vo, cloth. Is. $6 d$.

I4 Henrietta Street, Covent Garden, London, W.C. 
ALPHABETICAL LIST-Continued.

RÉVILLE (A.). ON NATIVE RELIGIONS OF MEXICO AND PERU. See Hibbert Lectures, p. I5.

- PROLEgomena OF THE History OF RELIGIONS. See Theological Translation Library, Old Series, p. 9.

REVILLE (JEAN). LIBERAL CHRISTIANITY. See Crown Theological Library. p. II.

- See also Sabatier's "Religions of Authority and Roligion of the Spirit," p. 4.

RHYS (J.). ON THE ORIGIN AND GROWTH OF RELIGION AS ILLUSTRATED BY CELTIC HEATHENDOM. See Hibbert Lectures, p. 15.

RIX (HERBERT). A DAWNING FAITH ; or, The World as a Spiritual Organism. Crown 8vo, cloth. 5 s.

ROBINSON (ALEX., M.A., B.D.). A STUDY OF THE SAVIOUR IN THE NEWER LIGHT, and Edition. Revised and partly re-written. Demy 8vo, cloth. 7 s. $6 d$.

OLD AND NEW CERTAINTY OF THE GOSPEL: A Sketch. Crown 8 vo, cloth. $2 s .6 d$.

SABATIER (AUGUSTE). THE RELIGIONS OF AUTHORITY AND THE RELIGION OF THE SPIRIT. With a Memoir by Professor J. Réville. See Theological Translation Library, New Series, p. 4.

- THE DOCTRINE OF THE ATONEMENT AND ITS HISTORICAL EVOLUTION; and RELIGION AND MODERN CULTURE. See Crown Theological Library, p. 12.

SADLER (Rev. Dr.). PRAYERS FOR CHRISTIAN WORSHIP. Crown 8vo, cloth. $3 s .6 d$.

CLOSET PRAYERS, Original and Compiled. $18 \mathrm{mo}$, cloth. I $s, 6 d$.

14 Henrietta Street, Covent Garden, London, W.C. 
ALPHABETICAL LIST-Continued.

SAUNDERS ( $T$. BAILEY). PROFESSOR HARNACK AND HIS OXFORD CRITICS. Crown 8vo, cloth. Is. $6 d$. net.

"It gives thoughtful and acutely reasoned support to the great historical student of Christianity who represents Berlin in theology against the pig. tailed opposition which Oxford has offered to his learning. A spirited piece of controversial writing, it cannot but prove stimulating to readers interested in modern divinity, no matter to which side of the debate their private preposses. sions incline them." - Scotsman.

"Mr. Saunders writes with sobriety and with a knowledge of the points at issue. Readers of 'Harnack and his Critics' will do well to read his comments."-Sheffield Daily Telegraph.

SAVAGE (M. J.). BELIEFS ABOUT THE BIBLE. 8vo, cloth. $7 s .6 d$.

SAYCE (A. H.). ON THE RELIGION OF ANCIENT ASSYRIA AND BABYLONIA. See Hibbert Lectures, p. 15 .

SCHRADER (E.). CUNEIFORM INSCRIPTIONS AND THE OLD TESTAMENT. See Theological Translation Library, Old Series, p. 9.

SEVERUS (Patriarch of Antioch). THE SIXTH BOOK OF THE SELECT LETTERS OF SEVERUS, PATRIARCH OF ANTIOCH, in the Syriac Version of Athanasius of Nisibis. Edited and translated by E. W. Brooks. Vol. I. (Text), Part I, and Vol. II. (Translation), Part I. 2 vols. 8 vo, cloth. 42s. net. Vol. I. (Text), Part 2, and Vol. II. (Translation), Part 2. 2 vols. 8vo, cloth. 42s. net. See Text and Translation Society, p. 38.

SHARPE (SAMUEL). HISTORY OF THE HEBREW NATION AND ITS LITERATURE. With an Appendix on the Hebrew Chronology. 5th Edition. Crown 8vo, cloth. $4 s .6 d$.

CRITICAL NOTES ON THE AUTHORISED ENGLISH VERSION OF THE NEW TESTAMENT. 2nd Edition. I $2 \mathrm{mo}$, cloth. $1 \mathrm{~s} .6 \mathrm{~d}$.

SMITH (MARTIN R.). WHAT I HAVE TAUGHT MY CHILDREN. 2nd Edition, Revised. Crown 8vo, cloth. 3s. $6 d$.

SODEN (H. von, D.D.). THE HISTORY OF EARLY CHRISTIAN LITERATURE. See Crown Theological Library, p. 13.

14 Henrietta Street, Covent Garden, London, W.C 


\section{ALPHABETICAL LIST-Continued.}

THE STATUTES OF THE APOSTLES. The hitherto unedited Ethiopic and Arabic Texts. Edited, with an Introduction and Translations of the Ethiopic, Arabic, and Coptic Texts, by Rev. G. Horner, M.A. With an Appendix-a recently discovered variant of the Coptic Text. I8s. net.

TAYLER (Rev. JOHN JAMES). AN ATTEMPT TO ASCERTAIN THE CHARACTER OF THE FOURTH GOSPEL, especially in its Relation to the First Three. 2nd Edition. 8vo, cloth. 5 s.

TAYLOR (Rev. C.). THE DIRGE OF COHELETH IN ECCLES. XII. DISCUSSED AND LITERALLY INTERPRETED. 8vo, cloth. 3 s.

TAYLOR (Rev. Dr. J.). THE MASSORETIC TEXT AND THE ANCIENT VERSIONS ON THE BOOK OF MICAH. Crown 8vo, cloth. 5s,

_ Sec also Kautzsch, "Outline," p. 2 I.

TEN SERVICES OF PUBLIC PRAYER, with Special Collects. $8 \mathrm{vo}$, cloth, 35 . ; or $32 \mathrm{mo}$, cloth, 1 s. $6 d$.

— PSALMS AND CANTICLES. 8vo, cloth. is. $6 d$. PSALMS AND CANTICLES, with Anthems. 8vo, cloth. 2s.

TEN SERVICES OF PUBLIC PRAYEK, taken in Substance from the Common Prayer for Christian Worship, with a few additional Prayers for particular Days. Svo, cloth, $2 s .6 d$.; or $32 \mathrm{mo}$, cloth, Is.

TESTAMENT, THE NEW. TISCHENDORF (C.). NOVUM TESTAMENTUM GRACE. 3 vols. 8vo. 7os. net.

CAMPBELL (Rev. Canon COLIN, M.A., D.D.). THE FIRST THREE GOSPELS IN GREEK. Arranged in parallel columns. 2nd Edition, Revised. Crown 8vo, cloth. 5s. net.

UPTON (C. B.). ON THE BASES OF RELIGIOUS BELIEF. Sec Hibbert Lectures, p. I5.

14 Henrietta Street, Covent Garden, London, W.C. 
ALPHABETICAL LIST-Continued.

VICKERS (J.). THE REAL JESUS : a Review of his Life, Character, and Death, from a Jewish Standpoint. Crown 8vo. $6 s$.

- THE CRUCIFIXION MYSTERY. Crown 8vo: cloth. 3s. $6 d$.

VIZARD (P. E.). PRAYERS, NEW AND OLD. New Edition. Printed at the Chiswick Press. Crown 8vo, buckram. Is. net.

VOYSEY (Rev. C.). THE SLING AND THE STONE. Vol. VIII. On the Lord's Prayer, 8vo, cloth. 3s. 6\%. Vol. IX. The Fatherhood of God. Sermon on the Mount, etc. 8vo, cloth. 7s. 6d. Vol. X. Revelation tested on Moral Grounds, etc. 8vo, cloth. IOs. $6 d$.

- THEISM AS A SCIENCE OF NATURAL THEOLOGY AND NATURAL RELIGION. $2 s .6 d$.

THEISTIC PRAYER BOOK. 3rd Edition. I 2mo, cloth. 3s. $6 \%$.

WEIR (T. H., B.D.). A SHORT HISTORY OF THE HEBREW TEXT OF THE OLD TESTAMENT. BY Thomas H. Weir, Assistant to the Professor of Oriental Languages in the University of Glasgow. Crown 8vo, sewed, 5s.; cloth, $6 s$.

WEIZSÄCKER (C. von). THE APOSTOLIC AGE, 2 vols. See Theological Translation Library, New Series, p. 7.

WERNLE (Paul). THE BEGINNINGS OF CHRISTIANITY. 2 vols. 8vo. See Theological Translation Library, New Series, p. 4.

WICKSTEED (Rev. P. H.). THE ECCLESIASTICAL INSTITUTIONS OF HOLLAND, treated with Special Reference to the Position and Prospects of the Modern School of Theology. A Report presented to the Hibbert Trustees, and published by their direction. 8vo, sewed. Is.

WIMMER (R.). MY STRUGGLE FOR LIGHT: Con. fessions of a Preacher. See Crown Theological Library, P. II.

I4 Henrietta Street, Covent Garden, London, W.C. 


\section{ALPHABETICAL LIST-Continued.}

WRIGHT (Rev. C. H. H.). BOOK OF GENESIS IN HEBREW TEXT. With a critically revised Text, various Readings, and Grammatical and Critical Notes. Demy 8vo. 3 s. $6 d$.

BOOK OF RUTH IN HEBREW TEXT. With a critically revised Text, various Readings, including a new Collation of Twenty-eight Hebrew MSS., and a Grammatical and Critical Commentary ; to which is appended the Chaldee Targum. Demy 8vo. 7s. 6d.

- DANIEL AND HIS PROPHECIES. Demy 8vo, cloth. 7s. $6 d$.

DANIEL, THE BOOK OF. A Critical and Grammatical Commentary with Appendix. Demy 8vo, cloth. 7 s. $6 d$.

WRIGHT (G. H. BATESON). THE BOOK OF JOB. A new critically revised Translation, with Essays on Scansion, Date, etc. 8 vo, cloth. $6 s$.

- WAS ISRAEL EVER IN EGYPT ? or, A Lost Tradition. By G. H. Bateson Wright, D.D., Queen's College, Oxford; Headmaster Queen's College, Hong-Kong; Author of "A Critical Revised Translation of the Book of Job." 8vo, art linen. $7 s .6 d$.

ZELLER (E.). CONTENTS AND ORIGIN OF THE ACTS OF THE APOSTLES. See Theological Translation Library, Old Series, p. 9.

I4 Henrietta Street, Covent Garden, London, W.C. 


\section{Philosophy, Psychology.}

BACON (ROGER), THE "OPUS MAJUS" OF. Edited, with Introduction and Analytical Table, by John Henry Bridges, Fellow of Royal College of Physicians, sometime Fellow of Oriel College. Complete in 3 vols., $3 \mathrm{Is}$. $6 d$. ; Vol. III. sold separately, $7 s .6 d$.

BREWSTER (H. B.). THE THEORIES OF ANARCHY AND OF LAW. A Midnight Debate. Crown 8vo, parch. ment. $5^{s}$.

- THE PRISON. A Dialogue. Crown 8vo, parchment. 5 s. THE STATUETTE AND THE BACKGROUND. Crown 8vo, parchment. 4s.

COLLINS (F. H.). AN EPITOME OF THE SYNTHETIC PHILOSOPHY. By F. Howard Collins. With a Preface by Herbert Spencer. 5th Edition. The Synthetic Philosophy Completed. 8vo, cloth. 2Is.

DENNYS (EDWARD N.). THE ALPHA; or, The First Mental Principle and Truth-Guide to General Well-Being and Progress: A Revelation but no Mystery. 6th Edition. With a Portrait of the Author. Crown 8vo, cloth. 3s. 6d.

DRUMMOND (Dr.). PHILO JUDEUS; or, The Jewish Alexandrian Philosophy in its Development and Completion. By James Drummond, LL.D., Principal of Manchester New College, Oxford. 2 vols. 8vo, cloth. 2 Is.

HODGSON (S. H.). PHILOSOPHY AND EXPERIENCE. An Address delivered before the Aristotelian Society. 8vo, sewed. 25.

THE REORGANISATION OF PHILOSOPHY. Address. 8vo, sewed. Is.

LAURIE (Professor SIMON). ETHICA: or, The Ethics of Reason. By Scotus Novanticus. 2nd Edition. 8vo, cloth. 6s.

METAPHYSICA NOVA ET VETUSTA: A Return to Dualism. 2nd Edition. Crown 8vo, cloth. 6s.

LODGE (Sir O.). LIFE AND MATTER. See Religion, p. 2 I.

14 Henrietta Street, Covent Garden, London. W.C. 
MACKENZIE (MALCOLM). SOCIAL AND POLITICAL DYNAMICS. An Exposition of the Function of Money as the measure of Contract, Trade, and Government, viewed from the Principles of Natural Philosophy and Jurisprudence, in refutation of Economic Dogmas. Demy 8vo, cloth. Ios. $6 d$.

MIND: A Quarterly Review of Psychology and Philosophy. Nos. I-64. I876-9o. 8vo, each $3 s$. Vols. III.-XVI. in cloth, each 13s. New Series, Nos. 1-32, each 3s.; 33 and after, $4 s$. Vols. I.-VIII., each 13s. Vols. IX.-XIV., each I7s. Annual Subscription, post free, I $2 s$.

MÜNSTERBERG (HUGO, Professor of Psychology at Harvard University). THE AMERICANS. Translated by Edwin B. Holt, Ph.D., Instructor at Harvard University. Royal $8 \mathrm{vo}$, cloth. I2s. $6 d$. net.

PERRIN (R. S.). EVOLUTION OF KNOWLEDGE, THE. A Review of Philosophy. See Religion, p. 22.

PIKLER (JUL.). THE PSYCHOLOGY OF THE BELIEF IN OBJECTIVE EXISTENCE. Part I. 8vo, cloth. $4 s .6 d$.

PROCEEDINGS OF THE ARISTOTELIAN SOCIETY FOR THE SYSTEMATIC STUDY OF PHILOS. OPHY. Proceedings. Vol. I., 4 Nos., I890-91. 8vo, I2s. Discontinued after Vol. III. Part 2. Or each Part separately.

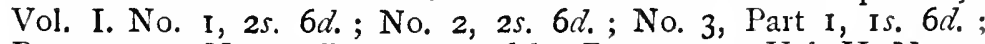
Part 2, 2s. ; No. 4, Part I, I s. 6d. ; Part 2, 2s. Vol. II. No. I, Part 1, Is. 6d. ; Part 2, 2s. ; No. 2, Part 1, 1s. 6d.; Part 2, 2s. ; No. 3, Part I, 2s.; Part 2, 2s. Vol. III. Part 1, 2s. 6d.; Part 2, 2s. NEW SERIES, Vols. I.-IV. Demy 8vo, buckram, each $10 s .6 d$. net.

ROBERTSON (G. C.). PHILOSOPHICAL REMAINS OF GEORGE CROOM ROBERTSON, Grote Professor of Mind and Logic, University College, London. With a Memoir. Edited by Alexander Bain, LL.D., Emeritus Professor of Logic, Aberdeen, and 'T. Whittakcr, B.A. (Oxon.). With Portrait. Med. 8vo, cloth. 9s. net.

SCHURMAN (J. GOULD). KANTIAN ETHICS AND THE ETHICS OF EVOLUTION. 8vo, cloth. $5 s$.

THE ETHICAL IMPORT OF DARWINISM. Crown $8 \mathrm{vo}$, cloth. $5 s$.

SCRIPTURE (EDWARD W., Ph.D.). STUDIES FROM THE YALE PSYCHOLOGICAL LABORATORY. Vols. I. -VI., each $4 s$. $2 d$. net.

×4 Henrietta Street, Covent Garden, London, W.C. 
SMITH (H. W.). THE GARDEN OF LIFE. Flowers of Thought on Culture, Conduct, and Character for every day in the year, gathered and arranged by H. W. Smith. Crown 8vo, cloth gilt. 5s, net.

\section{SPENCER (HERBERT). AN AUTOBIOGRAPHY.} 2 vols. demy 8vo. With Portraits. Green buckram, gilt top. 28 s. net.

"It is not too much to say that we close this book, the most interesting, and certainly one of the most important we have ever opened, feeling better, wiser, and humbler for having thus hastily read it."-Academy.

"It is a book for all men and for all time. In its pages the thinker may trace, step by step, the synthesis of synthetic philosophy. Here the poet will find not only a worthy inspiration, but a possibly surprising vein of sympathy. The statesman, the inventor, the litterateur, the man of theory, and the man of practice will find alike, within the covers of these two massive volumes, an almost inexhaustible treasury of interest and constructive thought. There is suggestion and instruction for all the world, and an almost indefinable fascination-whether it be due to the mere intrinsic beauty of the picture itself, or to the dignity of its execution, or to the sense of its almost laborious faithfulness, or to the combined attraction of all three."-St. James's Gazette.

\section{A SYSTEM OF SYNTHETIC PHILOSOPHY-}

Vol. I. First Principles. With an Appendix and a Portrait. Finally revised. New Edition, large crown 8vo, cloth. $7 s .6 d$.

Vols. II. and III. The Principles of Biology. 6th Thousand. 8vo, cloth. Revised and greatly enlarged. Vols. I. and II. I8s, each.

Vols. IV. and V. The Principles of Psychology. 5th Thousand. 2 vols. 8vo, cloth. $36 s$.

Vol. VI. The Principles of Sociology. Vol. I. Part I, The Data of Sociology; Part 2, The Inductions of Sociology; Part 3, Domestic Institutions. 4th Thousand, revised and enlarged. 8vo, cloth. $2 \mathrm{Is}$.

Vol. VII. The Principles of Sociology. Vol. II. Part 4, Ceremonial Institutions; Part 5, Political Institutions. 3rd Thousand. 8vo, cloth. I 8 s.

Vol. VIII. The Principles of Sociology. Vol. III. Part 6, Ecclesiastical Institutions; Part 7, Professional Institutions; Part 8, Industrial Institutions. 2nd Thousand. 8vo, cloth. $16 s$.

Vol. IX. The Principles of Ethics. Vol. I. Part I, The Data of Ethics ; Part 2, 'The Inductions of Ethics ; Part 3, The Ethics of Individual Life. 2nd Thousand. 8vo, cloth. I5s.

Vol. X. The Principles of Ethics. Vol. II. Part 4, Justice; Part 5, Negative Beneficence; Part 6, Positive Beneficence; Appendices. Demy 8vo, cloth. I 2s. $6 d$.

I4 Henrietta Street, Covent Garden, London. IXr.C. 
Also to be had separately:

SPENCER (HERBERT). JUSTICE. Being Part 4 of the Principles of Ethics. 2nd Thousand. 8vo, cloth. $6 s$.

Other Works.

— THE STUDY OF SOCIOLOGY. Library Edition (2Ist Thousand), with a Postscript. 8vo, cloth. 10s. $6 d$.

- EDUCATION : Intellectual, Moral, and Physical. Cheap Edition. Entirely reset. 46th Thousand. Crown 8vo, cloth. $2 s .6 d$.

- ESSAYS : Scientific, Political, and Speculative. A new Edition, rearranged, with additional Essays. 3 vols. 8vo, cloth. (Each IOs.) 3os.

- SOCIAL STATICS. Abridged and revised, together with "The Man v. The State." 8vo, cloth. Ios.

- VARIOUS FRAGMENTS. Uniform in Library binding. Demy 8vo, cloth. Enlarged Edition. $6 s$.

— FACTS AND COMMENTS. Demy svo, cloth. $6 s$.

- THE MAN versus THE STATE. I4th Thousand. Sewed. Is.

- A REJOINDER TO PROFESSOR WEISMANN. Sewed. $6 d$.

- - REASONS FOR DISSENTING FROM THE PHILOSOPHY OF M. COMTE. Sewed $6 d$.

DESCRIPTIVE SOCIOLOGY; or, Groups of Sociological Facts. Compiled and abstracted by Professor D. Duncan of Madras, Dr. Richard Scheppig, and James Collier. Folio, boards.

No. I. English. I $\delta s$.

No. 2. Ancient American Races. I6s.

No. 3. Lowest Races, Negritto Races, Polynesians. I8s.

No. 4. African Races. I6s.

No, 5. Asiatic Races. I8s.

No. 6. American Races. I $8 s$.

No. 7. Hebrews and Phœnicians. 21 s.

No. 8. The French Civilisation. 3os.

New volumes in preparation.

I4 Wenrietta Street, Covent Garden, London, W.C. 
SPENCER (HERBERT). COLLINS (F. H.). AN EPITOME OF THE SYNTHETIC PHILOSOPHY. By F. Howard Collins. Being a Digest of Mr. Herbert Spencer's Works. 5th Edition, the Synthetic Philosophy Completed. With a Preface by Herbert Spencer. 8vo, cloth. 2Is.

DREY (S.). HERBERT SPENCER'S THEORY OF RELIGION AND MORALITY. By Sylvan Drey. 8vo, sewed. Is.

\section{A THEORY OF LIFE DEDUCED FROM THE} EVOLUTION PHILOSOPHY. Demy 8vo, sewed. Is.

SPINOZA: Four Essays. By Professors Land, Van Vloten, and Kuno Fischer, and by E. Renan. Edited by Professor Knight, of St. Andrews. Crown 8vo, cloth. $5 s$.

STUDIES FROM THE YALE PSYCHOLOGICAL LABORATORY. Edited by Professor E. W. Scripture. With many Illustrations. 8vo, sewed. 4s. 2d. each net. Vol. I. I 892-93, I00 pages. Vol. II. I894, I24 pages. Vol. III. I895, I Io pages. Vol. IV. I896, I4I pages. Vol. V. I897, I05 pages. Vol. VI. I 898 , 105 pages.

WUNDT (WILHELM). OUTLINES OF PSYCHOLOGY. Translated, with the co-operation of the Author, by Charles Hubbard Judd, Ph.D., Instructor in the Wesleyan University. 2nd Enlarged Edition. Demy \&vo, cloth. 8s. net.

I4 Henrietta Street, Covent Garden, London, W.C. 


\section{Oriental Languages, Literature, and History.}

ABHIDHANARATNAMALA (THE) OF HALÂYUDHA. A Sanskrit Vocabulary (I 20 pp.). Edited, with a Sanskrit-English Glossary (180 pp.), by Dr. T. Aufrecht. 8vo, cloth. (Published at I8s.) IOs.

AVESTI, PAHLAVI, and ANCIENT PERSIAN STUDIES in Honour of the late SHAMS-UL-ULAMA DASTUR PESHOTANJI BEHRAMJI SANJANA, M.A., Ph.D. Paper cover, I2s. $6 \pi$. net; cloth, I3s. $6 d$. net.

BERNSTEIN and KIRSCH. SYRIAC CHRESTOMATHY AND LEXICON (Chrestomathia Syriaca cum Lexico). 2 vols. in I. 8vo, cloth boards. $7 s .6 d$. I. Chrestomathia, separately. Sewed. $3 s$.

DAVIDS (T. W. RHYS). LECTURES ON SOME POINTS IN THE HISTORY OF INDIAN BUDDHISM. See The Hibbert Lectures, p. I4.

DELITZSCH (Prof. F.). ASSYRIAN GRAMMAR. With Paradigms, Exercises, Glossary, and Bibliography. Translated by the Rev. Prof. A. R. S. Kennedy. Crown 8vo, cloth. I 5 s.

THE HEBREW LANGUAGE VIEWED IN THE LIGHT OF ASSYRIAN RESEARCH. Demy 8vo, cloth. $4 s$.

- BABEL AND BIBLE. See Crown Theological Library, p. IO.

DIETTRICH (GUSTAV). DIE MASSORAH DER ÖSTLICHEN UND WESTLICHEN SYRER IN IHREN ANGABEN ZUM PROPHETEN JESAIA nach fünf Handschriften des British Museum in Verbindung mit zwei Tractaten über Accente. Sewed. 8s. $6 d$. net.

DÎPAVAMSA (THE): A Buddhist Historical Record in the Pali Language. Edited, with an English Translation, by Dr. H. Oldenberg. 8vo, cloth. 2 Is.

The "Dipavamsa" is the most ancient historical work of the Ceylonese ; it contains an account of the ecclesiastical history of the Buddhist Church, of the conversion of the Ceylonese to the Buddhist faith, and of the ancient history of Ceylon.

I4 Henrietta Street, Covent Garden, London, W.C. 
ERMAN'S EGYPTIAN GRAMMAR. Translated, under Professor Erman's supervision, by J. H. Breasted, Professor of Egyptology in the University of Chicago. Crown 8vo, cloth. I $8 s$.

EVANS (GEORGE). AN ESSAY ON ASSYRIOLOGY. With 4to Tables of Assyrian Inscriptions. 8vo, cloth. $5^{s}$.

FAIZULLAH-BHAI (Shaikh, B.D.). A MOSLEM PRESENT. Part I., containing the famous poem of Al-Busaree. With an English Version and Notes. 8vo, cloth. 4s.

AN ESSAY ON THE PRE-ISLAMITIC ARABIC POETRY, with special reference to the Seven Suspended Poems. 8vo, sewed. 4 $d$.

FLINDERS PETRIE PAPYRI. See Cunningham Memoirs, vols. 8,9 , and II, p. $4 \delta$.

FRANKFURTER (Dr. O.). HANDBOOK OF PALI : Being an Elementary Grammar, a Chrestomathy, and a Glossary. 8 vo, cloth. $16 s$.

FUERST (Dr. JUL.). HEBREW AND CHALDEE LEXICON TO THE OLD TESTAMENT. 5th Edition, improved and enlarged. Translated by Rev. Dr. Samuel Davidson. Royal 8vo, cloth. 2Is.

HARDY (R. SPENCE). MANUAL OF BUDDHISM IN ITS MODERN DEVELOPMENT. Translated from Singhalese MSS. 2nd Edition, with a complete Index and Glossary. 8vo, cloth. 2Is.

HEBREW TEXTS. Large type. I6mo, cloth.

Genesis. (2nd Edition. Baer and Delitzsch's Text.) is. 6 $\%$. Psalms. Is.

Job. Is.

Isaiah. Is.

KENNEDY (Rev. JAS.). INTRODUCTION TO BIBLICAL HEBREW, presenting Graduated Instruction in the Language of the Old Testament. By James Kennedy, B.D., Acting Librarian in the New College, and one of the additional Examiners in Divinity at the University, Edinburgh. 8vo, cloth. I2s.

- STUDIES IN HEBREW SYNONYMS. Demy 8vo, cloth. 5 s.

I4 Henrietta Street, Covent Garden, London, W.C. 
LYALL (C. J., M.A., K.C.I.E.). ANCIENT ARABIAN POETRY, CHIEFLY PRA-ISLAMIC. Translations, with an Introduction and Notes. Fcap. 4to, cloth. ios. $6 d$.

MACHBEROTH ITHIEL. By Yehuda ben Shelomoh Alcharizi. Edited from the MS. in the Bodleian Library, by Thomas Chenery, M.A. 8vo, cloth. 3 s.

MILANDA PANHO, THE: Being Dialogues between King Milanda and the Buddhist Sage Nàgasena. The Pali Text, edited by V. Trenckner. $440 \mathrm{pp}$. 8vo, sewed. 21s. See also "Pali Miscellany."

MOSHEH BEN SHESHETH'S COMMENTARY ON JEREMIAH AND EZEKIEL. See p. 22.

MUSS-ARNOLT (W.). A CONCISE DICTIONARY OF THE ASSYRIAN LANGUAGE (Assyrian-EnglishGerman). By W. Muss-Arnolt. To be completed in about 15 parts. Parts I. to XIX., each 5 s, net.

NEW HEBREW SCHOOL of POETS of the SPANISHARABIAN EPOCH. Selected Texts with Introduction, Notes, and Dictionary. Edited by H. Brody, Ph.D., Rabbi in Nachod (Bohemia), and K. Albrecht, Ph.D., Professor in Oldenburg (Grand Duchy). English translation of the Introduction, etc., by Mrs Karl Albrecht. Cloth. 7s. 6d. net.

NOLDEKE (THEODOR, Professor of Oriental Languages in the University of Strassburg). COMPENDIOUS SYRIAC GRAMMAR. With a Table of Characters by Julius Euting. Translated (with the sanction of the author) from the second and improved German Edition by Rev. James A. Crichton, D.D. Royal 8vo. iss, net.

\section{- DELECTUS VETERUM CARMINUM ARABI-} CORUM GLOSSARIUM CONFECIT A. MULLER. Crown 8vo, cloth. 7s. $6 d$.

NORRIS (E.). ASSYRIAN DICTIONARY. Intended to further the Study of the Cuneiform Inscriptions of Assyria and Babylonia. Vols. I. to III. 4to, cloth. Each $28 s$.

OLDENBERG (Prof. H.). BUDDHA : His Life, his Doctrine, his Order. By Dr. Hermann Oldenberg, Professor at the University of Berlin. Translated by W. Hoey, M.A. 8vo, cloth gilt. $18 s$.

I4 Henrietta Street, Covent Garden, London, W.C. 
PALI MISCELLANY. By V. Trenckner. Part I. The Introductory Part of the Milanda Panho, with an English Translation and Notes. 8vo, sewed. 4 s.

PLATTS (J. T.). A GRAMMAR OF THE PERSIAN LANGUAGE. By John T. Platts, Hon. M.A. (Oxon.), Teacher of Persian in the University of Oxford; late Inspector of Schools in the Central Provinces of India. Part I. Accidence. Broad crown 8vo. IOs. $6 d$.

RENOUF (P. LE PAGE). LECTURES ON THE RELIGION OF ANCIENT EGYPT. See Hibbert Lectures, p. 15 .

SADI. THE GULISTAN (ROSE GARDEN) OF SHAIK SADI OF SHIRAZ. A new Edition of the Persian Text, with a Vocabulary, by F. Johnson. Square royal 8vo, cloth. I 5 .

SAYCE (Prof. A. H.). LECTURES ON THE RELIGIONS OF ANCIENT BABYLONIA AND SYRIA. See the Hibbert Lectures, p. I5.

SCHRADER (E.). THE CUNEIFORM INSCRIPTIONS AND THE OLD TESTAMENT. See Theological Trans. lation Library, Old Series, p. 9.

SHIHĀB AL DIN. FUTŪH AL-HABASHAH; or, The Conquest of Abyssinia. By Shināb al Din Ahmad B. 'Abd al Kädir B. Sālim B. 'Uthman. Edited, from an Arabic MS., by S. Arthur Strong. Part I. 8ro, sewed. 3s. net.

SOCIN (Dr. A.). ARABIC GRAMMAR. Paradigms, Literature, Exercises, and Glossary. 2nd Edition. Translated from the

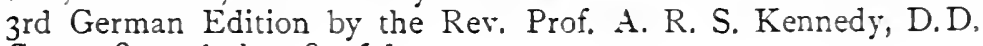
Crown 8vo, cloth. 8s. 6 d.

KEY FOR TRANSLATING THE GERMAN EXERCISES IN ABOVE GRAMMAR. Sewed. Is, $6 d$.

SÖRENSEN (S., Ph.D.), Compiled by. AN INDEX TO THE NAMES IN THE MAHABHARATA. With short explanations. Royal 4to, in twelve parts, which are not sold separately, at 7s. 6d. per part net. Parts I. and II. now ready.

STATUTES, THE, OF THE APOSTLES. The hitherto unedited Ethiopic and Arabic Texts, with translations of Ethiopic, Arabic, and Coptic Texts, by G. Horner, M. A. See p. 26.

I4 Henrietta Street, Covent Garden, London, W.C. 
TEXT AND TRANSLATION SOCIETY. Established for the purpose of editing and translating Oriental Texts chiefly preserved in the British Museum.

\section{Volumes already issued-}

THE SIXTH BOOK OF THE SELECT LETTERS OF SEVERUS, PATRIARCH OF ANTIOCH, in the Syriac Version of Athanasius of Nisibis. Edited and translated by E. W. Brooks, M.A. Vol. I. Text, Parts I. and II. Vol. II. Translation, Parts I. and II. 84s, net.

THE CANONS OF ATHANASIUS OF ALEXANDRIA, in Arabic, Ethiopic, and Coptic. Edited and Translated by Prof. W. Riedel (Griefswald) and W. E. Crum. 2Is, net.

A RABBINIC COMMENTARY ON THE BOOK OF JOB, contained in a unique MS. at Cambridge. Edited, with Translation and Commentary, by W. Aldis Wright, LL. D.

TURPIE (Dr. D. MCC.). MANUAL OF THE CHALDEE LANGUAGE. Containing Grammar of the Biblical Chaldee and of the Targums, and a Chrestomathy, with a Vocabulary. Square 8vo, cloth. $7 s$.

VINAYA PITAKAM : One of the Principal Buddhist Holy Scriptures. Edited in Pali by Dr. H. Oldenberg. 5 vols. 8vo, cloth. Each $2 \mathrm{I} s$.

WALLIS (H. W.). THE COSMOLOGY OF THE RIGVEDA: An Essay. 8vo, cloth. $5^{s}$.

I4 Henrietta Street, Covent Garden, London, W.C. 


\section{Modern Languages \& Literature.}

A complete list of Messrs. Williams \& Norgate's Educational Publi. cations on Modern Languages may be had on application.

ABBOTSFORD SERIES OF THE SCOTTISH POETS. Edited by George Eyre-Todd. I. Early Scottish Poetry; II. Mediæval Scottish Poetry; III. Scottish Poetry of the Sixteenth Century. Price of each vol., $3^{s}$. $6 d$. ; large paper, 5 s. net. IV. Scottish Ballad Poetry. $5 s$.; large paper, half-morocco, Roxburghe, $7 s .6 d$. net. V. Scottish Poetry of the Seventeenth Century. $5 s$. ; large paper, half-morocco, Roxburghe, $7 s .6 d$. net. Vol. VI. Scottish Poetry of the Eighteenth Century. Vol. I. $3^{s .} 6 d$. ; large paper, half-morocco, Roxburghe, 5s. net. Vol. II. cloth, $5 s$.; large paper, half-morocco, $7 s .6 d$. net.

\section{ARMY SERIES OF FRENCH AND GERMAN NOVELS.}

Edited, with short Notes, by J. T. W. Perowne, M.A.

This series is equally well adapted for general reading, and for those preparing for the Army, Oxford and Cambridge Certificates, and other Examinations-in fact, for all who wish to keep up or improve their French and German. The notes are as concise as possible, with an occasional etymology or illustration to assist the memory. The books selected being by recent or living authors, are adapted for the study of most modern French and German.

LE COUP DE PISTOLET, etc. Prosper Merimée. 2s. $6 d$.

"A book more admirably suited to its purpose could not be desired. The Editors deserve to be congratulated." - National Observer.

"The first two volumes are an excellent choice, and we advise any one, whether candidate or lay, to purchase the volume of Merimee." -Journal of Education.

VAILLANTE. Jacques Vincent. $2 s .6 d$.

"The books are well got up, and in Vaillante an excellent choice has been made."-Guardian.

"The notes are few and brief, but all are helpful. The story itself is a delightful one."-Scotsman.

\section{AUF VERLORNEM POSTEN AND NAZZARENA}

DANTI. Johannes v. Dewall. $3 s$.

"The two stories by Johannes v. Dewall are well suited for their purpose; the style and diction are not too difficult for those whose acquaintance with German is not extensive, and ample explanatory annotation is provided."Saturday Review.

"Well printed, well bound, and annotated just sufficiently to make the reading of them sure as well as easy."-Educational Times.

I4 Henrietta Street, Covent Garden, London, W.C. 
ARMY SERIES-Continued.

CONTES MILITAIRES. A. Daudet. $2 s .6 d$.

"These stories are mainly culled from a series called Contes du Lundi, originally contributed by their author to the Figaro. Written at fever heat immediately after the great 1870 war, they show Daudet's power in many ways at its highest. . . We therefore do more than recommend-we urge all readers of French to get the stories in some form, and the present one is both good and cheap. The paper is excellent, and the type clear and bold. . . A neat map of Paris will assist the reader in following the movement of the stories."-The Schoolmaster.

"The choice is an exceptionally good one, and the notes are excellent."Guardian.

\section{ERZÄHLUNGEN. E. Höfer. $3 s$.}

"The series has brought fascinating examples of fiction under the eyes of English readers in a neat and handy form. Besides having the military flavour, they are models of style."-Scotsman.

\section{ATKINSON (ROBERT, M.A., LL.D.). THE PASSIONS} AND HOMILIES FROM LEABHAR BREAC. With an Introductory Lecture on Irish Lexicography. $95^{8} \mathrm{pp}$. Todd Lecture Series, Vol. II. 8vo, sewed. Pages I-34 out of print; pages $35-958,6 s$.

BAYLDON (Rev. G.). ICELANDIC GRAMMAR. An Elementary Grammar of the Old Norse or Icelandic Language. 8vo, cloth. $7 s .6 d$.

BOYELLE (JAS.). FRENCH COMPOSITION THROUGH LORD MACAULAY'S ENGLISH. Edited, with Notes, Hints, and Introduction, by the late James Boïelle, B.A. (Univ. Gall.), Officier d'Académie, Senior French Master, Dulwich College, etc., etc. Crown 8vo, cloth. Vol. I. Frederick the Great. 3s. Vol. II. Warren Hastings. 3s. Vol. III. Lord Clive. $3 s$.

See Victor Hugo, "Les Misérables" and "Notre Dame."

BOOK OF BALLYMOTE (THE). A Collection of Pieces in the Irish Language, dating from the end of the Fourteenth Century. Now published in Photo-Lithography from the Original Manuscript in the Library of the Royal Irish Academy. With Introduction, Analysis of Contents, and Index, by Robert Atkinson, M.A., LL.D., Professor of Sanskrit and Comparative Philology in the University of Dublin; Secretary of Council, Royal Irish Academy.

The Book of Ballymote contains nunierous articles of interest to the scholar and to the antiquary. The original portion consists of-Genealogical Lists Histories and Legends; a fragment of the Brehon Laws; a copy of the Dindsenchas; Treatise on Grammatical Topics, etc. The other portion contains translations from Latin originals: the Destruction of Troy, the Wandering of Ulysses, the Story of the Eneid, and the life of Alexander the Great.

In imperial folio, reproduced by Photo-Lithography. Halfmorocco, Roxburghe, cloth sides. $£ 5,5^{5}$. (200 copies only printed.) 
BOOK OF LEINSTER (THE), sometime called The Book of Glendalough. A Collection of Pieces in the Irish Language, compiled in part about the middle of the Twelfth Century. From the original MS. in Trinity College, Dublin. With Introduction, Analysis of Contents, and Index, by Robert Atkinson, M.A., LL.D., Professor of Sanskrit and Comparative Philology in the University of Dublin; Secretary of Council, Royal Irish Academy. In imperial folio, on toned paper, with a Photograph of a page of the Original. Half-roan, Roxburghe, cloth sides. $£ 6,6$ s. (200 copies only printed.)

DELBOS (L.). NAUTICAL TERMS IN ENGLISH AND FRENCH AND FRENCH AND ENGLISH. With Notes and Tables. For the use of Naval Officers and Naval Cadets. By Leon Delbos, M.A., of H.M.S. Britannia, Dartmouth. 4th Edition, thoroughly revised and considerably enlarged, with additional Plates. Crown 8vo, cloth. 7 s. $6 d$. net.

EUGENE'S STUDENT'S COMPARATIVE GRAMMAR OF THE FRENCH LANGUAGE, with an Historical Sketch of the Formation of French. For the use of Public Schools. With Exercises. By G. Eugène-Fasnacht, late French Master, Westminster School. 23rd Edition, thoroughly revised. Square crown 8vo, cloth, 5s.; or separately, Grammar, 3s.; Exercises, 2s. $6 d$.

GOETHE (W. v.). ANNOTATED TEXTS. See Educational Catalogue.

HOGAN (E.). CATH RUIS NA RIG FOR BOINN. With Preface, Translation, and Indices; also a Treatise on Irish Neuter Substantives, and a Supplement to the Index Vocabulorum of Zeuss's "Grammatica Celtica." Todd Lecture Series, Vol. IV. 8vo, sewed. 3s. 6 .

THE LATIN LIVES OF THE SAINTS AS AIDS TOWARDS THE TRANSLATION OF IRISH TEXTS AND THE PRODUCTION OF AN IRISH DICTIONARY. By Edmund Hogan, S.J., F.R.U.I., M.R.I.A., Royal Irish Academy's Todd Professor of Celtic Languages. Todd Lecture Series, Vol. V. $2 s .6 d$.

THE IRISH NENNIUS FROM L. NA HUIDRE, AND HOMILIES AND LEGENDS FROM L. BREAC. Alphabetical Index of Irish Neuter Substantives. Todd Lecture Series, Vol. VI. $2 s .6 \%$.

HUGO (VICTOR). LES MISÉRABLES: Les Principaux Episodes. Fdited, with Life and Notes, by the late J. Boïelle. 2 vols. 6th Edition. Crown 8vo, cloth. Each $35.6 d$.

I4 Henrietta Street, Covent Garden, London, W.C. 
HUGO (VICTOR). NOTRE DAME DE PARIS. Adapted for the use of Schools and Colleges. By the late J. Boïelle. 2 vols. 2nd Edition. Crown 8vo, cloth. Each $3 s$.

LEABHAR BREAC. The "Speckled Book," otherwise styled, "The Great Book of Dun Doighre" : a Collection of Pieces in Irish and Latin, transcribed towards the close of the Fourteenth Century. "The oldest and best Irish MS. relating to Church History now preserved" (G. Petrie). Now first published, from the original MS. in the Royal Irish Academy's Library. In imperial folio, on toned paper. In one vol., half-calf, $£ 4,4 s$. (200 copies only printed.)

LEABHAR NA H-UIDHRI. A Collection of Pieces in Prose and Verse, in the Irish Language, transcribed about A.D. I Ioo; the oldest volume now known entirely in the Irish language, and one of the chief surviving native literary monuments-not ecclesiastical-of ancient Ireland; now for the first time published, from the original in the Library of the Royal Irish Academy, with account of the Manuscript, description of its contents, index, and facsimiles in colours. In folio, on toned paper, half-calf. $£ 3,3^{5}$. (200 copies only printed.)

LILJA (The Lily). An Icelandic Religious Poem. By Eystein Asgrimson. Edited, with Translation, Notes, and Glossary, by E. Magnusson. Crown 8vo, cloth extra. Ios. $6 d$.

\section{LODGE (Sir O.). SCHOOL TEACHING AND SCHOOL} REFORM. A Course of Four Lectures on School Curricula and Methods, delivered to Secondary Teachers and Teachers in Training at Birmingham during February 1905. 3 .

"The work of a sensible iconoclast, who does not pull down for the sake of mere destruction, but is anxious to set up something more worthy in place of the mediævalism he attacks."-Outlook.

"Let me commend this wise volume not only to teachers but to all concerned in national education. And especially to the politician. Half an hour with Sir Oliver Lodge would make him realise that there are problems on the inner side of the school door not dreamt of in his philosophy-would make him feel that the more he knows of these the better will he be able wisely to handle those others about which he is glibly talking every day."-Dr MACNAMARA in the Daily Chronicle.

\section{MAORI. NEW AND COMPLETE MANUAL OF} MAORI CONVERSATIONS. Containing Phrases and Dialogues on a variety of Topics, together with a few general rules of Grammar, and a comprehensive Vocabulary. 4s. net. See also Williams.

NIBELUNGENLIED. "The Fall of the Nibelungens," otherwise "The Book of Kriemhild." An English Translation by W. N. Lettsom. 4th Edition. 8vo, cloth. $5^{s}$. 
O'GRADY (STANDISH H.). SILVA GADELICA (I.XXXI.). A Collection of Tales in Irish, with Extracts illus. trating Persons and Places. Edited from MSS. and translated. 2 vols. royal 8vo, cloth. 42s. Or separately, Vol. I., Irish Text ; and Vol. II., Translation and Notes. Each vol. 2 Is.

OORDT (J. F. VAN, B.A.). CAPE DUTCH. Phrases and Dialogues, with Translations, preceded by short Grammatical Notes. Crown 8vo, cloth. 2s. $6 d$. net.

PHILLIPPS (V., B.A.). A SHORT SKETCH OF GERMAN LITERATURE, for Schools. By Vivian Phillipps, B.A., Assistant Master at Fettes College, Edinburgh. 2nd Edition, revised. Pott 8vo, cloth. Is.

ROGET (F. F.). AN INTRODUCTION TO OLD FRENCH. History, Grammar, Chrestomathy, and Glossary. 2nd Edition. Crown 8vo, cloth. 6s.

FIRST STEPS IN FRENCH HISTORY, LITERATURE, AND PHILOLOGY. For Candidates for the Scotch Leaving Certificate Examinations, the various Universities Local Examinations, and the Army Examinations. 4th Edition. Crown $8 \mathrm{vo}$, cloth. 5 s.

- See also Voltaire.

ROSING (S.). ENGLISH-DANISH DICTIONARY. New Edition. Large 8vo, strongly bound, half-roan. I Is. 6d.

SCHILLER (F. VON). THE BALLADS AND SHORTER POEMS. Translated into English Verse by Gilbert Clark. Fcap. 8vo, cloth. 5 s.

ANNOTATED TEXTS. See Educational Catalogue.

STOKES (WHITLEY). OLD IRISH GLOSSARIES. Cormac's Glossary. O'Davoran's Glossary. A Glossary to the Calendar of Oingus the Culdee. Edited, with an Introduction and Index. 8vo, cloth. IOS. $6 d$.

- THE CREATION OF THE WORLD. A Mystery in Ancient Cornish. Edited, with Translations and Notes. 8vo, cloth. $6 s$.

ON THE FELIRE OF CENGUS. Vol. I., Part I. Trans. R.I.A.'s Irish MSS. Series. 4to, sewed. $6 s$.

THE LIFE OF ST. MERIASEK. A Cornish Drama. Edited, with Translation and Notes. Royal 8vo. One 8vo fac. simile. Cloth. $5 s$.

I4 Henrietta Street, Covent Garden, London, W.C. 
STOKES (WHITLEY). BRETON GLOSSES AT ORLEANS. Edited by W. Stokes. 8vo, sewed. Is.

OLD IRISH GLOSSES AT WUERZBURG AND CARLSRUHE. Edited by W. Stokes. 8vo, sewed. 3s. $6 d$.

SULLIVAN (W. K.). CELTIC STUDIES FROM THE GERMAN OF EBEL. With an Introduction on the Roots, Stems, and Derivatives, and on Case-endings of Nouns in the Indo-European Languages. 8vo, cloth. IOs.

TODD LECTURE SERIES (Royal Irish Academy)-

Vol. I. Part I. Mesca Ulad; or, The Intoxications of the Ultonians. Irish Text, with Translation and Notes, by W. M. Hennesy. 8vo, sewed. Is. $6 d$.

Vol. II. Leabhar Breac, Passions and Homilies from. Irish Text, Translation, and Glossary, with Lecture on Irish Lexicography, by Dr. R. Atkinson. 8vo, cloth. Part I, pages I-34, out of print. Part 2, pages 35-958, 6s.

Vol. III. The Codex Palatino-Vaticanus. No. 830. Texts, Translations, and Indices, by B. MacCarthy, D.D. 8vo, sewed. 2s. $6 d$.

Vol. IV. Cath Ruis na Rig for Boinn. With Preface, Translation, Indices, a Treatise on Irish Neuter Substantives, and a Supplement to the Index Vocabulorum of Zeuss's "Grammatica Celtica." By E. Hogan. 8vo, sewed. 3s. $6 d$.

Vol. V. The Latin Lives of the Saints as aids towards the Translation of Irish Texts and the Production of an Irish Dictionary. By Edmund Hogan, S.J., F.R.U.I., M.R.I.A., Royal Irish Academy's Todd Professor of the Celtic Languages. 2s. $6 d$.

Vol. VI. The Irish Nennius from L. Na Huidre, and Homilies and Legends from L. Breac. Alphabetical Index of Irish Neuter Substantives. By Edmund Hogan, S.J., F.R. U.I., M.R.I.A., Royal Irish Academy's Todd Professor of the Celtic Languages. 2s. $6 d$.

VELASQUEZ. LARGER SPANISH DICTIONARY. Composed from the Dictionaries of the Spanish Academy, Terreros and Salva. Spanish-English and English-Spanish. 1279 pp., triple columns. 2 vols. in I. Imp. 8vo, cloth. $24 s$.

VIGA GLUMS SAGA. Transiated from the Icelandic, with Notes and an Introduction, by Sir Edmund Head, Bart. Fcap. 8vo, cloth. $5^{s}$.

WEISSE ( $T$. H.). SYSTEMATIC CONVERSATIONAL EXERCISES FOR TRANSLATING INTO GERMAN, adapted to his Grammar. New Edition. Crown 8vo, cloth. (Key, 5s. net.) 3s. 6d.

I4 Henrietta Street, Covent Garden, London, W.C. 
WEISSE (T. H.). A SHORT GUIDE TO GERMAN IDIOMS : being a Collection of the Idioms most in use. With Examination Papers. 3 rd Edition. Cloth. $2 s$.

WERNER'S ELEMENTARY LESSONS IN CAPE DUTCH (AFRIKANDER TAAL). By A. Werner and G. Hunt. I6mo, cloth. Is. $6 d$.

"We most cordially recommend this book to anyone going out to settle in South Africa. ... The dialogues and exercises are admirably planned."Reformer.

"To those outward bound such a book is sure to be useful."-Practical Teacher.

WILLIAMS (The Right Rev. W. L., D.C.L.). A DICTIONARY OF THE NEW ZEALAND LANGUAGE. 4th Edition. Edited by the Right Rev. Bishop W. L. Williams, with numerous additions and corrections. Demy 8 vo, cloth. I $2 s .6 d$.

LESSONS IN MAORI. 3rd Edition. Fcap. 8vo, cloth. $3^{s .}$

YELLOW BOOK OF LECAN. A Collection of Pieces (Prose and Yerse) in the Irish Language, in part compiled at the end of the Fourteenth Century; now for the first time published from the original Manuscript in the Library of Trinity College, Dublin, by the Royal Irish Academy. With Introduction, Analysis of Contents, and Index, by Robert Atkinson. 30 and $468 \mathrm{pp}$. (Royal Irish Academy's Irish facsimiles.) Large post folio, 18g6, halfroan, Roxburghe, cloth sides. $£ 4,4 s$.

ZOEGA (G. T.). ENGLISH-ICELANDIC DICTIONARY. 8vo, cloth. 6s. net.

ZOMPOLIDES (Dr. D.). A COURSE OF MODERN GREEK; or, The Greek Language of the Present Day. I. The Elementary Method. Crown 8vo, cloth. $5^{s}$.

14 Henrietta Street, Covent Garden, London, W.C. 


\section{Science.}

\section{MEDICINE-CHEMISTRY-BOTANY-ZOOLOGY- MATHEMATICS.}

ABRAHAM (P. S.). LEPROSY : A Review of some Facts and Figures. 8vo. Is.

ANNETT (H. E., M.D., D.P.H.), J. EVERETT DUTTON, M.B., B.Ch., and J. H. ELLIOTT, M.D., Toronto. REPORT OF THE MALARIA EXPEDITION TO NIGERIA (I900). Part I. Malarial Fever, etc. (Liverpool School of Tropical Medicine, Memoir III.). Ios. 6d. Part II. Filariasis (Liverpool School of Tropical Medicine, Memoir IV.). Out of print separately, but is contained in the Thompson-Yates Laboratory Reports, Vol. IV., Part I. Price $20 s$.

BASTIAN (H. CHARLTON, M.A., M.D., F.R.S.). STUDIES IN HETEROGENESIS. With 825 Illustrations from Photomicrographs. Royal 8vo, cloth. 3is. 6d.

BENTHAM and HOOKER. GENERA PLANTARUM AD EXEMPLARIA IMPRIMIS IN HERBARIIS KEWENSIBUS SERVATA DEFINITA. Auctoribus G. Bentham et J. D. Hooker. 3 vols., $€ 8$, $2 s$. Vol. I. (not sold separately). Vol. II., 56s. Vol. III. (Parts I and 2), 56s.; or separately, Part I, 24s.; Part 2, $32 s$.

BERGMANN (Prof. E. von, M.D.). A SYSTEM OF PRACTICAL SURGERY. Edited by William T. Bull, M.D. In five imperial 8 vo volumes, containing 4174 pages, with 1976 illustrations in the text, and I02 superb full-page plates in colours and monochrome. Extra cloth, $£ 6,6 s$. ; half-leather, marble sides and edges, $£ 7,7 s$.; half-morocco, $£ 8,8 s$.

"We regard it as a valuable exposition of modern surgery. The main characteristics of the system are the fulness with which the subjects are treated and the wealth of illustrations. Many of these are in colours, and are very successful examples of colour-printing. The vast majority of the articles are very good, but we desire especially to praise those on Injuries of the Head and Diseases of the Breast."-Lancet.

\section{BERZELIUS (JÖNS JAKOB) and SCHCENBEIN} (CHRISTIAN FREDERICK). LETTERS, I836-I847. Edited by George W. A. Kahlbaum. Translated by Francis V. Darbishire and N. V. Sidgwick. Crown 8vo, cloth. $3 s$.

BOGHURST (W.). LOIMOGRAPHIA. An Account of the Great Plague of London in the year 1665. By William Boghurst, Apothecary. Now first printed from the B.M. Sloane MS. 349, and edited by Joseph Frank Payne, M.D. 8vo, cloth. 5s, net.

I4 Henrietta Street, Covent Garden, London, W.C. 
BOYCE (RUPERT, M.B., F.R.S.). THE ANTI-MALARIA MEASURES A'T ISMAILIA. (Liverpool School of Tropical Medicine, Memoir XII.) Price Is.

BRUCE (ALEX., M.A., M.D., F.R.C.P.E., F.R.S.E.) A TOPOGRAPHICAL' ATLA'S OF THE SPINAL CORD. Fcap. folio, half-leather. $£ 2$, 2s. net.

BRUHNS. A NEW MANUAL OF LOGARITHMS TO SEVEN PLACES OF DECIMALS. Royal 8vo. Stereo. typed. Cloth. 5s. $6 d$.

CATON (R., M.D., F.R.C.P., J.P.). HOW TO LIVE. A Simple Manual of Hygiene for the Older Pupils in Primary Schools. $3^{d}$.

CAVERHILL (T. F. S., M.B., F.R.C.P.Ed., Surgeon-Major, The Lothians and Berwickshire Yeomanry Cavalry). SELF-AID IN WAR. With Practical Hints for Cavalry Wounded. With Illustrations and Diagrams, Small 8vo. Is. net.

CHAPMAN (E. J., Ph.D.). MINERAL SYSTEMS. With Outline of an attempted Classification of Minerals in Natural Groups. Crown 8vo, cloth. 2s. 6d.

CHURCH (A. H.). ON THE RELATION OF PHYLLOTAXIS TO MECHANICAL LAWS. Part I. Construction by Orthogonal Trajectories, illustrated with 35 Figures. Large 8vo. 3s. 6d. Part II. Assymmetry and Symmetry, with 60 Illustrations. Large 8vo. 5s. Part III. Secondary Growth Phenomena, with 34 Illustrations. 5s. Parts I., II., and III., bound, cloth, I 5 s.

CLELAND, MACKAY, YOUNG (Professors). MEMOIRS AND MEMORANDA OF ANATOMY. Vol. I. I6 Plates. 8vo, cloth. 7s. $6 d$.

COOKE (M. C.). MYCOGRAPHIA SEU ICONES FUNGORUM. Figures of Fungi from all parts of the World. Vol. I. (in 6 Parts, each I2s, 6d.). 406 coloured Plates. Royal 8vo, cloth. 8os.

ILLUSTRATIONS OF BRITISH FUNGI (HYMENOMYCETES). In 8 vols. I ig8 coloured Plates. Royal 8vo, cloth gilt. $£ 30,5$ s. 6 d.

BRITISH DESMIDS. A Supplement to "British Freshwater Algæ." 66 coloured Plates. 8vo, cloth. 52s. $6 d$.

14 Henrietta Street, Covent Garden, London, W.C. 4 
COOKE (M.C.). HANDBOOK OF AUSTRALIAN FUNGI. With 36 Plates. 8vo, cloth. £2.

- See also "Grevillea."

\section{CUNNINGHAM MEMOIRS-}

I. Cubic Transformations. By John Casey, LL.D. 4to, sewed. $2 s, 6 d$.

2. On the Lumbar Curve in Man and the Apes. By D. J. Cunningham, M.D. I3 Plates. 4to, sewed. 5 s.

3. New Researches on Sun-heat, Terrestrial Radiation, etc. By Rev. Samuel Haughton, M.A., M.D. 9 Plates. 4to, sewed. Is. $6 d$.

4. Dynamics and Modern Geometry. A New Chapter in the Theory of Screws. By Sir Robert S. Ball, LL.D. 4to, sewed. $2 s$.

5. The Red Stars. Observations and Catalogue. New Edition. Edited by Rev. T. Espin, M.A. 4to, sewed. 3s. $6 d$.

6. On the Morphology of the Duck Tribe and the Auk Tribe. By W. K. Parker, F.R.S. 9 Plates. 4to, sewed. 3s. $6 d$.

7. Contribution to the Surface Anatomy of the Cerebral Hemispheres. By D. J. Cunningham, M.D. With a Chapter upon Cranio-Cerebral Topography by Victor Horsley, M.B., F.R.S. 4to, sewed. 8s. $6 \mathrm{~d}$.

9. On the Flinders Petrie Papyri. Part II. With I 8 Autotypes. 4to, sewed. 42s. net. Appendix to 8 and 9. 5s. net.

10. The Decorative Art of British New Guinea. A Study in Papuan Ethnography. By Alfred C. Haddon, M.A. With I2 Plates, and numerous other Illustrations. 4to, sewed. I4s. net.

II. On the Flinders Petrie Papyri. With Transcriptions, Commentaries, and Index. By John P. Mahaffy, D.D., and Prof. J. Gilbert Smyly. With 7 Autotypes. 4to, sewed. 42s. net.

DITTMAR (Prof. W.). CHEMICAL ARITHMETIC. Part I. A Collection of Tables, Mathematical, Chemical, and Physical, for the use of Chemists, etc. 8vo, cloth. 6s. net.

- EXERCISES IN QUANTITATIVE CHEMICAL ANALYSIS, with a short Treatise on Gas Analysis. 8vo, cloth. IOs. $6 d$.

DURHAM (H. E., M.A., M.B., F.R.C.S.), and the late WALTER MYERS, M.B. REPORT OF THE YELLOW FEVER EXPEDITION TO PARA (I900). (Liverpool School of Tropical Medicine, Memoir VII.) 4to, $7 s .6 d$.

DUTTON (J. E., M.B., Ch.B.). REPORT OF THE MALARIA EXPEDITION TO THE GAMBIA. (Liverpool School of Tropical Medicine, Memoir X.) 4to. Ios. $6 d$. net.

I4 Henrietta Street, Covent Garden, London, W.C. 
DUTTON (J. E., M.B., Ch.B.), and JOHN L. TODD, B.A., M.D., C.M., M'Gill. FIRST REPORT OF THE TRYPANOSOMIASIS EXPEDITION TO SENEGAMBIA (1902). (Liverpool School of Tropical Medicine, Memoir XI.) 4to. Ios. 6d. net.

FARADAY and SCHCENBEIN, LETTERS OF, 1836-1862. With Notes, Comments, and References to Contemporary Letters. Edited by George W. A. Kahlbaum and Francis V. Darbishire, with Portraits of Faraday and Schœnbein in Photogravure. Demy 8vo, cloth. 13s. net.

FASCICULI MALAXENSES. Anthropological and Zoological results of an Expedition to Perak and the Siamese Malay States, 1901-I902, undertaken by Nelson Anrandale and Herbert C. Robinson. 4to. Now ready. Anthropology, Part I., I5s. Part IIA. Ios. net. Zoology, Vol. I., Parts I., II., III., and Appendix. 52s. Supplement (Itinerary), $5 s$.

GREVILLEA : A Record of Cryptogamic Botany and its Literature. Edited by M. C. Cooke. Parts. 8vo. Each is. 6d. Plates. Vols. I.-XVIII. In 9 vols. Cloth (each I4s.). £6, 6s.

HARNACK (AXEL). INTRODUCTION TO THE ELE. MENTS OF THE DIFFERENTIAL AND INTEGRAL CALCULUS. From the German. Royal 8vo, cloth, IOs. $6 d$. HERBERT (AUBERON) and HAROLD WAGER. BAD AIR AND BAD HEALTH. Crown 8vo, sewed, Is.; cloth, Is. $6 d$.

HOFF (J. H. VAN'T). STUDIES IN CHEMICAL DYNAMICS. Revised and enlarged by Dr. Ernst Cohen, Assistant in the Chenical Laboratory of the University of Amsterdam. Translated by Thomas Ewan, M.Sc., Ph.D., Demonstrator of Chemistry in the Yorkshire College, Leeds. Royal 8vo, cloth. IOS. $6 d$.

JAEGER (GUSTAV, M.D.). PROBLEMS OF NATURE. Selected, edited, and translated by H. G. Schlichter, D.Sc., with a Facsimile of a Letter from Charles Darwin to the Author. Demy 8 vo, cloth. $4 s$.

JOHNSTONE (J.). BRITISH FISHERIES: Their Administration and their Problems. A short account of the Origin and Growth of British Sea Fishery Authorities and Regulations. Ios. $6 d$. net.

JOURNAL OF THE FEDERATED MALAY STATES MUSEUMS. Issued Quarterly. Single numbers, is. $6 d$. net. Subscription, 5s. per annum.

JOURNAL OF THE LINNEAN SOCIETY. Botany. At various prices. Index to Journal (Botany), 20s. Zoology. At various prices. General Index to the first 20 vols. of the Journal (Zoology) and the Zoological portion of the Proceedings, 20 s.

I4 Henrietta Street, Covent Garden, London, W.C. 
JOURNAL OF THE ROYAL MICROSCOPICAL SOCIETY, containing its transactions and Proceedings, with other Microscopical information. Bi-monthly. Previous to 1893 at various prices; after that date bi-monthly, each $6 s$. net.

JOURNAL OF THE QUEKETT MICROSCOPICAL CLUB. Nos. I-26, Is, net; Nos. 27-3I, 2s. 6d. net. I893, No. 32, and following Nos., half-yearly, $3 s .6 d$. net.

\section{LIVERPOOL MARINE BIOLOGY COMMITTEE.} MEMOIRS ON TYPICAL BRITISH MARINE PLANTS AND ANIMALS. Edited by W. A. Herdman, D.Sc., F.R.S. All demy 8 vo, stiff boards.

I. Ascidia. By W. A. Herdman. With 5 Plates. Price 2s, net.

2. Cardium. By J. Johnstone, Fisheries Assistant, University College, Liverpool. With 7 Plates. Price 2s. $6 d$. net.

3. Echinus. By Herbert Clifton Chadwick, Curator of the Port Erin Biological Station. With 5 Plates. Price 2s. net.

4. Codium. By R. J. Harvey Gibson, M.A., F.L.S., Professor of Botany in University College, Liverpool, and Helen P. Auld, B.Sc., With 3 Plates. Price Is. $6 d$. net.

5. Alcyonium. By Sydney J. Hickson, M.A., D.Sc., F.R.S., Beyer Professor of Zoology in Owens College, Manchester. With 3 Plates. Price Is. $5 d$. net.

6. Lepeophtheirus and Lernea. By Andrew Scott, Resident Fisheries Assistant at the Peel Hatchery. With 5 Plates. 2s, net. 7. Lineus. By R. C. Punnett, B.A., with 4 Plates. 2s. net.

8. Pleuronectes. By Frank J. Cole, Jesus College, Oxford, Lecturer in the Victoria University, Demonstrator of Zoology, University, Liverpool, and James Johnstone, B.Sc. Lond., Fisheries Assistant, University, Liverpool. With I I Plates. 7s. net.

9. Chondrus. By Otto V. Darbishire, Owens College, Manchester. With 7 Plates. 2s. 6 d. net.

Io. Patella (the Common Limpet). By J. R. Ainsworth Davis, M.A., Professor of Zoology in the University College of Wales, Aberystwyth, and H. J. Fleure, B.Sc., Fellow of the University of Wales. With 4 Plates. 2s. $6 d$. net.

II. Arenicola (the Lug-Worm). By J. H. Ashworth, D.Sc., Lecturer in Invertebrate Zoology in the University of Edinburgh. With 8 Plates. Price $4 s$. $6 d$. net.

12. Gammarus. By Margaret Cussans, B.Sc., Zoological Department, University of Liverpool. With 4 Plates. 2s. net.

\section{LIVERPOOL MARINE BIOLOGY COMMITTEE.} FIFTH REPORT UPON THE FAUNA OF LIVERPOOL BAY AND THE NEIGHBOURING SEAS.

Written by the Members of the Liverpool Marine Biology Committee and other Naturalists ; and edited by W. A. Herdman, D.Sc., F.R.S., Professor of Natural History, the University, Liverpool. Demy 8vo, cloth. 12 Plates. $8 s .6 d$. net. 
MEMOIRS OF THE LIVERPOOL SCHOOL OF TROPICAL MEDICINE.

I. Ross (R.) Malarial Fever: Its Cause, Prevention, and Treatment. 8vo. 2s. $6 d$.

II. Ross (R.), H. E. Annett, and E. E. Austen. Report of the Malaria Expedition to Sierra Leone (1899). 4to. 2 Is.

III. Annett (H. E.), J. E. Dutton, and J. H. Elliott. Report of the Malaria Expedition to Nigeria (1900). I. Malarial Fever. 4to. Ios. $6 d$.

IV. Annett (H. E.), J. E. Dutton, and J. H. Elliott. Report of the Malaria Expedition to Nigeria (1900). II. Filariasis. 4to. [This is out of print separately, but is also con. tained in the Report of the Thompson-Yates Laboratories, Vol. IV. Part I. Price 20s.]

V. Ross (R.) and M. L. Taylor. Progress Reports of the Campaign against Mosquitoes in Sierra Leone. Part I. I90I. With a Letter from Dr. Daniels regarding the results arrived at to date. 8vo. Is. Part II. 1902. 8vo. Is.

VI. [Not issued yet.]

VII. Durham (H. E.) and W. Myers. Report of the Yellow Fever Expedition to Para (I900). 4to. 7s. $6 d$.

VIII. Taylor (M. L.). Report on the Sanitary Conditions of Cape Coast Town. Svo. Is.

IX. Ross (R.). Report on Malaria at Ismailia and Suez. 8vo. Is.

X. Dutton (J. E.). Report of the Malaria Expedition to the Gambia. 4to. Ios. $6 d$. net.

XI. Dutton (J. E.) and J. L. Todd. First Report of the Trypanosomiasis Expedition to Senegambia (I902). 4to. IOs. $6 d$. net. [Also contained in Thompson-Yates Laboratories Reports, V. 2.]

XII. Boyce(R.). The Anti-Malaria Measures at Ismailia. 8vo. Is.

XIII. Dutton (J. E) and J. L. Todd. Reports of the Trypanosomiasis Expedition to the Congo (I903-I904). With a Comparison of the 'Trypanosomes of Uganda and the Congo Free State by H. W. Thomas, M.D. M'Gill, and Stanley F. Linton, B.Sc., M.B. Liverpool ; and a Note on Tsetse Flies by E. E. Austen, Zoological Department, British Museum. Paper covers. I 5 s.

LOCKWOOD (Prof. C. B.). HUNTERIAN LECTURES ON THE DEVELOPMENT AND TRANSITION OF THE TESTIS, NORMAL AND ABNORMAL. Three 4to Plates. 8vo, cloth. 5s.

I4 Henrietta Street, Covent Garden, London, W.C. 
MIERS (J.). ON THE APOCYNACEE OF SOUTH AMERICA. With some preliminary Remarks on the whole family. 35 Plates. 4to, cloth. 30 s.

MOORE (T.). INDEX FILICUM: A Synopsis of the Genera of Ferns. 20 Parts. 84 Plates. I2mo, sewed. 20 s.

MURRAY (ANDREW). LIST OF COLEOPTERA FROM OLD CALABAR, ON THE WEST COAST OF AFRICA, RECEIVED AND DESCRIBED. 8vo, sewed. 8s.

NOTES ON SANITARY CONDITIONS OBTAINING IN PARA. By the Members of the Yellow Fever Expedition. (Published by the Liverpool School of Tropical Medicine.) Is.

PALLIN (Capt. W. A., F.R.C.V.S.). A TREATISE ON EPIZOOTIC LYMPHANGITIS. Second Edition. Demy 8 vo, cloth. $3 s .6 d$. net. ; $3 s .9 d$. post free. Nearly 100 pages, I 7 full-page Plates.

PATERSON (ANDREW MELVILLE, M.D., Derby Professor of Anatomy in the University of Liverpool, Hunterian Professor at the Royal College of Surgeons of England). THE HUMAN STERNUM. Three Lectures delivered at the Royal College of Surgeons, England, November 1903. With Io Plates. Crown 4to. IOs. net.

PIDDINGTON (HENRY). THE SAILORS' HORN-BOOK FOR THE LAW OF STORMS. Being a Practical Exposition of the Theory of the Law of Storms, and its uses to Mariners of all Classes in all Parts of the World. Shown by transparent Storm Cards and useful Lessons. 7th Edition. Demy 8vo, cloth. IOs. $6 d$.

PRAY (Dr.). ASTIGMATIC LETTERS. Printed on Millboard, size 22 by 14 inches. Is.

PRIOR. ON THE POPULAR NAMES OF BRITISH PLANTS. Being an Explanation of the Origin and Meaning of the names of our indigenous and most communly cultivated species. 3rd Edition. Post 8vo. 7s. 6d.

RANSOM (W. H., M.D., F.R.S., F.R.C.P.). THE INFLAMMATION IDEA IN GENERAL PATHOLOGY. Demy Svo, clotin. $7 s .6 d$.

RAY (PRAPHULLA CHANDRA, D.Sc., Professor of Chemistry, Presidency College, Calcutta). A HISTORY OF HINDU CHEMISTRY FROM THE EARLIEST TIMES TO THE MIDDLE OF THE SIXTEENTH CENTURY, A.D. With Sanscrit Texts, Variants, Translation, and Illustrations. Vol. I. Royal 8vo, cloth. 12s. $6 d$. net. Out of print. Vol. II. in preparation.

I4 Henrietta Street, Covent Garden, London, W.C. 
REPORTS OF THE THOMPSON-YATES AND JOHNSTON LABORATORIES. Demy 4to, with Illustrations. Vol. I. I898-9. IOs. 6d. Vol. II. I 898-9. 25s. Vol. III. Part I. I900. 7s. 6d. Vol. III. Part 2. I90I. I2s. 6d. Vol. IV. Part I. I901. 20s. Vol. IV. Part 2. I902. 21s. New Series. Vol. V. Part I. I903. Limp, 20s.; cloth, 21 s. Vol. V. Part 2. I903. Limp, I2s. 6d. ; cloth, I3s. 6d. Vol. VI. Part I. 1905. Limp, I2s. 6d. ; cloth, I3s. $6 d$.

ROSS (RONALD, C.B., F.R.S., etc., Major I.M.S. (retired)). MALARIAL FEVER: Its Cause, Prevention, and Treatment. (Liverpool Schuol of Tropical Medicine, Memoir I.) Svo, cloth. 2s. $6 d$.

H. E. ANNETT, M.D., D.P.H., and E. E. AUSTEN. REPORT OF THE MALARIA EXPEDITION TO SIERRA LEONE (1899). (Liverpool School of Tropical Medicine, Memoir II.) 4to. 2 Is.

FIRST PROGRESS REPORT OF THE CAMPAIGN AGAINST MOSQUITOES IN SIERRA LEONE (I9OI). With a Letter from Dr. Daniels regarding the results arrived at to date. (Liverpool School of Tropical Medicine, Memoir V. I.) Is.

SECOND PROGRESS REPORT OF THE CAMPAIGN AGAINST MOSQUITOES IN SIERRA LEONE (1902). By M. Logan Taylor, M.B. (Liverpool School of Tropical Medicine, Memoir V. 2.) is.

REPORT ON MALARIA AT ISMAILIA AND SUEZ. (Liverpool School of Tropical Medicine, Memoir IX.) I $s$.

SANDERS (A., M.R.C.S., F.L.S.). RESEARCHES IN THE NERVOUS SYSTEM OF MYXINE GLUTINOSA. 4to, sewed. 8 Plates. Ios. $6 d$.

SANG'S LOGARITHMS. A new Table of Seven-place Loga. rithms of all Numbers continuously up to 200,000. 2nd Edition. Royal 8vo, cloth. 2Is.

SCHCENBEIN. CORRESPONDENCE WITH FARADAY. See Faraday.

CORRESPONDENCE WITH BERZELIUS. See Berzelius.

I4 Henrietta Street, Covent Garden, London, W.C. 
SCHREBER (D. G. M.). MEDICAL INDOOR GYMNASTICS, or a System of Hygienic Exercises for Home Use, to be practised anywhere, without apparatus or assistance, by young and old of either sex, for the preservation of health and general activity. Revised and Supplemented by Rudolf Graefe, M.D. With a large plate and 45 illustrations in the text. Royal 8vo, cloth. 3s. net.

"The exercises described, when efficiently used, will undoubtedly be of value in strengthening and developing the muscular system. The descriptions of the exercises and the figures in the text are excellent."-Physician and Surgeon.

"Well worthy of the attention of those who go in for regular physical train. ing as a means for the preservation of health." - Scotsman.

"A very sensible little treatise."-Glasgow Herald.

SCHROEN (L.). SEVEN-FIGURE LOGARITHMS OF NUMBERS from I to 108,000, and of Sines, Cosines, Tangents, Cotangents to every ro Seconds of the Quadrant. With a Table of Proportional Parts. By Dr. Ludwig Schroen, Director of the Observatory of Gena, etc., etc. $5^{\text {th }}$ Edition, corrected and stereotyped. With a description of the Tables by A. De Morgan, Professor of Mathematics in University College, London. Imp. 8vo, cloth, printed on light green paper. 9 s.

SNELLEN'S OPHTHALMIC TEST TYPES. Best Types for the Determination of the Acuteness of Vision. I $4^{\text {th }}$ Edition, considerably augmented and improved. 8vo, sewed. 4s. Single Sheets : ET B, M O V, B D E, 山山山, and Large Clock Sheet. 8d. each. Small Clock Sheet and R T V Z. 4d. each.

ASTIGMATIC TEST CHART. Long folio, varnished, mounted on rollers. $2 s$. net.

SONNTAG (C. O.). A POCKET FLORA OF EDINBURGH AND THE SURROUNDING DISTRICT. A Collection and full Description of all Phanerogamic and the principal Cryptogamic Plants, classified after the Natural System, with an artificial Key and a Glossary of Botanical Terms. By the late C. O. Sonntag, the Royal High School, Edinburgh ; formerly' Secretary of the Microscopical Society of Glasgow, etc. Fcap. 8vo, limp cloth, round corners, with Map of the Environs of Edinburgh. 3 s. $6 d$. net.

SPENCER (W. G.). INVENTIONAL GEOMETRY. With a Preface by Herbert Spencer. 8vo, cloth. Is.

A SYSTEM OF LUCID SHORTHAND. With a Prefatory Note by Herbert Spencer. Cloth. Is.

14 Henrietta Street, Covent Garden, London, W.C. 
STEPHENS (J. W. W., M.D. Cantab., D.P.H.) and S. R. CHRISTOPHERS, M.B. Vict., I.M.S. PRACTICAL STUDY OF MALARIA AND OTHER BLOOD PARA. SITES. (Published for the Liverpool School of Tropical Medicine). 8vo, cloth. 2nd Edition. 12s. $6 d$. net.

TAYLOR (M. LOGAN, M.B., Ch.B.). REPORT ON THE SANITARY CONDITIONS OF CAPE COAST TOWN. (Liverpool School of Tropical Medicine, Memoir VIII.) 8vo. Is.

REPORT OF THE CAMPAIGN AGAINST THE MOSQUITOES IN SIERRA LEONE. See Ross and Taylor.

TRANSACTIONS OF THE EPIDEMIOLOGICAL SOCIETY OF LONDON. New Series. Vol. XXIII. Session 1903-1904. Demy 8vo, cloth. 6s. net. The earlier volumes of the New Series, I.-XXII., are still obtainable. Price 6s. net each. Commemoration Volume, containing an account of the Founda. tion of the Society and of the Commemoration Dinner, together with an Index of the papers read at its meetings between 1855 and 1900. 8vo, cloth. 5s. net.

TRANSACTIONS OF THE ROYAL SOCIETY OF EDINBURGH. Vol. XXXVIII. Part I, 40s. Part 2, 25s. Part 3, 30s. Part 4, 7s. 6d. Vol. XXXIX. Part I, 30s. Part 2, I 9s. Part 3, 43s. Part 4, 9s. Vol. XL. Part I, 25s. General Index to First Thirty-four Volumes (1783-1888), with History of the Institution. 4to, cloth. 2 Is.

TRANSACTIONS OF THE ROYAL IRISH ACADEMY, DUBLIN. Vols. I. -XX. 4to. £22, 5s, 6d. Vols. XXI.XXXI. Various prices.

TRANSACTIONS OF THE ROYAL DUBLIN SOCIETY. Various volumes at various prices.

VEGA. LOGARITHMIC TABLES OF NUMBERS AND TRIGONOMETRICAL FUNCTIONS. Translated from the 4oth, or Dr. Bremiker's Edition, thoroughly revised and en. larged, by W. L. F. Fischer, M.A., F.R.S., Fellow of Clare College, Cambridge,; Professor of Naturai Philosophy in the University of St. Andrews. 75th Stereotyped Edition. Koyal 8vo, cloth. 75 .

I4 Henrietta Street, Covent Garden, London, W.C. 


\section{Miscellaneous.}

\section{ANTHROPOLOGY-SOCIOLOGY-MYTHOLOGY- BIBLIOGRAPHY-BIOGRAPHY, ETC.}

AVEBURY (Lord, D.C.L., F.R.S., etc.) (Sir John Lubbock). PREHISTORIC TIMES, as Illustrated by Ancient Remains and the Manners and Customs of Modern Savages. 6th Edition, revised, with 239 Illustrations, a large number of which are specially prepared for this Edition. Demy 8vo, cloth, gilt tops. I8s.

"To anyone who wishes to obtain a succinct conspectus of the present state of knowledge on the subject of early man, we recommend the perusal of this comprehensive volume."-Jour. Brit. Archaolog. Assoc.

"The fact that this well-known standard work has reached a sixth edition is evidence of its value to ethnologists and archæologists. The many and beautiful illustrations are most helpful in better understanding the plain but accurate letterpress. Lord Avebury is to be congratulated on the new edition, which is sure to further popularise a fascinating subject for investigation by cultured people."-Science Gossip.

"It is necessary to compare the present volume with the fifth edition in order to see how much it has been improved. The illustrations to this sixth edition are immeasurably superior to the fifth."-Knowledge.

BIBLIOGRAPHICAL REGISTER. Published Quarterly. $6 d$. net ; $2 s .2 d$. per annum post free.

BLACKBURN (HELEN). WOMEN'S SUFFRAGE. A Record of the Women's Suffrage Movement in the British Isles, with a Biographical Sketch of Miss Becker. Portraits. Crown 8vo, cloth. 6s.

- See also Vynne, Nora, and Blackburn, "Women under the Factory Acts."

BROWN (ROBERT, JUn., F.S.A.). SEMITIC INFLUENCE IN HELLENIC MYTHOLOGY. With special reference to the recent mythological works of the Right Hon. Prof. Max Müller and Mr. Andrew Lang. Demy 8vo, cloth. 7 s. $6 d$.

RESEARCHES INTO THE ORIGIN OF THE PRIMITIVE CONSTELLATIONS OF THE GREEKS, PHCENICIANS, AND BABYLONIANS. With a large map of the Northern Hemisphere as viewed at Phœnicia I 200 B.c., and other maps. 2 vols. demy 8vo, cloth. ros. $6 d$. each.

MR. GLADSTONE AS I KNEW HIM, and other Essays. Demy 8vo, cloth. $7 s .6 d$.

I4 Henrietta Street, Covent Garden, London, W.C. 
CATALOGUE OF THE LONDON LIBRARY, St James's Square. By C. T. Hagberg Wright, LL.D., etc. xiv + I626 pp. 4 to, cloth. 42s, net. Supplement I., 1902-3. Buckram, I vol., 196 pp. 5s. net. Supplement II. I98 pp. I903-4. Buckram. 5s. net.

"The present catalogue is essentially a working catalogue. ... The general level of accuracy in the printing and editing of the work appears to us to be an unusually high one. ... We heartily applaud the work, both as a landmark in library land, and as a inonument standing upon a firm foundation of its own." -The Tines.

CURTIN (JEREMIAH). CREATION MYTHS OF PRIMITIVE AMERICA IN RELATION TO THE RELIGIOUS HISTORY AND MENTAL DEVELOP. MENT OF MANKIND. Contains twenty long myths taken down word for word by Mr. Curtin from Indians who knew no religion or language but their own, and many of whom had not seen a white man until they had attained years of maturity. With an elaborate Introduction and Notes. Demy $8 \mathrm{vo}$, cloth. IOs. $6 \%$. net.

ENGELHARDT (C.). DENMARK IN THE EARLY IRON AGE. Illustrated by recent Discoveries in the PeatMosses of Slesvig. 33 Plates (giving representations of upwards of a thousand objects), Maps, and numerous other Illustrations on wood. I866. 4to, cloth. 3Is. $6 d$.

ENGLISHWOMAN'S REVIEW (THE) OF SOCIAL AND INDUSTRIAL QUESTIONS. Edited by Antoinette $M$. Mackenzie. Issued quarterly, sewed. Is.

FARNELL (L. R., D.Litt.). EVOLUTION OF RELIGION. See Crown Theological Library, Vol. XII., p. I3.

GOLDAMMER (H.). THE KINDERGARTEN. A Guide to Fröbel's Method of Education. 2 vols. in 1.120 pp. of Illus. trations. $8 \mathrm{vo}$, cloth. IOs. $6 \%$.

HARRISON (A., D.Sc.). WOMEN'S INDUSTRIES IN LIVERPOOL. An Inquiry into the Economic Effects of Legisla. tion regulating the Labour of Women. 8vo. $3^{s}$.

HENRY (JAMES). ENEIDEA ; or, Critical, Exegetical and Esthetical Remarks on the Eneis. With a personal collation of all the first-class MSS., and upwards of Ioo second-class MSS., and all the principal editions. Vol. I. (3 Parts), Vol. II. (3 Parts), Vol, III. (3 Parts), Vol. IV. (I Part). Royal 8vo, sewed. $£ 2$, 2s. net.

HERBERT (Hon. A.). THE SACRIFICE OF EDUCATION TO EXAMINATION. Letters from "All Sorts and Conditions of Men." Edited by Auberon Herbert. Half-cloth boards. 2s.

I4 Henrietta Street, Covent Garden, London, W.C. 
HERBERT (Hon. A.). WINDFALL AND WATERDRIFT. Verse Miniatures. Square 12mo, cloth limp, gilt tops. $2 s$.

\section{- and WAGER (HAROLD). BAD AIR AND BAD} HEALTH. Dedicated to Professor Clifford Allbutt. Reprinted from the "Contemporary Review." 8vo, cloth, Is. $6 d$. ; sewed, is.

JOHNSON (E.). THE RISE OF ENGLISH CULTURE. With a brief account of the Author's Life and Writings. Demy 8vo, cloth. 15s. net.

KIEPERT'S NEW ATLAS ANTIQUUS. Twelve Maps of the Ancient World, for Schools and Colleges. Third hundred thousand. I2th Edition, with a complete Geographical Index. Folio, boards. 6s. Strongly bound in cloth. 7s. $6 d$.

\section{- WALL-MAPS OF THE ANCIENT WORLD-}

Wall-map of Ancient Italy. Italia antiqua. For the study of Livy, Sallust, Cicero, Dionysius, etc. Scale I : 800,000. Mounted on rollers, varnished. 20s.

General Wall-map of the Old World. Tabula orbis terrarum antiqui ad illustrandam potissimum antiquissimi ævi usque ad Alexandrum M. historiam. For the study of ancient history, especially the history of the Oriental peoples: the Indians, Medes, Persians, Babylonians, Assyrians, Egyptians, Phœnicians, etc. Scale I : 5,400,000. Mounted on rollers, varnished, 20 .

General Wall-map of the Roman Empire. Imperii Romani tabula geographica. For the study of the development of the Roman Empire. Scale I: 300,000. Mounted on rollers, varnished. 24s.

Wall-map of Ancient Latium. Latii Veteris et finitimarum regionum tabula. For the study of Livy, Dionysius, etc. Scale I : 125,000. With supplement: Environs of Rome. Scale I : 25,000. Mounted on rollers, varnished. I 8 s.

Wall-map of Ancient Greece. Græciæ Antiquæ tabula. For the study of Herodotus, Thucydides, Xenophon, Strabo, Cornelius Nepos, etc. Scale I : 500,000. Mounted on rollers, vamished. 24 s.

Wall-Map of the Empires of the Persians and of Alexander the Great. Imperia Persarum et Macedonum. For the study of Herodotus, Xenophon, Justinian, Arian, Curtius. Scale I : 300,000. Mounted on rollers and varnished. 20s.

Wall-Map of Gaul, with portions of Ancient Britain and Ancient Germany. Galliæ Cisalpinæ et Transalpinæ cum partibus Britanniæ et Germaniæ tabula. For the study of Cæsar, Justinian, Livy, Tacitus, etc. Scale I : I,000,000. Mounted on rollers and varnished. $24 s$. 
KIEPERT'S WALL-MAPS OF THE ANCIENT WORLD-Contd.

Wall-Map of Ancient Asia Minor. Asiæ Minoris Antiquæ Tabula. For the study of Herodotus, Xenophon, Justinian, Arian, Curtius, etc. Scale 1 : 800,000 . Mounted on rollers and varnished, 20s.

LAING and HUXLEY. PREHISTORIC REMAINS OF CAITHNESS. By Samuel Laing, Esq., with Notes on the Human Remains by Th. H. Huxley, F.R.S. 150 Engravings. 8 vo, cloth. $4 s .6 d$.

MARCKS (ERICH, Professor of Modern History at the University of Leipzig). ENGLAND AND GERMANY : Their Relations in the Great Crises of European History, I500-I900. Demy 8vo, stiff wrapper. Is.

OTIA MERSEIANA. The Publication of the Arts Faculty of the University of Liverpool, Vols. I.-III. 8vo. 1899-1903. Each IOs. $6 d$.

PEDDIE (R. A.). PRINTING AT BRESCIA IN THE FIFTEENTH CENTURY. A List of the Issues. 5 s. net.

ST. CLAIR (GEORGE, Author of "Creation Records," "Buried Cities and Bible Countries," etc.). MYTHS OF GREECE EXPLAINED AND DATED. An Embalmed History from Uranus to Perseus, including the Eleusinian Mysteries and the Olympic Games. Demy 8vo. 2 vols. $16 s$.

SCHLOSS (DAVID F.). METHODS OF INDUSTRIAL REMUNERATION. 3rd Edition, revised and enlarged. Crown 8vo, cloth. $7 s .6 d$.

"In its new as in its old form the book is well nigh indispensable to the student who desires to get some insight into the actual facts about the various methods of industrial remuneration, and the degree of success with which they have been applied in the various trades."-Manchester Guardian.

"More useful than ever to the students of the labour problem."-Political Science Quarterly.

SPENCER (HERBERT). AN AUTOBIOGRAPHY. Sec P. 31 .

PRINCIPLES OF SOCIOLOGY. See p. $3^{1}$.

STUDY OF SOCIOLOGY. See p. 32.

DESCRIPTIVE SOCIOLOGY. See p. $3^{2}$.

I4 Henrietta Street, Covent Garden, London, W.C. 
STEPHENS STUDIES ON NORTHERN MYTHOLOGY EXAMINED. Illustrations. 8vo, cloth. $8 s$.

- THE RUNES, WHENCE CAME THEY? 4to, sewed. 6s.

OLD NORTHERN RUNIC MONUMENTS. Vol. IV. Folio. 20s, net.

VEILED FIGURE (THE), and Other Poems. Large post 8vo, buckram, gilt, cover designed by Mr. T. Blake Wirgman. 2s. $6 d$.

VYNNE (NORA) and HELEN BLACKBURN, and with the Assistance of $\mathrm{H}$. W. ALLASON. WOMEN UNDER THE FACTORY ACTS. Part I. Position of the Employer Part 2. Position of the Employed. Crown 8vo, cloth. Is, net.

WELD (A. G.). GLIMPSES OF TENNYSON AND OF SOME OF HIS FRIENDS. With an Appendix by the late Bertram Tennyson. Illustrated with Portraits in photogravure and colour, and with a facsimile of a MS. poem. Fcap. 8vo, art linen. $4 s, 6 d$. net.

"This is a delightful little book, written by one who has all the qualifications for the task - the opportunities of observation, the interest of relationship, and the sympathetic and appreciative temper. . . We do not attempt to criticise, but only to give such a description as will send our readers to it."-Spectator.

"Everyone who reads the book will understand Tennyson a little better, and many will view him in a new aspect for the first time."-Daily Chronicle. Herald.

"It is quite worthy of a place side by side with the larger 'Life." "-Glasgow

I4 Henrietta Street, Covent Garden, London, W.C. 


\title{
LIST OF PERIODICALS, REVIEWS, AND TRANSACTIONS AND PROCEEDINGS OF LEARNED SOCIETIES
}

\author{
PUBLISHED BF WILLIAMS \& NORGATE.
}

THE HIBBERT JOURNAL: A Quarterly Review of Religion, Theology, and Philosophy. Single numbers, 2s. 6i. net. Subscription, 10s. per annum, post free.

"There is. for English readers at least. no existing medium for expression of free-thought in this best sense; and should anything but success await the venture of publishing 'The Hibber: Journal.' we shall confess painful surprise.

It will be a reflection on our theological and philosophical students if they do not show full appreciation of a journal so admirably planned and so strongly commenced. . . For the form of the jotrmal we have nothing but praise, the print being large and the margins ample. We have never with more sincerity wished well to a new undertaking; and should it fulfil its undoubted possibilities, 'The Hibbert Journal must be of immense service to all serious and' progressive students of the suojects with which it deals."-Christian Ul"orld.

MIND: A Quarterly Review of Psychology and Philosophy. Edited by Dr. G. F. Stout. Published in the first week of January; April, July, and October. 4s. Per annum, I2s., post free.

THE LIBERAL CHURCHMAN: A Quarterly Review. Subscription, 4. per annum, post free. Single numbers, 1s. net ; Is. $2 d$. post free.

THE ENGLISHWOMAN'S REVIEW OF SOCIAL AND INDUSTRIAL QUESTIONS. Edited by Antoinette M. Mackenzie. Issued quarterly on 1 ith January, April, Tuly, and October. Price Is. Per annum, 4j.6i., post free.

JOURNAL OF THE FEDERATED MALAY STATES MUSEUMS. Issued quarterly. Single numbers, Is. $6 \%$ net. Subscription, js. per annum.

JOURNAL OF THE ROYAL MICROSCOPICAL SOCIETY, containing its Transactions and Proceedings, with other Microscopical Information. Bi-monthly. 6i, net. Yearly subscriptions, $37 s .6 \%$, post free.

I4 Henrietta Street, Covent Garden, London, W.C. 
LIST OF PERIODICALS, Etc.-Continued.

JOURNAL OF THE QUEKETT MICROSCOPICAL CLU B. Issued half-yearly, April and November. Price $3 s .6 d$. net. $7 s .6 d$. per annum, post free.

LINNEAN SOCIETY OF LONDON. Journal of Botany and Journal of Zoology. Published irregularly at various prices.

ROYAL SOCIETY OF EDINBURGH. Transactions. Issued irregularly at various prices.

\section{LIVERPOOL MARINE BIOLOGY COMMITTEE.} Memoirs. I.-XII. already published at various prices. Fauna of Liverpool Bay. Fifth Report written by Members of the Committee and other Naturalists. Cloth. 8s. 6d. net. See p. 50.

MEMOIRS OF THE LIVERPOOL SCHOOL OF TROPICAL MEDICINE. See p. 5I.

ROYAL ASTRONOMICAL SOCIETY. Memoirs and Monthly Notices. Yearly volumes at various prices.

ROYAL IRISH ACADEMY. Transactions and Proceedings issued irregularly; prices vary. Cunningham Memoirs. Vols. I. $-\mathrm{X}$. already issued at various prices.

ROYAL DUBLIN SOCIETY. Transactions and Proceedings. Issued irregularly at various prices.

REPORTS OF THE THOMPSON-YATES LABORATORIES. See p. 53.

TRANSACTIONS OF THE EPIDEMIOLOGICAL SOCIETY OF LONDON. See p. 55. 


$$
-
$$







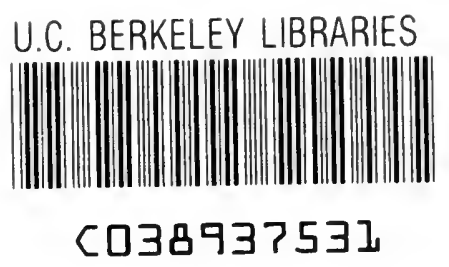


